Med Klin Intensivmed Notfmed 2019 ·114:372-396 https://doi.org/10.1007/s00063-019-0580-9 c) Springer Medizin Verlag $\mathrm{GmbH}$, ein Teil von Springer Nature 2019

\title{
Abstracts der 51. Gemeinsamen Jahrestagung der DGIIN und ÖGIAIN
}

\section{Kompetenz + Verantwortung}

\author{
Berlin, 12.-14. Juni 2019
}

\section{Einsatz der VA-ECMO bei der Reanimation}

\section{FV01}

\section{Schockleber nach Herzkreislaufstillstand: Risikofaktoren und neurologisches Outcome}

\author{
K. Roedl', A. Spiel' ${ }^{2}$, S. Sterz'², H. Herkner', V. Fuhrmann' \\ ${ }^{1}$ Klinik für Intensivmedizin, Zentrum für Anästhesiologie und \\ Intensivmedizin, Universitätsklinikum Hamburg-Eppendorf, Hamburg, \\ Deutschland; ${ }^{2}$ Universitätsklinik für Notfallmedizin, Medizinische Universität \\ Wien, Wien, Österreich
}

Hintergrund: Die Schockleber, auch bekannt als hypoxische Hepatitis, stellt auf der Intensivstation ein häufiges und lebensbedrohliches Krankheitsbild dar. Die Schockleber tritt bei bis zu 10 \% der kritisch kranken Patienten auf. Bei Patienten nach kardiopulmonaler Reanimation (CPR) ist die Studienlage schlecht. Insbesondere die klinische Bedeutung des Auftretens einer Schockleber nach CPR ist aktuell nicht untersucht. Zielsetzung dieser Studie war es deshalb neben der Häufigkeit des Auftretens die Risikofaktoren und das Outcome von Patienten mit Schockleber nach erfolgreicher CPR zu untersuchen.

Methode: Aus 1068 erfolgreich reanimierten Patienten an der Medizinischen Universität Wien konnten 219 (21 \%) mit Entwicklung einer Schockleber identifiziert werden. Es wurden die Patientencharakteristika, Aufnahmediagnose, Schwere der Erkrankung und 28-Tages-Mortalität erhoben.

Ergebnisse: Von insgesamt 1068 Patienten entwickelten 219 (21 \%) Patienten im Verlauf nach erfolgreicher CPR eine Schockleber. Hinsichtlich des Auftretens der Schockleber zeigte sich kein Unterschied zwischen inner- und außerklinischem Herzkreislaufstillstand (HKS). Die multivariate Regressionsanalyse konnte die Reanimationszeit [OR 1,18, 95 \% CI (1,01 to 1,38$) ; p<0,05$ ], Auftreten von kardiogenem Schock [OR 2,57, $95 \%$ CI $(1,65$ to 4,01$) ; p<0,001]$ und Charlson Komorbiditäts Index [OR 0,83, $95 \%$ CI $(0,72$ to 0,95$) ; p<0,01]$ als unabhängige Prädiktoren für das Auftreten einer Schockleber nach HKS identifizieren. Gutes neurologisches Outcome nach Reanimation (CPC I/II) war signifikant seltener in Patienten mit Schockleber nach 28 -Tagen ( $35 \%$ vs. $48 \%, p<0,001)$ und nach 1 -Jahr (34 \% vs. $44 \%, p<0,001)$. Das Auftreten einer Schockleber war in der multivariaten Regressionsanalyse signifikant mit schlechtem neurologischem Outcome [OR 1,74, $95 \%$ CI $(1,16$ to 2,61$) ; p<0,01]$ assoziiert. Zusammenfassung: Das Neuauftreten einer Schockleber ist sowohl beim inner- als auch außerklinischen Herzkreislaufstillstand ein häufiges Ereignis. Die Schockleber ist mit einer erhöhten Mortalität und schlechtem neurologischem Outcome nach Reanimation vergesellschaftet.

\section{Therapiezieldefinition und -begrenzung}

\section{FV02}

Outcome of cardiopulmonary resuscitation in critically ill cancer patients; was it all worth it?

A. Tzalavras', M. Rieger-Langenberg '2, A. Turki', E. Bayraktar', R. Bogdanov', N. K. Steckel', D. Beelen', T. Liebregts'

'Klinik für Knochenmarktransplantation, Westdeutsches Tumorzentrum, Universitätsklinikum Essen, Essen, Germany; ${ }^{2}$ Klinik für Anästhesiologie, Intensivmedizin und Notfallmedizin, Evangelisches Klinikum Niederrhein, Duisburg, Germany

Objective: The number of cancer patients needing ICU care has dramatically increased. Already up to $20 \%$ of ICU beds are occupied by cancer patients. Although there is substantial increase in ICU survival cardiopulmonary resuscitation (CPR) in cancer patients is seriously debated. However, outcome data on CPR in intensive care units in cancer patients are scarce. We therefore aimed to analyze survival rates and prognosis associated factors in critically ill cancer patients undergoing CPR.

Method: We conducted a retrospective cohort study of critically ill cancer patients admitted to our specialized tertiary care ICU who required cardiopulmonary resuscitation during their ICU stay.

Results: Of 931 patients with cancer admitted to ICU between February 2012 and January 2018, 100 (10.7\%) received in-ICU CPR. Invasive mechanical ventilation was initiated in $96 \%$ prior to the need for CPR. Forty-eight patients underwent CPR within $24 \mathrm{~h}$ of ICU admission. While ROSC was achieved in $60 \%$, the ICU survival rate was $25 \%$. Twenty-one patients were discharged from hospital. Overall 1-month, 6-month and 1 -year survival rates were $20 \%, 16 \%$ and $14 \%$. Non-surviving patients demonstrated longer duration of CPR with longer time to ROSC, higher APACHE II, SOFA and impaired $\mathrm{PaO}_{2} / \mathrm{FiO}_{2}$ ratio at admission compared to ICU-survivors. No CPR survival difference was observed between patients with solid tumors and hematological malignancies or allogeneic hematopoietic stem cell recipients.

Conclusion: Overall survival rates of critically ill cancer patients with inICU CPR are similar compared to the non-cancer ICU population depicted in current published literature. Severities of critical illness rather than underlying malignancy associated factors are associated with CPR-outcome. 


\section{Der komplexe Patient}

\section{FV03}

Vergleich von Blutungskomplikationen unter Antikoagulanzientherapie in der Notfallmedizin

\section{N. Willamowski, A. Slagman, M. Möckel}

Notfallmedizin/Rettungsstellen Nordcampi, Campus Virchow-Klinikum und Campus Charité Mitte, Charité - Universitätsmedizin Berlin, Berlin, Deutschland

Hintergrund: Neben Vitamin-K-Antagonisten (VKA) und parenteralen Antikoagulanzien (NMH, UFH, Fondaparinux) werden seit einigen Jahren auch die sog. Neuen (o. Nicht Vitamin-K abhängigen, direkten) oralen Antikoagulanzien (NOAK) eingesetzt. Bisherige Studien adressierten das Blutungsrisiko in spezifischen, diagnosebezogenen Patientengruppen. Ziel dieser Arbeit ist die Betrachtung aus Sicht der Notfallmedizin, welche mit Blutungskomplikationen eines ungefilterten Patientenkollektivs konfrontiert wird.

Methode: In einer automatisierten Abfrage identifizierten wir 515 Fälle, die sich 2014 und 2015 im Rahmen der stationären Aufnahme über eine der drei Notaufnahmen zweier Standorte der Maximalversorgung mit der Diagnose „Hämorrhagische Diathese durch Antikoagulanzien und Antikörper " vorstellten. 30 weitere wurden bei der Auswertung identifiziert, 284 erfüllten die Einschlusskriterien (• Abb. 1 | FV03).

Ergebnisse: Das Durchschnittsalter lag bei 72 Jahren, 193 (68 \%) Pat. waren männlich, 91 (32\%) weiblich. Die Hauptindikation bestand in VHF (71,5\%), gefolgt von TVT/LAE $(19,0 \%)$ und mechan. Herzklappenersatz (7,4 \%), mehr als eine Indikation bei 15,5\%. 186 (65,5\%) wurden als „major-“, 98 (34,5\%) als „minor-“ Blutungen klassifiziert (nach ISTH; - Abb. 2|FV03). 95 Pat. (33,5\%) erhielten zusätzlich eine Thrombozytenaggregationshemmung (TAH), 13 davon eine duale. Insgesamt erhielten 119 Pat. (41,9\%) Erythrozytenkonzentrate, 75 (26,4 \%) PPSB, 25 (8,8 \%)

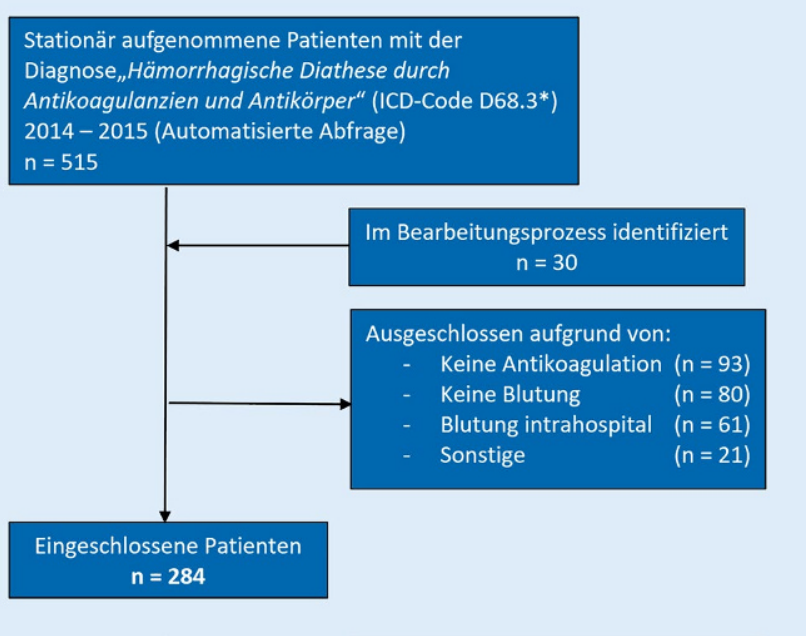

Abb. 1 | FV03 $\triangle$ wurden TKs, 25 (8,8 \%) FFP verabreicht. In 115 (40,5 \%) Fällen erfolgte invasive Diagnostik, bei 34 mit therapeut. Interventionen. 67 Pat. (23,6 \%) wurden operiert. Kein Pat. unter NOAKs erhielt ein spezifisches Antidot, Vitamin K wurde 91 Pat. (47,2 \%) unter VKA verabreicht. Die Krankenhausmortalität lag bei 6,3\% $(n=18)$. Von den verstorbenen 18 Pat. erhielten 14 VKA, in 6 Fällen mit zusätzlicher TAH, ein Pat. erhielt „Bridging“ mit UFH, 2 Pat. erlitten die Blutung unter Rivaroxaban, einer unter Dabigatran. 14 letale Blutungen waren intrakraniell.

Zusammenfassung: Der Großteil der Blutungen und letalen Verläufe trat unter Therapie mit VKA auf. Blutungen unter NOAKs ließen sich trotz der nicht-Verfügbarkeit spezifischer Antidota in dem Beobachtungszeitraum kontrollieren. Die vorliegenden „Real-Life“-Daten lassen auf ein gutes Sicherheitsprofil der NOAKs in einem unselektionierten Kollektiv von Notaufnahmepatienten schließen.

\section{FV04}

\section{Coronary angiography in out-of hospital cardiac arrest patients with non-pathologic ECG on admission: Criteria for decision making}

J. Stiepak, S. Brockenauer, E. Gamerdinger, F. Muhler, S. Spaich, F. Steger, T. Zelniker, H. A. Katus, M. Preusch

Kardiologie, Angiologie und Pneumologie, Klinik für Innere Medizin III, Universitätsklinikum Heidelberg, Heidelberg, Germany

Objective: Myocardial ischemia is the leading cause for out-of-hospital cardiac arrest (OHCA). However, a large number of patients following resuscitation does not show significant ECG changes on admission. Within this cohort a large proportion of patients exhibit clinically relevant coronary stenosis when coronary angiography (CAG) is performed. According to 2015 ERC guidelines CAG should be performed in all patients with primarily unknown cause of cardiac arrest. The aim of the present study is, to identify criteria for decision making towards CAG in patients with OHCA and non-pathologic ECG on admission.

Method: We performed a retrospective analysis of initial heart rhythm and serum levels of hsTnT in patients with OHCA of non-traumatic origin. Data were obtained from the Heidelberg Resuscitation Registry between 2013 and 2017. A total of 450 patients were eligible for data analysis. Results: 116 patients (25.8\%) did not receive CAG since non-cardiac causes for cardiac arrest were clearly identified (e.g. bolus aspiration, subarachnoid hemorrhage) or limitation of therapy for other reasons was performed. Of the remaining patients, $123(36.8 \%)$ were classified as STEMI or equivalent after survey of the ECG on admission. However, a total of $211(63.2 \%)$ patients without significant ECG-changes received CAG. Within this cohort, 105 subjects (49.8\%) exhibited significant coronary artery disease and subsequently received percutaneous coronary intervention (PCI).

Patients without clearly pathological ECG-changes and the need for PCI had significantly more often ventricular fibrillation as initial rhythm $(68.6 \%$ vs. $45.3 \%, p=0.0003$ ) and higher levels of hsTnT on admission compared to patients with no need for PCI $(510 \pm 1003 \mathrm{ng} / \mu \mathrm{l}$ vs. $348 \pm 738 \mathrm{ng} / \mu \mathrm{l}$; $p=0,016)$. However, no reasonable cut-off value for hsTNT could be determined to rule out significant coronary stenosis.

\begin{tabular}{|l|ll|l|l|l|l|}
\hline ISTH & VKA & Rivaroxaban & Parenteral* & Dabigatran & Apixaban \\
\hline Major & 117 & $(66,1 \%)$ & $41(70,7 \%)$ & $26(56,5 \%)$ & $4(44,4 \%)$ & $3(60,0 \%)$ \\
\hline Minor & $60 \quad(33,9 \%)$ & $17(29,3 \%)$ & $20(43,5 \%)$ & $5(55,6 \%)$ & $2(40,0 \%)$ \\
\hline $\begin{array}{l}\text { Gesamt } \\
\text { (n=284) ** }\end{array}$ & $\mathbf{1 7 7} \mathbf{( 6 2 , 3 \% )}$ & $\mathbf{5 8 ( 2 0 , 4} \%)$ & $\mathbf{4 6 ( 1 6 , 2 \% )}$ & $\mathbf{9 ( 3 , 2} \%)$ & $\mathbf{5 ( 1 , 7 6 \% )}$ \\
\hline $\begin{array}{l}\text { * NMH, UFH, Fondaparinux } \\
\text { ** 11 Patienten erhielten 2 Substanzen: 9 VKA + Parenteral, 1 Rivaroxaban + Parenteral, 1 VKA + Rivaroxaban }\end{array}$ \\
\hline
\end{tabular}

Abb. 2 |FV03 $<$ Darstellung der verabreichten Antikoagulanzien gesamt und aufgeteilt nach "Major" und "Minor" Blutungen 
Conclusion: Our data strongly suggest CAG should be performed independently from initial heart rhythm or hsTnT values on admission in patients with OHCA without significant ECG changes.

\section{Choosing wisely in der Intensiv- und Notfallmedizin}

\author{
FV05 \\ Left without beeing seen (LWBS) - Warum Patientinnen und \\ Patienten die Notaufnahme verlassen, bevor eine Ärztin oder ein \\ Arzt kommt \\ M. Schmiedhofer, T. Wrobel, A. Fischer-Rosinsky, J. Searle, A. Slagman, \\ M. Möckel \\ Notfallmedizin/Rettungsstellen Nordcampi, Campus Virchow-Klinikum \\ und Campus Charité Mitte, Charité - Universitätsmedizin Berlin, Berlin, \\ Deutschland
}

Hintergrund: Ca. $3 \%$ aller Patient ${ }^{*}$ innen verlassen die Notaufnahme vor einem Arztkontakt. Dies ist aus internationalen Studien bekannt und gilt auf für die Notaufnahmen der Charité-Universitätsmedizin Berlin. Über die Motive zum Verlassen der Notaufnahme und die anschließende Nutzung alternativer Versorgungsangebote (niedergelassene Ärzte, andere Notaufnahmen) gibt es kaum Informationen.

Methode: Um mehr über die Hintergründe dieser Personengruppe zu erfahren, wurden an den beiden Notaufnahmen der Charité Campi Nord alle Patient ${ }^{*}$ innen kontaktiert, die während eines Jahres (Okt. 2015 bis Sept. 2016) die Notaufnahme vor einem Arztkontakt verlassen hatten. Von diesen 3266 Erwachsenen wurden 1067 erreicht und machten Angaben zum Grund des Verlassens, zu Wartezeiten und der Beanspruchung alternativer Behandlungsangebote. Im Abstract wurden die Daten qualitativ für die Motive zum Verlassen der Notaufnahmen analysiert.

Ergebnisse: Patient ${ }^{*}$ innen, die telefonisch oder schriftlich die Fragen nach den Beweggründen zum Verlassen der Notaufnahme beantwortet haben, führten eine Bandbreite von Motiven auf, die geordnet werden können in a) persönliche Gründe, die eine längere Wartezeit nicht zulassen (z.B. Kinderbetreuung) b) die unkomfortable Wartesituation und die Wahrnehmung unfreundlicher Behandlung durch die Pflegekräfte, die das Gefühl des „Vergessen werdens“ auslösten. c) Eine weitere Gruppe von Patient*innen berichtete hingegen über die Erfüllung ihrer Anliegen durch Pflegekräfte oder über eine spontane Besserung ihrer Beschwerden im Laufe der Wartezeit.

Zusammenfassung: Die Vielfalt der angegebenen Gründe zeigt die Funktionsbreite der Notaufnahmen. Neben der Anlaufstelle für notfallmedizinische Behandlung wird sie häufig für die akutmedizinische Versorgung ggf. weniger dringlicher Beschwerden genutzt. Das Unverständnis über die Unplanbarkeit der verbleibenden Wartezeit weist auf die veränderten Ansprüche hin, denen das Notaufnahmepersonal ausgesetzt ist. Die Beanspruchung der Notaufnahmen zur akutmedizinischen Versorgung macht die gestiegene Bedeutung innerhalb der Versorgungsstrukturen deutlich. Eine patientenorientierte Versorgung muss deren Bedürfnisse aufgreifen und die notwendigen Ressourcen auch für die akutmedizinische Versorgung bereitstellen.

\section{FV06}

\section{Der chronische Intensivpatient: Demografie und Outcome}

D. Amann, G. de Heer, V. Fuhrmann, A. Nierhaus, K. Roedl, J. Müller, S. Kluge Klinik für Intensivmedizin, Zentrum für Anästhesiologie und Intensivmedizin, Universitätsklinikum Hamburg-Eppendorf, Hamburg, Deutschland

Hintergrund: Patienten, die nach einer akuten schweren Erkrankung unter einem protrahierten Organversagen leiden, werden als chronisch kritisch krank bezeichnet. Eine konsentierte Definition dieses Zustandes besteht nicht und Informationen über die Überlebenswahrscheinlichkeiten sind wenig vorhanden.

Wir haben in dieser Studie Patienten mit einer prolongierten Intensivtherapie untersucht und insbesondere Patientencharakteristika, Therapieverläufe und das Überleben betrachtet.

Methode: Es wurden die Daten aller Intensivpatienten retrospektiv ausgewertet, die 90 Tage oder länger auf einer der 12 Stationen der Klinik für Intensivmedizin im Zeitraum von 2008 bis einschließlich 2016 behandelt wurden. Es wurden demografische Daten, Vorerkrankungen, Aufnahmegründe, Therapieverläufe und der Status ein Jahr nach der mindestens 90-tägigen intensivmedizinischen Behandlung erhoben, statistisch berechnet und Überlebenszeitanalysen mittels der Cox-Regression und der Kaplan-Meier-Analyse durchgeführt.

Ergebnisse: In dem Beobachtungszeitraum wurden von über 65.000 in der Klinik für Intensivmedizin behandelten Patienten 96 mit einem Intensivaufenthalt von $\geq 90$ Tagen identifiziert. Die Mehrheit war männlich (69 \%), im Median 61 Jahre (Minimum-Maximum: 18-82 Jahre) alt und wurde überwiegend mit einer chirurgischen Diagnose aufgenommen (74 \%). Die mediane Liegedauer betrug 110 Tage (90-349 Tage), die Beatmungsdauer 74 Tage (7-224 Tage). Am Aufnahmetag wurden der SOFA- und SAPS IIScore erhoben (Median: SAPS II-Score 42 (9-82), SOFA-Score 10 (0-20) Punkte). 74 (77\%) Patienten wurden im Verlauf dialysepflichtig und 67 (70 \%) waren zumindest phasenweise isolierungspflichtig.

63 (66 \%) Patienten überlebten den Intensivaufenthalt, die Krankenhaussterblichkeit betrug $43 \%$. Ein Jahr nach mindestens 90-tägiger intensivmedizinischer Therapie waren noch 24 (25\%) Patienten am Leben, wobei nur acht ( $8 \%$ ) Patienten weitestgehend selbständig leben konnten. Von diesen Überlebenden waren 20 chirurgisch behandelt worden und im Median signifikant jünger als die Verstorbenen ( 51 versus 64 Jahre; $p=0,031$ ). Zusammenfassung: Die in der Studie untersuchten Langzeit-Intensivpatienten überlebten zu $75 \%$ das erste Jahr nach einer prolongierten Intensivtherapie nicht. Als Überlebensvorteil zeigten sich ein jüngeres Alter und die chirurgische Aufnahme. Ein zufriedenstellendes funktionelles Outcome erreichten lediglich $8 \%$ der Patienten.

\section{Neue Entwicklungen in der Therapie}

\section{FV07}

Frailty ist mit chronischer Inflammation und proinflammatorischen Monozytensubpopulationen assoziiert

C. Pflücke', S. Wydra' , K. Berndt' ${ }^{2}$, D. Poitz ${ }^{3}$, P. Barthel', A. Linke', K. Ibrahim'

'Innere Medizin, Kardiologie und Intensivmedizin, Herzzentrum Dresden, Technische Universität Dresden, Dresden, Deutschland; ${ }^{2}$ Klinik und Poliklinik für Kardiologie, Universität Leipzig, Leipzig, Deutschland; ${ }^{3}$ Klinische Chemie und Labormedizin, Technische Universität Dresden, Dresden, Deutschland

Hintergrund: Patienten mit Gebrechlichkeit (engl. Frailty) stellen ein wachsendes Patientengut in der Intensivmedizin dar. Eine Verbindung von Frailty mit Inflammation wird vermutet. Patienten mit hochgradiger Aortenklappenstenose (AS) und Frailty, die einer Transkatheter-Aortenklappenimplantation (TAVI) unterzogen werden, weisen eine hohe Mortalität auf. Eine systemische Inflammationsreaktion in den ersten Tagen auf Intensivstation nach TAVI fördert vermutlich einen ungünstigen Verlauf. Genauere Mechanismen sind noch offen. Monozyten-Subpopulationen sind bekannt dafür sowohl mit kardiovaskulären Erkrankungen, als auch mit hohem APACHE II-Score bei kritisch kranken Patienten assoziiert zu sein. Diese Studie untersuchte den Zusammenhang von Frailty auf zelluläre und systemische inflammatorische Mechanismen und Mortalität nach TAVI.

Methode: 120 Patienten mit symptomatischer AS sind einer TAVI unterzogen worden. Zuvor ist der Zustand von Frailty überprüft worden. Bei allen Patienten erfolgten durchflusszytometrische Analysen. Monozytensubpopulationen sind wie folgt definiert worden: Mon1 (CD14 $\left.{ }^{++} \mathrm{CD} 16^{-}\right)$, Mon2 $\left(\mathrm{CD} 14^{++} \mathrm{CD} 16^{+}\right)$und Mon3 $\left(\mathrm{CD} 14^{+} \mathrm{CD} 16^{++}\right)$. Als Maß für monozytäre Aktivation wurde die CD11b-Expression gemessen. Pro-inflammato- 
rische Zytokine wie Interleukin IL-8, sowie CRP sind mittels Cytometric Bead Array oder Standardlabormethoden bestimmt worden.

Ergebnisse: Innerhalb von 3 Monaten verstarben 15 der 120 Patienten, vornehmlich ohne relevante Dysfunktion der implantierten Aortenklappe. Bei 8 von 15 (53\%) der Verstorbenen wurde, im Gegensatz zu 20 von 100 $(19 \%)$ der Überlebenden, Frailty vor TAVI attestiert $(p=0,003)$. Patienten mit Frailty wiesen vor TAVI sowohl Zeichen einer erhöhten chronischen Inflammation, CRP (3,7 vs. $5,9 \mathrm{mg} / \mathrm{l}, p=0,001)$, als auch einen gesteigerten Anteil der als pro-inflammatorisch geltenden Mon2-Monozyten 37 vs. 53, $p=0,001$, auf. Die CD11b-Expression, als auch IL-8 zeigten sich bei Patienten mit Frailty im Trend gesteigert. Frailty, die monzytären Marker, sowie IL8 und CRP vor TAVI korrelierten auch eigenständig mit erhöhter Frühmortalität nach TAVI.

Zusammenfassung: Ein beträchtlicher Anteil von älteren Patienten mit hochgradiger Aortenklappenstenose muss als Gebrechlich bezeichnet werden. Dieses Syndrom ist mit erhöhter Mortalität als auch mit Zeichen von chronischer systemischer Inflammation und pro-inflammatorischen Monozyten assoziiert.

\section{Weiterbildung in der Akut- und Notfallmedizin}

\section{FV08}

\section{Implementierung und Evaluation eines standardisierten Einarbeitungs- und Fortbildungscurriculums auf der Intensivstation}

\section{Prautzsch, M. Spacek}

Intensivstation Türkis, Klinik 2, Klinik Bavaria Kreischa, Kreischa, Deutschland

Hintergrund: Zielstellung der Arbeit ist die Entwicklung und Implementierung eines Einarbeitungs- und Fortbildungscurriculums für die Intensivstation, um eine höhere Patientensicherheit und Mitarbeiterzufriedenheit zu erreichen.

Methode: Initial erfolgte die Ist-Analyse mittels einer Umfrage. Basierend auf den Ergebnissen wurde ein Grundkonzept für ein Curriculum erstellt und dieses über Monate pilotiert und angepasst. Nach Implementierung des Curriculums führten wir eine erneute Umfrage durch, um die Auswirkungen des Curriculums zu reevaluieren. Diese Umfrage erfolgte wiederum mit Fokus auf allgemeine Zufriedenheit, Qualität der Einarbeitung, Vorbereitung auf Dienste sowie Sicherheit im Dienstsystem.

Ergebnisse: Die Ergebnisse der ersten Umfrage (27 Mitarbeiter, RQ 86 \%), zeigten Streuungen der allgemeinen Zufriedenheit, der Einarbeitungsqualität und der Dienstvorbereitung. Bedarf gab es bei den Anfängern in theoretischen Grundlagen sowie beim Erlernen technischer Skills und bei dem Management von Notfallsituationen. Aus den Erkenntnissen entstand ein dreistufiges Curriculum. Stufe A richtet den Fokus auf Grundlagen der täglichen Arbeit sowie das Erreichen der Dienstfähigkeit. Stufe B wendet sich Ärzten zu, welche bereits dienstfähig sind und tiefere Fachkenntnisse erwerben sollen. Stufe C dient schließlich der Erweiterung der Fachkompetenz u. a. mit dem Ziel der Leitung die Notfallteams zu übernehen. Die zweite Umfrage fand 12/2018 statt (20 Mitarbeiter, RQ 83 \%). Die Reevaluation ergab eine höhere Allgemeinzufriedenheit (MW von 7,03 auf 7,56, Skala 1-10). Weiterhin zeigte sich ein Anstieg der Bewertung in den Aspekten Qualität der Einarbeitung (MW von 6,62 auf 7,19), Vorbereitung auf Dienste (MW von 5,38 auf 7,25) und Sicherheit in den Diensten (MW von 6,76 auf 7,00). Außerdem bestand eine geringere Streuung der Werte. In Wilcoxon-test zeigten sich bei der Bewertung der Vorbereitung auf Dienste $(p<0,0031)$ und der Einarbeitungsqualität $(p<0,001)$ statistische Signifikanzen in Bezug auf die ermittelten Werte.

Zusammenfassung: Durch Analyse und Evaluation der Anforderungen und Bedürfnisse ist ein dreistufiges Curriculum entstanden. Dieses Curriculum wurde mehrere Monate nach der Implementierung im Rahmen einer erneuten Mitarbeiterumfrage reevaluiert. Die Ergebnisse zeigten eine messbare Verbesserung sowie die Sinnhaftigkeit einer standardisierten Einarbeitung der Ärzte auf Intensivstation.

\section{Akut- und Notfallmedizin 1 (P01-P06)}

\section{P01}

\section{Neutrophil extracellular traps in erfolgreich reanimierten} Patienten mit außerklinischem Herzkreislaufstillstand

A. Merrelaar', N. Buchtele', L. Muracher ${ }^{3}$, C. Schörgenhofer ${ }^{2}$, H. Herkner', C. Weiser', M. Schwameis ${ }^{1}$

'Universitätsklinik für Notfallmedizin, Medizinische Universität Wien, Wien, Österreich; ${ }^{2}$ Univ. Klinik für Klinische Pharmakologie, Medizinische Universität Wien, Wien, Österreich; ${ }^{3} \mathrm{Abt}$. für Hämatologie und Hämostaseologie, Univ. Klinik für Innere Medizin I, Medizinische Universität Wien, Wien, Österreich

Hintergrund: Mechanismen, durch die neutrophile Granulozyten nach Herzkreislaufstillstand (HKS) zu einem sekundären Hirnschaden beitragen, sind unbekannt. Wir hypothetisierten, dass neutrophil extracellular traps (NETs), extrazelluläre DNA-Netze, die nach ischämischer Reperfusion von Neutrophilen freigesetzt werden können, an der Entwicklung

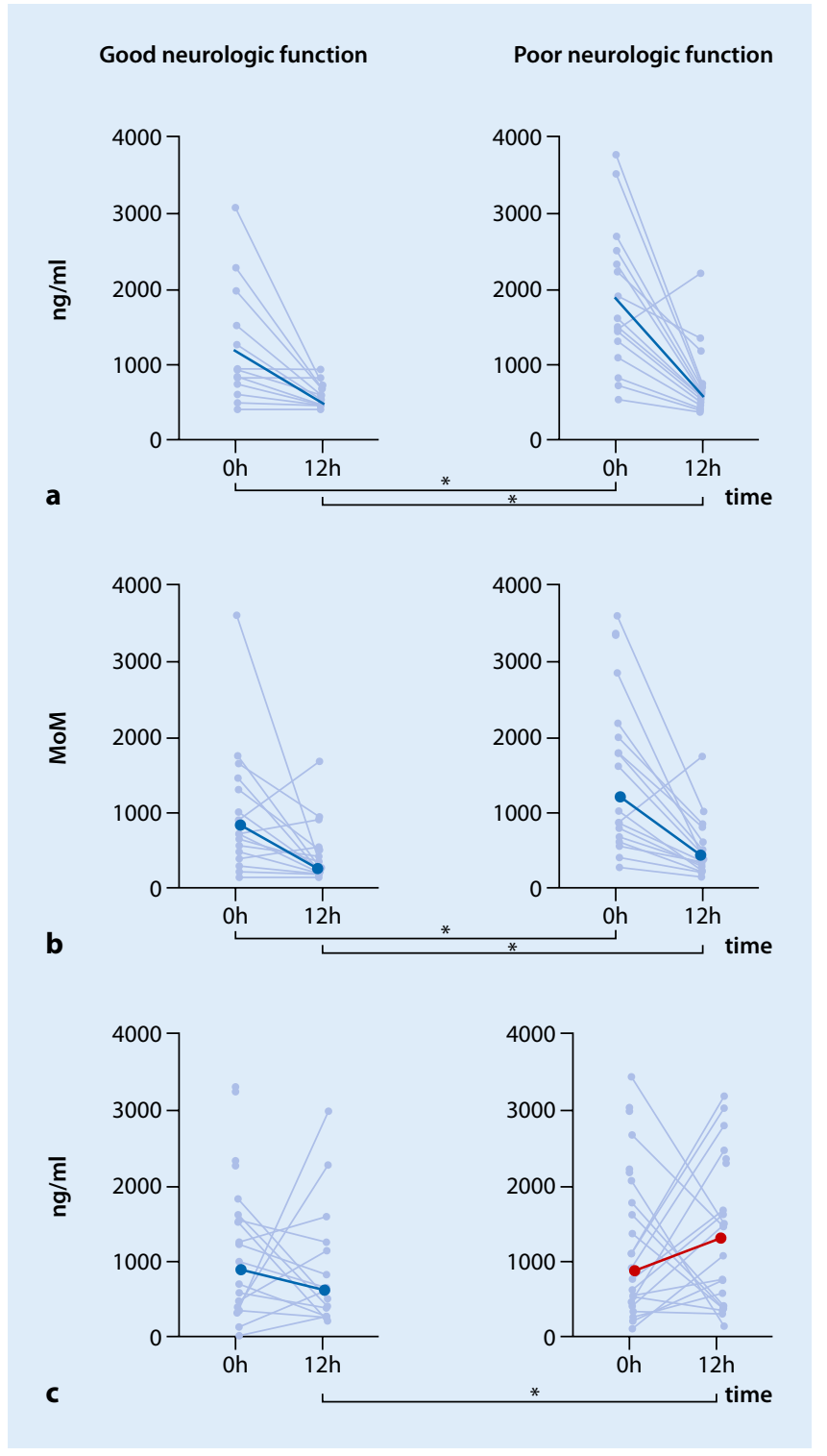

Abb. 1 | P01 $\Delta$ a cfDNA, b Nucleosomes, c H3Cit 
eines sekundären Hirnschadens nach primär erfolgreicher Reanimation beteiligt sein könnten.

Methode: Diese prospektive Beobachtungsstudie schloss erwachsene $\mathrm{Pa}$ tienten mit außerklinischem Herzkreislaufstillstand ein, die eine vermutete kardiale Genese und vor der Krankenhausaufnahme eine Rückkehr des Spontankreislaufs erzielt hatten. Als NETs-spezifischer Biomarker wurden citrullinierte $\mathrm{H} 3$ Histone (H3Cit) im Plasma bei Aufnahme $(0 \mathrm{~h})$ und $12 \mathrm{~h}$ danach bestimmt. Der primäre Outcome-Parameter war die neurologische Funktion am Tag 30 entsprechend der cerebral performance category scale (CPC 3-5 = schlechte neurologische Funktion). Der Effekt von H3Cit sowie klinisch plausibler Covariablen auf das primäre Outcome wurde mittels bivariater logistischer Regression geschätzt und als odds ratio(OR, +95\%CI) angegeben. Die H3Cit Plasmaspiegel wurden vor der Analyse in Quintilen eingeteilt.

Ergebnisse: Von Jänner 2014 bis Jänner 2017 wurden 62 Patienten (79 \% männlich, 57 Jahre) eingeschlossen. $98 \%$ der Patienten $(n=61)$ hatten eine kardiale HKS Ursache. $52 \%$ der Patienten $(n=32)$ hatten eine schlechte neurologische Funktion 30 Tage nach Aufnahme. Die Wahrscheinlichkeit einer schlechten neurologischen Funktion am Tag 30 stieg über die Verteilung der $12 \mathrm{~h} \mathrm{H} 3 \mathrm{Cit}$ Plasmaspiegel linear an $(1,6,1,1-2,3 ; p=0,029)$ und war bei Patienten in der fünften Quintile am höchsten (OR 9, 1,3-63). Der Effekt war nicht durch Co-variablen erklärbar (• Abb. 1|P01).

Zusammenfassung: Erhöhte Plasmaspiegel citrullinierter H3 Histone $12 \mathrm{~h}$ nach Krankenhausaufnahme sind mit einem schlechten neurologischen 30-Tage Überleben bei primär erfolgreich reanimierten erwachsenen $\mathrm{Pa}$ tienten mit kardialer HKS Genese verbunden.

\section{P02}

\section{CardioSecur, a mobile 4-electrode/22-lead ECG device demonstrates user-friendliness, feasibility and safety in emergency patients}

S. Spaich', H. Kern', T. Zelniker', J. Stiepak', E. Popp², H. A. Katus', M. Preusch'

${ }^{1}$ Kardiologie, Angiologie und Pneumologie, Klinik für Innere Medizin

III, Universitätsklinikum Heidelberg, Heidelberg, Germany; ${ }^{2}$ Sektion Notfallmedizin, Klinik für Anästhesiologie, Universitätsklinikum Heidelberg, Heidelberg, Germany

Objective: Prehospital diagnostic tools for acute chest pain are limited. In this regard, conventional 12-lead electrocardiogram (cECG) derived from 10 electrodes serves as a critical pillar of prehospital risk stratification and management. This study analyzes the preclinical value of CardioSecur (CSECG), a hand-held 4-electrode/22-lead ECG-device in comparison to gold standard cECG, providing first real-world data on feasibility, diagnostic yield and safety, as well as user-friendliness and patient comfort of CSECG recordings in the emergency setting.

Method: CS-ECG systems were provided for two physician-staffed emergency ambulances. Parallel recordings of cECG and CS-ECG were obtained from all patients presenting with suspected acute coronary syndrome. Treating emergency physicians and their teams were asked to evaluate the CS-ECG system with a standardized questionnaire. All ECG tracings were separately analyzed by two independent physicians blinded to other medical records and data of respective patients. Definitive diagnoses, results of cardiac catheterization and lab tests were obtained from the patients' records.

Results: Over a period of 17 months a total of 203 patients were included in our study. Cardiac catheterization was performed in 87 (43\%) patients, with 58 patients receiving coronary interventions. Hospital records of these 87 patients classified 65 patients $(74.7 \%)$ to have suffered from myocardial infarction (STEMI/NSTEMI). Out of a total of 35 patients diagnosed with STEMI according to hospital records, prehospital cECG tracings had identified 29 (82.8\%) STEMI patients while CS-ECG recordings had yielded 34 (97.1\%) STEMI diagnoses.

Comparative evaluation of cECG and CS-ECG systems using a standardized questionnaire demonstrated $79 \%$ of emergency medical professionals to prefer application of the CS-ECG, with $87 \%$ of teams even judging
CS-ECG to be advantageous for the patient and $79 \%$ of physicians to find time to diagnosis accelerated with implementation of CS-ECG. A majority of users attested user-friendliness and feasibility of CS-ECG in terms of simplified general handling (94\%), application (93\%) and easy placement of electrodes (98\%).

Conclusion: According to this first real-world feasibility study, implementation of a CardioSecur ECG system demonstrated user-friendliness and feasibility in a prehospital emergency setting. Importantly, diagnostic yield of CS-ECG was similar to CECG recordings with emergency teams generally favoring application of CS-ECG over cECG.

\section{P03}

Screening multimorbider Notfallpatient*innen mit kardialen ambulant sensitiven Krankenhausfällen auf das Vorliegen psychischer Komorbiditäten

\section{S. L. Kuhlmann' , A. Figura ${ }^{2}$, M. Rose ${ }^{2}$, L. Schenk ${ }^{3}$, A. Slagman' ', M. Möckel ${ }^{7}$}

${ }^{1}$ Notfallmedizin/Rettungsstellen Nordcampi, Campus Virchow-Klinikum und Campus Charité Mitte, Charité - Universitätsmedizin Berlin, Berlin, Deutschland; ${ }^{2}$ Medizinische Klinik mit Schwerpunkt Psychosomatik, Campus Charité Mitte, Charité - Universitätsmedizin Berlin, Berlin, Deutschland; ${ }^{3}$ Institut für Medizinische Soziologie und Rehabilitationswissenschaft, Charité - Universitätsmedizin Berlin, Berlin, Deutschland

Hintergrund: Psychische Komorbiditäten treten gehäuft bei Patient*innen mit kardialen Erkrankungen auf und führen neben einer geringeren Lebensqualität sowie einer ungünstigen Prognose hinsichtlich Morbidität und Mortalität zu einer erhöhten Inanspruchnahme des Gesundheitswesens, u. a. der Notaufnahmen. In der vorliegenden Untersuchung wurde ein systematisches Screening von Notaufnahmepatient ${ }^{\star}$ innen mit kardialen ambulant sensitiven Krankenhausfällen (ASK) auf das Vorliegen psychischer Komorbiditäten durchgeführt.

Methode: In einer prospektiven Kohortenstudie wurden Notaufnahmepatient ${ }^{*}$ innen mit akut kardialen Beschwerden zwischen Juni 2017 und September 2018 in den acht Notaufnahmen des Bezirks Berlin-Mitte rekrutiert. Psychische Komorbiditäten (Depression, Angststörungen, Somatoforme Störungen, Alkoholabusus) wurden mittels Patient Health Questionnaire (PHQ) erfasst.

Ergebnisse: Von insgesamt $\mathrm{N}=644$ Notaufnahmepatient ${ }^{*}$ innen (Mittleres Alter (SD) 69 (11); 42 \% Frauen) wiesen 54 \% eine hohe Symptomlast mindestens einer psychischen Komorbidität auf: Depression (24\%), Angststörungen (15\%), Somatoforme Störungen (44\%), Alkoholabusus (4\%). Zusammenfassung: Ein systematisches Screening auf psychische Komorbiditäten ist im Notaufnahmesetting implementierbar. Die aktuellen Ergebnisse kennzeichnen den Bedarf an Versorgungsstrukturen im Notaufnahmesetting, die eine frühzeitige Erkennung und Ermittlung eines potentiellen Behandlungsbedarfs psychischer Komorbiditäten gewährleisten.

\section{P04 \\ Versorgung kardialer Beschwerden bei möglichen psychischen Komorbiditäten: Die Patient*innenperspektive}

M. Schmiedhofer', A. Schneider', J. Deutschbein'2, S. L. Kuhlmann' ', A. Figura ${ }^{3}$, A. Slagman', M. Rose ${ }^{3}$, M. Möckel'

'Notfallmedizin/Rettungsstellen Nordcampi, Campus VirchowKlinikum und Campus Charité Mitte, Charité - Universitätsmedizin Berlin, Berlin, Deutschland; ' Institut für Medizinische Soziologie und Rehabilitationswissenschaft, Campus Charité Mitte, CharitéUniversitätsmedizin Berlin, Berlin, Deutschland; ${ }^{3}$ Medizinische Klinik mit Schwerpunkt Psychosomatik, Campus Charité Mitte, Charité Universitätsmedizin Berlin, Berlin, Deutschland

Hintergrund: Mental Health Conditions (MHC) bei kardialen Erkrankungen sind unterdiagnostiziert und haben einen signifikanten Einfluss auf Lebensqualität, physische Gesundheit und Selbstmanagement. Die- 
se Personengruppe fordert Notaufnahmen heraus, da mögliche lebensbedrohliche Zustände die durchgeführte Diagnostik bestimmen und für die Berücksichtigung psychischer Erkrankungen Behandlungsressourcen regelhaft nicht zur Verfügung stehen. MHC wirken sich auf Symptompräsentation, Therapieentscheidungen und Adhärenz aus.

Methode:ZurPrävalenzerhebungvon MHCbeiNotaufnahmepatient ${ }^{\star}$ innen mit kardialen Beschwerden wurden 644 Patient*innen aller acht Notaufnahmen des Bezirks Berlin-Mitte auf MHC gescreent und zum Nutzungsmuster ambulanter und stationärer Versorgung sowie zur Behandlungszufriedenheit befragt. Die quantitative Erhebung wurde um 20 Leitfaden gestützte Patienteninterviews ergänzt. Präsentiert werden die Ergebnisse der qualitativen Befragung von 10 Männern und 10 Frauen.

Ergebnisse: Die Befragten berichteten von psychischen Belastungen, die nur bedingt im Zusammenhang zur Schwere bzw. einer diagnostizierten kardialen Erkrankung standen. Große Übereinstimmung zeigt sich hinsichtlich der Wahrnehmung des Notaufnahmesettings als „rettender Ort“. Menschen mit Symptomen einer Somatisierungsstörung berichteten, dass bei ihnen Angstanfälle durch „medizinische Autoritäten“ einer Notaufnahme beendet werden. Für Patient*innen, die nach einer mit Einschränkungen im Lebensalltag einhergehenden kardialen Erkrankung unter depressiven Verstimmungen leiden, spielen kardialen Beschwerden eine verunsichernde Rolle, die sie regelmäßig in Notaufnahmen führen. Die meisten Befragten hatten Erfahrungen häufigen Wechselns zwischen ambulanter und stationärer Versorgung.

Zusammenfassung: Die Versorgung im Notaufnahmesetting ist fokussiert auf körperlicher Untersuchung und Behandlung akuter gesundheitlicher Probleme. Dabei können psychische Komorbiditäten die Symptompräsentation und Adhärenz beeinflussen und die Nutzungsfrequenz von Notaufnahmen erhöhen. Sensibilisierung und Kompetenzentwicklung zur Diagnostik von MHC bei kardialer Symptomatik sind notwendig, um ressourcenschonende Therapie zu gewährleisten und Patient ${ }^{\star}$ innen ein zielgerichtetes Behandlungsangebot unterbreiten zu können.

\section{P05}

\section{Aortale Notfälle in einer Zentralen Notaufnahme - Daten aus sechs Jahren}

\section{A. E.-M. I. Salaymeh', G. Ripberger', E. Kotorova' , R. Somasundaram²,} M. Oppert ${ }^{3}$

${ }^{1}$ Klinik für Notfall- und Internistische Intensivmedizin, Zentrum für Innere Medizin I, Klinikum Ernst von Bergmann, Potsdam, Deutschland; ${ }^{2}$ Notfallmedizin/Rettungsstellen Nordcampi, Campus Virchow-Klinikum und Campus Charité Mitte, Charité - Universitätsmedizin Berlin, Berlin, Deutschland; 'Zentrale Notaufnahme, Klinikum Ernst von Bergmann, Potsdam, Deutschland

Hintergrund: Epidemiologie der klinischen Präsentation, der signifikanten Laborveränderungen, des hämodynamischen Status sowie des Outcomes der Patienten mit akuter Aortenerkrankung.

Methode: Retrospektive Arbeit an Hand von Daten von 70 Patienten mit einer akuten Aortenerkrankung, die über die zentrale Notaufnahme im Zeitraum 2012-2017 im Klinikum Ernst von Bergmann Potsdam aufgenommen wurden, erfasst. Die Daten wurden mittels IBM SPSS Programm analysiert. Ergebnisse wurden mittels logistischer Regression und Chi-Quadrat-Test ausgewertet.

Ergebnisse: In den Jahren 2012 bis Ende 2017 stellten sich 70 Patienten (Durchschnittsalter 72 Jahre alt, SD $\pm 11,9 ; 80 \%$ Männer) mit einer akuten Aortenerkrankung vor. Bei $80 \%$ der Patienten $(n=56)$ wurde die Diagnose in der Zentralen Notaufnahme bzw. auf der Aufnahmestation gestellt. Die mittlere Zeit zwischen der Vorstellung der Patienten in der Notaufnahme und der Durchführung der CT-Diagnostik betrug 1,5 h $(\mathrm{SD} \pm 17,5)$. Die Symptome bei diesen Patienten waren in $98 \%$ plötzlich aufgetreten. $39 \%$ waren initial im Schock. Die häufigsten angegebenen Symptomatiken waren Rückenschmerzen (50 \%), Bauchschmerzen (40 \%), Übelkeit und Erbrechen (31,4\%), Schwindel und neurologische Defizite (30 \%) und thorakale Schmerzen (28,6\%). 28,6\% von den Patienten waren synkopiert. In $10 \%$ der Fälle erfolgte notfallmäßig eine Koronarangiographie. Bei den meisten Patienten waren die klassischen klinischen Befunde wie z. B. Pulsdefizit, pathologische Herzgeräusche und Blutdruckdifferenzen zwischen beiden Armen nicht dokumentiert. Die Gesamtmortalität lag bei $40 \%$, 22 der verstorbenen Patienten hatten eine Aortenruptur, 5 Patienten hatten ein AAS und 1 Patient hatte ein Endoleak. In der Analyse ergab sich keine signifikante Korrelation zwischen Outcome und Laborveränderungen oder EKG-Veränderungen. Es konnte keine signifikante Korrelation zwischen Outcome und der Zeit zwischen dem Eintreffen der Patienten in der Notaufnahme und der Durchführung einer CT-Diagnostik festgestellt werden. Signifikant war eine Korrelation zwischen Schock und Verschlechterung des Outcomes.

Zusammenfassung: Akute Aortennotfälle sind seltene Erkrankungen mit hoher Mortalität. Die Symptomatologie ist sehr vielfältig. Welche Befundkonstellationen die höchste Sensitivität und Spezifität hinsichtlich einer frühen Diagnosestellung haben, muss noch weitergehend untersucht werden.

\section{P06}

\section{Leitsymptom Thoraxschmerz in der internistischen Rettungsstelle}

M. Stierholz, A. Slagman, J. Searle, R. Somasundaram, M. Möckel Notfallmedizin/Rettungsstellen Nordcampi, Campus Virchow-Klinikum und Campus Charité Mitte, Charité - Universitätsmedizin Berlin, Berlin, Deutschland

Hintergrund: Gegenstand aktueller Forschung in der Notfallmedizin ist bei steigenden Patientenzahlen die Effizienzsteigerung der Patientenversorgung. Dabei zeigt sich ein Wechsel vom diagnosebezogenen hin zum symptombezogenen Arbeiten. Angesichts dieser Entwicklung beschäftigt sich diese Arbeit mit der Analyse der Patientencharakteristika, der Diagnosen und des Krankenhausverlaufes eines nicht vorselektierten Patientenkollektivs mit dem Leitsymptom Thoraxschmerz. Dies trägt bei, eine valide Grundlage für evidenzbasierte Entscheidungsprozesse in den Bereichen Diagnostik, Therapie, SOP's und perspektivisch Leitlinien zu schaffen.

Methode: Über einen Betrachtungszeitraum von 12 Monaten erfolgte die prospektive Identifikation von Patienten mit Thoraxschmerz und eine nachfolgend deskriptive Analyse dieser, aus einer insgesamt 34.333 umfassenden Kohorte von unselektierten, internistischen Notaufnahmepatienten.

Ergebnisse: Das Leitsymptom Thoraxschmerz stellt mit 11,8 \% $(n=3954)$ das häufigste Leitsymptom dar. Das bedeutet eine tägliche Frequentierung von 10,8 Brustschmerzpatienten, wobei $47,5 \%$ stationärer Weiterversorgung bedürfen. Der Männeranteil beträgt $58,3 \%$, das mediane Alter 60 Jahre. Bezüglich der Diagnoseverteilung entfallen 23,0 \% auf AP, $15,8 \%$ auf Hals-und Brustschmerz sowie 7,0 \% auf AMI. Für die Krankenhausmortalität wurden $0,4 \%$ ermittelt. Die Wartezeiten bis zur Triage und dem Arztkontakt betrugen im Median 12 bzw. 30 min. Für die mediane Krankenhausverweildauer wurden 3-4 d gemessen. Auf die Patientengruppe mit zugleich diagnostiziertem ACS entfallen innerhalb der Diagnosenverteilung 57,9 \% auf instabile AP, 25,9 \% auf STEMI und 16,1 \% auf NSTEMI. Die intrahospitale Mortalität betrug 1,3\% bei einer ACSspezifischen Wartezeit bis zur Triage und Arztkontakt von im Median 8 min bzw. 16 min. Die Krankenhausverweildauer von ACS-Patienten ergab im Median $4 \mathrm{~d}$.

Zusammenfassung: Der akute Thoraxschmerz ist häufig in der Notaufnahme, jedoch ist nur selten tatsächlich ein ACS die Ursache der Symptomatik. Die niedrige Krankenhausmortalität, eine kurze Wartezeit, sowie die geringe stationäre Verweildauer verdeutlichen, dass aktuell implementierte Prozesse (CPU, SOP) effektiv sind. Es zeigt sich jedoch ein erhöhter Anteil von Patienten, welche die unspezifische Diagnose „Hals-und Brustschmerz" erhalten. Zukünftige Forschungsprojekte sollten diese Patientengruppe weiter adressieren um Ursachen zu evaluieren. 


\section{Akut- und Notfallmedizin 2 (P07-P12)}

\section{P07 \\ Routinedaten des pädiatrischen Patienten in der Erwachsenen- Notaufnahme aus akutmedizinischer Sicht \\ A. Fischer-Rosinský, S. L. Kuhlmann, K. Schmieder, T. Lindner, M. Bolanaki, A. Slagman, M. Möckel \\ Notfallmedizin/Rettungsstellen Nordcampi, Campus Virchow-Klinikum und Campus Charité Mitte, Charité - Universitätsmedizin Berlin, Berlin, Deutschland}

Hintergrund: Die Inanspruchnahme der Notaufnahmen steigt stetig und generiert große Herausforderungen für eine adäquate Versorgung. Eine besondere Gruppe sind pädiatrische Patienten in Notaufnahmen für Erwachsene. Wie lässt sich das pädiatrische Kollektiv in drei Notaufnahmen für Erwachsene im Vergleich zu volljährigen Patienten aus akutmedizinischer Sicht charakterisieren?

Methode: Die Analyse basiert auf Routinedaten des Jahres 2016, der dre Notaufnahmen der Charité Universitätsmedizin Berlin Nord-Campi, welche aus verschiedenen Dokumentationssystemen ausgeleitet wurden.

Ergebnisse: Insgesamt kam es zu 96.717 Patientenkontakten im Jahr 2016. Der Anteil pädiatrischer Patienten betrug davon insgesamt 4,3\% $(n=4175)$.

Hinsichtlich der Behandlungsdringlichkeit sind 1,1 \% der minderjährigen Patienten mit „rot“ triagiert (Manchester Triage System), 4,0\% orange, $27,1 \%$ gelb, 56,2 \% grün und 3,3 \% blau (vgl. Erwachsene 1,0 \%/8,6 \%/43, $8 \% / 39,2 \% / 3,1 \%)$. Die häufigste gesicherte Notaufnahmediagnose ist bei Kindern, als auch Erwachsenen, die Klasse der „Verletzungen und Vergiftungen“ (37,0 \% $(n=2995) / 23,9 \%(n=63.521))$. „Krankheiten des Auges“ ist die zweithäufigste Diagnoseklasse bei Kindern (17,0 \%/7,5 \%) und die dritthäufigste „Krankheiten des Ohres“ (10,1 \%/3,9\%).

Ein erhöhtes klinisches Risiko, wie ein GCS-Score $\leq 8$ Punkten als Trigger für die Auslösung eines Komaalarms, bestand für 0,2 \% der Kinder und $0,6 \%$ der Erwachsenen. Ein Laktatwert $>20 \mathrm{mg} / \mathrm{dl}$ als Marker für eine gestörte Kreislaufsituation und schlechtes prognostisches Outcome lag bei 2,3 \% der Kinder und 8,4 \% der Erwachsenen vor. Der EPICS-Score nach Slagman et al. (berücksichtigt CRP und RDW) welcher das Mortalitätsrisiko abbildet, teilt die pädiatrische Notfälle $(n=664)$ in die Risikoklassen „geringes Risiko“ mit 59,0 \%, „mittleres Risiko“ mit 38,3\% und „hohes Risiko“ mit 2,7 \% ein (Erwachsene $n=47.530: 56,7 \%, 34,0 \%$, $9,2 \%)$.

Zusammenfassung: Der pädiatrische Patient in der Notaufnahme für Erwachsene wird vorwiegend auf Grund spezieller Versorgungsbedarfe (Chirurgie, Augen, HNO) vorstellig. Insofern die benötigte Spezialversorgung nicht bei einem spezialisierten anderen Leistungserbringer im regionalen Umfeld erfolgen kann, sollten die entsprechenden Ressourcen in einer Notaufnahme vorgehalten werden.

\section{P08}

\section{Left Without Being Seen: Hohe Prävalenz von Patient*innen,} welche die Notaufnahme vor Arztkontakt verlassen

T. Wrobel, A. Slagman, J. Searle, A. Fischer-Rosinský, M. Schmiedhofer, M. Möckel

Notfallmedizin/Rettungsstellen Nordcampi, Campus Virchow-Klinikum und Campus Charité Mitte, Charité - Universitätsmedizin Berlin, Berlin, Deutschland

Hintergrund: Durch die zunehmende Überfüllung der Rettungsstellen steigt auch die Anzahl der Patient*innen, die die Notaufnahme vor Arztkontakt verlassen. In Deutschland gibt es kaum Studien zu dieser Patientenpopulation und es ist unklar, wie hoch der Anteil dieser Patient*innen ist, welche typischen Merkmale diese Patientengruppe aufweist, was die Gründe für das Verlassen der Notaufnahme sind und wie sich der folgende Verlauf darstellt.
Ziel der Studie war die Quantifizierung und Charakterisierung dieser Patientengruppe, sowie das Erfassen von Gründen für das Verlassen der Notaufnahme und des weiteren Verlaufes.

Methode: Im Zeitraum vom 01.10.2015-30.09.2016 wurden diese Patient*innen in den Notaufnahmen der Charité-Universitätsmedizin am Campus Charité Mitte und am Campus Virchow Klinikum erfasst. Dabei wurden folgende Parameter in dieser Patientengruppe näher betrachtet: Soziodemographie, Triagekategorie, Tageszeit und der Wochentag der Vorstellung, Vital- und Laborwerte, die Zeitdifferenz zwischen Aufnahme und Ersteinschätzung, sowie der theoretischen Behandlung oder dem Verlassen der Notaufnahme. Gleichzeitig wurde ein FollowUp durchgeführt, in welchem telefonisch bzw. schriftlich die Gründe des Verlassens der Notaufnahme und die weitere Versorgung ihrer Beschwerden befragt wurden.

Ergebnisse: Es waren 3266 Patient*innen, die während dieses Jahres vor Arztkontakt die Notaufnahme verließen (ca. 3,4\% der Patienten in der Notaufnahme). Eine Follow-up Befragung liegt für 1067 Patient ${ }^{*}$ innen vor. Die genaue Auswertung der einzelnen charakteristischen Daten dieser Patientengruppe ist aktuell in Bearbeitung.

Zusammenfassung: Ein hoher Anteil von Patient ${ }^{*}$ innen verlässt die Notaufnahmen vor Arztkontakt. Es zeigte sich insgesamt eine hohe Responserate für die Follow-up Befragung (ca. 1/3). Die weiteren Analysen der Follow-up Befragung werden dazu beitragen, Gründe für das Verlassen der Notaufnahme zu identifizieren und zu quantifizieren, sowie den folgenden Verlauf einzuschätzen.

\section{P09}

\section{EPICS 10 - Risikofaktoren für die Entwicklung eines Deliriums in} der Notaufnahme

R. Spode, C. Römer, A. Fischer-Rosinský, A. Slagman, L. Kollertz, N. Recknagel, M. Möckel

Notfallmedizin/Rettungsstellen Nordcampi, Campus Virchow-Klinikum und Campus Charité Mitte, Charité - Universitätsmedizin Berlin, Berlin, Deutschland

Hintergrund: In der Notaufnahme ist das Delirium ein sich häufig präsentierendes Krankheitsbild: 7-24 \% der älteren Patienten weisen bei Ankunft in der Notaufnahme ein Delirium auf. In den Notaufnahmen des Charité Campus Virchow Klinikum führten wir 2017/18 die Studie EPICS-10 durch, in welcher zwei schnell anwendbare, einfach zu erlernende, sensitive und spezifische Screeningtools zur Deliriumdetektion evaluiert wurden. Ein weiteres Ziel dieser Studie war es, Risikofaktoren für die Entwicklung eines Deliriums in der Notaufnahme zu identifizieren.

Methode: $\mathrm{Zu}$ diesem Zweck wurde eine Analyse der prospektiv erhobenen Daten der EPICS - 10 Studie durchgeführt. Bei den untersuchten Daten handelte es sich um Routinedaten wie Alter, Geschlecht und Liegedauer in der Notaufnahme, sowie Laborparameter, krankheitsspezifische und medikamentenbezogene Daten. Insgesamt konnten 174 Patienten in die Studie eingeschlossen werden. Die Diagnose „Delirium“ wurde mittels Confusion Assessment Method (CAM) gestellt. Es erfolgte die Analyse von Risikofaktoren für die Entwicklung eines Deliriums.

Ergebnisse: Es zeigte sich, dass u. a. hohes Alter, vorbestehender Pflegegrad, vorbestehende Unterbringung in einer Pflegeeinrichtung, neurologische Vorerkrankungen, Demenz, Psychopharmaka in der Dauermedikation sowie ein internistischer Konsultationsgrund der Notaufnahme Risikofaktoren für die Entwicklung eines Deliriums darstellten (• Abb. 1 | P09).

Zusammenfassung: Bei Vorhandensein eines oder mehrerer Risikofaktoren für die Entwicklung eines Deliriums in der Notaufnahme, sollten $\mathrm{Maßnahmen} \mathrm{zur} \mathrm{Deliriumprävention} \mathrm{ergriffen} \mathrm{werden.} \mathrm{Um} \mathrm{die} \mathrm{frühe}$ Identifikation von Patienten mit einem erhöhten Risiko für das Entstehen eines Deliriums in der Notaufnahme zu verbessert, sollten zukünftige Forschungsprojekte die identifizierten Risikofaktoren in Kombination mit etablierten Scores prospektiv untersuchen. 


\begin{tabular}{|l|l|l|l|l|}
\hline & Alle Patienten & CAM negative & CAM positive & P-Wert \\
\hline Parameter & $\mathrm{n}=174$ & $\mathrm{n}=163(93.7 \%)$ & $\mathrm{n}=11(6.3 \%)$ & \\
\hline Geschlecht, m/f (\%) & $98 / 76(56.3 / 43.7)$ & $73 / 90(44.8 / 55.2)$ & $8 / 3(72.7 / 27.3)$ & 0.26 \\
\hline Alter, median (min. - max.) & $76(65-92)$ & $76(65-92)$ & $86(75-92)$ & $<0.001$ \\
\hline $\begin{array}{l}\text { Grund für das Aufsuchen der } \\
\text { Notaufnahme; } \\
\text { internistisch/chirurgisch (\%) }\end{array}$ & $101 / 73(58.0 / 42.0)$ & $91 / 72(55.8 / 44.2)$ & $10 / 1(90.9 / 9.1)$ & $<0.001$ \\
\hline Bekannte Demenz & $16(9.2 \%)$ & $10(6.1 \%)$ & $6(54.5 \%)$ & $<0.001$ \\
\hline Neurologische Vorerkrankung & $52(29.9 \%)$ & $43(26.4 \%)$ & $9(81.4 \%)$ & $<0.001$ \\
\hline $\begin{array}{l}\text { Vorbestehende Unterbringung } \\
\text { im Pflegeheim }\end{array}$ & $16(9.2 \%)$ & $10(6.1 \%)$ & $6(54.5 \%)$ & $<0.001$ \\
\hline Vorbestehender Pflegegrad & $14(8.1 \%)$ & $11(6.7 \%)$ & $3(27.3 \%)$ & 0.015 \\
\hline $\begin{array}{l}\text { Psychopharmaka in } \\
\text { der Dauermedikation }\end{array}$ & $32(19.4 \%)$ & $27(16.1 \%)$ & $5(45.5 \%)$ & 0.017 \\
\hline
\end{tabular}

\section{Abb. $1 \mid$ P09 $<$}

\section{P10}

\section{Ein Fall mit Meningokokkensepsis: Praktische Implikationen für das Sepsisscreening in der Notaufnahme}

\section{Bolanaki, A. Slagman, M. Möckel}

Notfallmedizin/Rettungsstellen Nordcampi, Campus Virchow-Klinikum und Campus Charité Mitte, Charité - Universitätsmedizin Berlin, Berlin, Deutschland

Hintergrund: Die „Sepsis-3“ Definition stellt den qSOFA (quick Sequential Organ Failure Assessment Score) als ein neues Screening Tool in der Notaufnahme vor. Um den Stellenwert von qSOFA zum Sepsisscreening zu hinterfragen, stellen wir eine 80-jährige Patientin mit initialem Verdacht auf Schlaganfall vor: Die Patientin war am Vorabend symptomfrei zu Bett gegangen, beim Aufwachen fühlte sie sich unwohl, hatte unwillkürlichen Harnabgang und erbrach sich. Der Sohn der Patientin und die Patientin selbst berichteten über eine leichte Erkältungssymptomatik, sowie eine leicht veränderte Sprache. Vorerkrankungen und Dauermedikation lagen nicht vor. Es bestand kein Meningismus, keine Kopfschmerzen und keine Photophobie.

Methode: Der qSOFA-Score ergab einen Punktwert von „0“:AF 16/min, syst.RR $151 \mathrm{~mm} \mathrm{Hg}$, GCS 15 (wach,orientiert). Die Infektparameter waren initial nur diskret erhöht (Leukozyten 8,34/nl, CRP von $17 \mathrm{mg} / \mathrm{l}$, PCT $0,33 \mu \mathrm{g} / \mathrm{l}$ ), es bestand Fieber und im EKG zeigte sich ein zuvor nicht bekanntes Vorhofflimmern. Laktat war mit $17 \mathrm{mg} / \mathrm{dL}$ normal. Neurologische Vorstellung, CT-Angiographie sowie cMRT ergaben keinen Anhalt auf eine intrakranielle Blutung oder einen Hirninfarkt. Nebenbefundlich stellte sich eine große bilaterale zerebelläre Arachnoidalzyste dar, die als relative Kontraindikation für eine Liquorpunktion gewertet wurde. Im Rahmen der Suche nach einem Infektfokus erfolgten ein Röntgen-Thorax und eine Urin-Status ohne wegweisende Befunde. Auf eine antibiotische Behandlung wurde zunächst verzichtet.

Ergebnisse: Im Verlauf veränderte sich der Zustand der Patientin mit einem GCS von 14 (somnolent) und einer Tachypnoe;qSOFA Score "2“. Nach Aufnahme auf die Stroke Unit verschlechterte sich die Patientin rasch, sodass mit dem Bild einer respiratorischen Insuffizienz mit septischem Schock eine notfallmäßige Verlegung auf Intensivstation erfolgte. Das CT-Thorax ergab eine bilaterale Pneumonie. Retrospektiv muss die milde neurologische Symptomatik als minimale cerebrale Dysfunktion gewertet werden. Später konnte zudem eine Meningokokkenbakteriämie und -meningitis diagnostiziert werden.

Zusammenfassung: Dieser Fall illustriert, dass insbesondere die „mental changes" des qSOFA mit dem GCS nur unzureichend abgebildet werden und bei anhaltend unklarer Diagnose insbesondere bei älteren Patienten mit Infektsymptomatik eine frühzeitige antibiotische Therapie großzügig indiziert ist.

\section{P11}

\section{Analyse zur Opioidverabreichung in der Notaufnahme}

C. Römer, R. Spode, A. Fischer-Rosinsky, A. Slagman, M. Möckel Notfallmedizin/Rettungsstellen Nordcampi, Campus Virchow-Klinikum und Campus Charité Mitte, Charité - Universitätsmedizin Berlin, Berlin, Deutschland

Hintergrund: Die Prävalenz des Leitsymptoms Schmerz wird in der Literatur zwischen 45 bis $70 \%$ angegeben. Bei Betrachtung der Opiatverordnungen waren die häufigsten Gründe für eine Opiatverordnung in der Notaufnahme: Rückenschmerzen (10,2 \%), gefolgt von abdominellen Beschwerden $(10,1 \%)$ und Frakturen der Extremitäten (7,1 \%). Im Jahr 2017 verstarben in den USA ca. 71.568 Menschen an einer direkt mit Opiaten in Verbindung zu bringenden Ursache. Etwa jede fünfte Verschreibung in der Notaufnahme beinhaltet ein Opiat. Eine scheinbar tragende Rolle der Notaufnahmen in der Opioidkrise wird zur Zeit in den USA kontrovers diskutiert. Daten zur Opioidanwendung in deutschen Notaufnahmen liegen nicht vor.

Methode: Wir untersuchten in einer retrospektiven Analyse die manuelle Opioiddokumentation unserer internistischen Notaufnahme des Campus Virchow-Klinikum im Jahr 2015. Hierbei wurden ausschließlich Patienten eingeschlossen, welche folgende Medikamente in der Notaufnahme erhielten: MSI, MST, Piritramid oder Dolantin. Die präsentierten Daten beziehen sich auf eine Voranalyse des ersten Quartals mit einer Stichprobengröße von $n=240,52,9 \%$ männlich und $49,1 \%$ weiblich. Die statistische Analyse erfolgte mittels SPSS.

Ergebnisse: Im Mittel waren die Patienten 52 Jahre alt. Patienten, die ein Opioid appliziert bekamen, waren überwiegend orange $(51,9 \%)$ und gelb (35\%) triagiert. Das führende Leitsymptom war der Bauchschmerz, (38,3\%), gefolgt von Dyspnoe (19,2\%) und Brustschmerzen (7,1\%). Ein Großteil der Patienten wurde im Anschluss stationär aufgenommen $(71,8 \%)$. Die drei vorrangigen Diagnosen, welche die stationäre Aufnahme bedingten, waren Bauch- und Beckenschmerzen (12 Pat.), akute Pankreatitis (14 Pat.) und Pneumonie (14 Pat.), 23,9 \% der Patienten wurden ambulant weiterversorgt, weitere $3,4 \%$ wurden auf die Intensivstation verlegt.

Zusammenfassung: Steigende Opioidverordnungen in den USA und in Deutschland machen es unabdingbar für die Opioidanwendung und -vergabe in der Notaufnahme zu sensibilisieren, die zugrundeliegenden Diagnosen zu ermitteln bzw. den tatsächlichen Bedarf kritisch zu evaluieren. Die vorliegende Studie stellt eine erste Statuserhebung dar. Eine nachfolgende prospektive Studie zur Erfassung des weiteren, auch ambulanten, Behandlungsverlaufes ist geplant um Assoziationen von Opioidbehandlungen in der Notaufnahme mit der Entstehung bzw. Verschlechterung eines prolongierten Opioidmissbrauchs zu erfassen. 


\section{P12}

\section{MSSA/MRSA-Kolonisation bei Patient*innen der Notaufnahme: eine Prävalenzerhebung}

\section{Riedlinger', F. Holert' ', P. Gastmeier', A. Kola², A. Slagman' ', M. Möckel'} 'Notfallmedizin/Rettungsstellen Nordcampi, Campus Virchow-Klinikum und Campus Charité Mitte, Charité - Universitätsmedizin Berlin, Berlin, Deutschland; ${ }^{2}$ Institut für Hygiene und Umweltmedizin, Campus Benjamin Franklin, Charité - Universitätsmedizin Berlin, Berlin, Deutschland

Hintergrund: Nosokomiale Infektionen stellen ein großes Gesundheitsrisiko dar. Hierbei sind vor allem endogene Infektionen aus dem Erregerreservoir der Patient ${ }^{*}$ innen eine Herausforderung. Mit circa $17 \%$ bilden Staphyococcus aureus (SA) Infektionen einen großen Anteil an den nosokomialen Infektionen. Eine frühzeitige Erkennung einer Kolonisation im Krankenhausaufenthalt ermöglicht gezielte Präventionsmaßnahmen. Die Prävalenz von Staphylokokken-Kolonisationen im Patientenkollektiv der Notaufnahme ist bisher nicht beschrieben.

Ziel dieser Studie ist eine Prävalenzerhebung einer Kolonisation des NasenRachen-Raums mit Methicillin-sensiblem und Methicillin-resistentem Staphylococcus aureus (MSSA/MRSA) bei Notaufnahmepatient*innen und die Ermittlung von Risikofaktoren dieses Kollektivs.

Methode: Aufeinanderfolgende volljährige Notaufnahmepatient ${ }^{*}$ innen erhielten im Rahmen der Studie bei Aufnahme in die Notaufnahmeversorgung eine Screeninguntersuchung auf eine Besiedelung des Nasen-Rachen-Raums mit MSSA/MRSA. Zusätzlich wurde bei allen Patient ${ }^{*}$ innen ein Screeningfragebogen zu Risikofaktoren für eine Kolonisation mit MSSA/MRSA erhoben. Die Proben wurden mit dem cobas ${ }^{\circ} 4800$ MSSA/ MRSA PCR-Assay untersucht.

Ergebnisse: Im Zeitraum vom 09.10.2017 bis zum 12.11.2017 wurden 1238 Patient ${ }^{\star}$ innen untersucht. Bei 987 Patient ${ }^{*}$ innen lagen Fragebogen und ein Abstrich vor. Das mittlere Alter der Kohorte war 50 Jahre (SD \pm 20,3), 49,3\% der Teilnehmer*innen (TN) waren männlich. Es wurden 27 Personen MRSA positiv getestet, eine MSSA-Kolonisation wurde bei $33,1 \%$ der TN nachgewiesen. Anamnestisch bekannt waren die MRSABesiedelungen bei 31 TN-bei 11,5\% der MRSA- und bei 2,1 \% der MSSA-Screening-positiven war eine MRSA-Besiedelung dokumentiert. Einen Krankenhausaufenthalt innerhalb der letzten 12 Monate hatten 51,9 \% der MRSA-Positiven und 23,7 \% der MSSA-kolonisierten Personen, eine Antibiotikatherapie in den vorausgegangenen 6 Monaten erhielten 29,6\% (MRSA) und 21,0\% (MSSA) der Patient ${ }^{\star}$ innen.

Zusammenfassung: Anamnestische Angaben über Staphylokokken-Kolonisationen sind alleine nicht hinreichend zur Indikationsstellung für $\mathrm{Hy}-$ gienemaßnahmen, da ein großer Anteil der Patienten nicht erfasst wird. Bei Patientenkollektiven mit besonders hohem Risiko für endogene Infektionen - Indikation zur Akutoperation, Aufnahme bei schwerer Infektion oder zur Beatmung - sollte eine Screeninguntersuchung erfolgen.

\section{Allgemeine Intensivmedizin (P13-P17)}

\section{P13}

\section{Letale Sichelzellkrise}

T.S. Meisel', M. Haab' ${ }^{2}$, T. Volk

${ }^{1}$ Klinik für Anästhesiologie, Intensivmedizin und Schmerztherapie, Universitätsklinik Homburg, Universität des Saarlandes, Homburg/ Saar, Deutschland; ${ }^{2}$ Institut für Pathologie, Universitätsklinik Homburg, Universität des Saarlandes, Homburg/Saar, Deutschland

Hintergrund: Anhand einer Kasuistik wird die Erkrankung und Komplikationen einer HBSbeta0 Thalassämie beschrieben.

Methode: Eine 36-jährige Patientin wurde mit Fieber, Schmerzen und gastrointestinalen Beschwerden in die Klinik eingewiesen. Als Grunderkran kung bestand eine HBSbeta0 Thalassämie. Die Patientin war vigilanzgemindert (GCS 11). Ausgeprägte generalisierte Schmerzen wurden durch
Hydromorphon behandelt. Im septischen Schock mit Kreislaufinstabilität, respiratorische Globalinsuffizienz wurde die Patientin auf die Intensivstation verlegt und intubiert. Radiologisch zeigten sich fleckig konfluierende Infiltrate im rechten Mittel- und Unterfeld. Mittels Bronchoskopie wurde purulentes Sekret zur mikrobiologische Diagnostik gewonnen. Eine antiinfektive Therapie mit Piperacillin/Tazobacam um Cipofloxacin nach Asservierung von Blutkulturen innerhalb der ersten Stunde etabliert. Eine virale Genese der Pneumonie konnte ausgeschlossen werden. Laborchemisch zeigte sich eine Hämolyse, so dass die Diagnose einer Sichelzellkrise gestellt wurde.

Ergebnisse: Im Verlauf entwickelte die Patientin ein Multiorganversagen mit Nierenversagen und septischer Cardiomyopathie. Trotz CVVHD, manueller Blutaustauschtransfusion $(3 \mathrm{~L}$ ) verstarb die Patientin innerhalb von $8 \mathrm{~h}$ auf der Intensivstation. Postmortem wurde eine Obduktion durchgeführt. Zusammenfassung: Bei der HBSbeta0 Thalassämie besteht eine geemischte Heterozygotie mit einerseits einer HBS: Mutation der beta-Kette $\beta 6$ Glu $\rightarrow$ Val, was unter Hypoxie zur intraerythrozytäre Aggregation der HB Moleküle und Sichelzellbildung mit hämolytischer Anämie und lebensbedrohlicher Sichelzellkrise führt. Zum anderen ist die $\beta 0$ Thalassämie durch fehlende Synthese der beta-Ketten Ursache schwergradiger Anämien.

Die Erkrankung ist in der Mittelmeerregion häufig und die Patienten im Umgang mit ihrer Erkrankung geschult. Auslösende Faktoren wie Dehydration, Unterkühlung, Hypoxie, Azidose und Infektionen sollten durch gezielte Maßnahmen sowie der frühzeitigen ärztliche Vorstellung bei Zeichen von Infektionen frühzeitig behandelt werden. Fieberepisoden rechtfertigen eine stationäre Aufnahme.

\section{P14}

Kardiogener Schock bei hypokalzämischer Kardiomyopathie mit hochgradig reduzierter linksventrikulärer Pumpfunktion bei primärem Hypoparathyreoidismus

\section{U. Schon, I. Tanev, A. Schmeißer, R. Braun-Dullaeus}

Klinik für Kardiologie, Angiologie und Pneumologie, Universitätsklinikum, Otto-von-Guericke-Universität Magdeburg, Magdeburg, Deutschland

Hintergrund: Die hypokalzämische Kardiomyopathie ist eine seltene Erkrankung, die im Einzelfall zur lebensbedrohlichen akuten kardialen Dekompensation führen kann. Mit Ausgleich des Serumkalziums ist diese Erkrankung in den meisten Fällen reversibel.

Methode: Wir berichten über einen 53-jährigen Patienten mit akuter globaler Herzinsuffizienz bei hypokalzämischer Kardiomyopathie bei primärem Hypoparathyreoidismus.

Ergebnisse: Ein 53-jähriger Patient stellte sich in unserer Notaufnahme mit progredienter Dypsnoe NYHA III und Unterschenkelödemen vor. In den Vordiagnosen war ein primärer Hypoparathyreoidismus bekannt der mit $500 \mathrm{mg}$ Calcium und 0,5 $\mu \mathrm{g}$ Calcetriol pro Tag therapiert wurde. Laborchemisch detektierte sich ein erhöhtes NT-pro BNP von $18.913 \mathrm{pg} /$ $\mathrm{ml}$, röntgenologisch eine pulmonale Stauung. Nach stationärer Aufnahme verschlechterte sich die respiratorische Situation des Patienten. Bei respiratorischer Globalinsuffizienz erfolgte im Verlauf die Intubation und Verlegung auf Intensivstation. In einer durchgeführten transthorakalen Echokardiographie präsentierte sich eine hochgradig reduzierte LVEF von $20 \%$ mit Kinetikstörungen. Der Patient war katecholaminpflichtig mit einem initialem Arterenolbedarf von $900 \mu \mathrm{g} / \mathrm{h}$ und einem Laktat von max. 2,2 mmol/L im kardiogenen Schock. Laborchemisch zeigte sich ein deutlich verminderter Kalziumserumwert von 1,51 mmol/l. Wir erhöhten die Therapie auf täglich 1500 mg Kalzium. Nach Stabilisierung konnte mit initiierter Herzinsuffizienztherapie eine verbesserte respiratorische Situation erreicht werden und der Patient wurde folgend rekompensiert. Eine im Verlauf durchgeführte Herzkatheteruntersuchung schloss eine Koronare Herzerkrankung aus und zeigte nach 2-wöchigem stationären Aufenthalt, ausgeglichenem Calcium und Herzinsuffizienztherapie eine verbesserte LVEF von $50 \%$. Nach 4-wöchigem intensivmedizinischen Aufenthalt konnte der Patient in die Rehabilitation verlegt werden.

Zusammenfassung: Die hypokalzämische Kardiomyopathie ist eine seltene Krankheitsform, die in seltenen Fällen auch zum kardiogenen Schock 
führen kann. Meist werden die Patienten im Vorfeld mit neurologischen Symptomen auffällig, worunter die Kalziumsubstitution bereits optimiert wird. In der akuten Situation ist neben der intensivmedizinischen Behandlung des kardiogenen Schocks die hochdosierten Kalzium-Substitution für die Reversibilität der Erkrankung entscheidend.

\section{P15}

\section{Patientencharakteristika und Outcome-Analyse für Patienten mit nekrotisierender Fasziitis auf den Intensivstationen des Universitätsklinikums Hamburg-Eppendorf}

\section{A. I. Ogica, C. Burdelski, S. Kluge, G. de Heer}

Klinik für Intensivmedizin, Zentrum für Anästhesiologie und Intensivmedizin, Universitätsklinikum Hamburg-Eppendorf, Hamburg, Deutschland

Hintergrund: Die nekrotisierende Fasziitis (NF) ist eine fulminante, bakterielle Weichteilinfektion, die häufig mit einer Sepsis bzw. einem septischem Schock einhergeht. Bekannte Risikofaktoren sind Verletzungen der Haut (traumatisch, chirurgisch etc.), sowie Immunsuppression. Die Letalität dieses seltenen Krankheitsbildes ist hoch.

Methode: In dieser retrospektiven Analyse wurden die Daten aller Patienten der Klinik für Intensivmedizin des Universitätsklinikums HamburgEppendorf, die im Zeitraum von 2009 bis 2017 behandelt wurden, hinsichtlich der Hauptdiagnose einer nekrotisierenden Fasziitis untersucht. Die so detektierten Patienten wurden hinsichtlich ihrer demographischen Daten, der klinischen Parameter sowie des Outcomes analysiert. Die statistische Auswertung erfolgte mittels SPSS, Version 25.

Ergebnisse: Im angegebenen Untersuchungszeitraum konnten 59 Patienten detektiert werden. 41 (62 \%) waren männlich. Das mediane Alter betrug 53 Jahre (19-89 Jahre). Die mediane Verweildauer betrug fünf Tage (1-71 Tage). Alle Patienten wurden operativ versorgt. Auf der Intensivstation verstarben 15 (25\%) Patienten, sie zeigten zum Aufnahmezeitpunkt einen septischen Schock (OR 1,69; $95 \%$ CI 1,32-2,16, $p=0,003)$. Die
30-Tage-Mortalität lag bei $29 \%$. Der Mittelwert $( \pm$ SD) des Laktats bei Aufnahme betrug 4,22 $\pm 5,42 \mathrm{mmol} / \mathrm{l}$, bei Laktat $>10 \mathrm{mmol} / \mathrm{l}$ lag die Mortalität bei $100 \%$ (OR 5,88; $95 \%$ CI 3,24-10,68, $p<0,0001) .20$ (34 \%) zeigten eine NF Typ I (polymikrobiell) und 34 (58 \%) eine NF Typ II (monomikrobiell). Bei 5 (9\%) Patienten gelang kein Keimnachweis. Wie erwartet korrelierte ein erhöhter SAPSII/SOFA Score mit einer erhöhten Mortalität. Eine Anzahl von vier oder mehr Organdysfunktionen erhöhte das Sterblichkeitsrisiko auf das 8,7fache ( $p=0,001) .49$ (83\%) Patienten zeigten Infektionen mit grampositiven Kokken in den Wundabstrichen; gramnegative Bakterien wurden bei 20 Patienten (34 \%) nachgewiesen. Bei Beteiligung gramnegativer Keime handelte es sich meist um eine Mischinfektion.

Zusammenfassung: Die NF imponiert klinisch oftmals als ein fulminant septisches Krankheitsbild. Die Sterblichkeit für Patienten mit dem Vollbild eines septischen Schocks ist hoch. Bereits bei Verdacht auf eine NF muss frühzeitig und unmittelbar eine breite antiinfektive Therapie eingeleitet und eine schnellstmögliche chirurgische Sanierung angestrebt werden.

\section{P16}

\section{Effect of HA330 resin-directed hemoadsorption in critically ill} patients with septic shock-a pilot observational trial

\section{A. Kersten, M. Dreher, N. Marx}

Medizinische Klinik I, Kardiologie, Angiologie und Internistische Intensivmedizin, Universitätsklinikum, Rheinisch-Westfälische Technische Hochschule Aachen, Aachen, Germany

Objective: In the early phases of sepsis, an overshoot of pro-inflammatory mediators is often observed. Reducing this excess cytokine release might be associated with positive outcomes. We present the use of a novel cytokine removal cartridge (HA 330) in patients (pts) with refractory septic shock. Method: We analyzed data of 15 pts treated for septic shock and multiorgan failure between January 2018 and December 2018 in the cardiologic-pneumologic ICU of the University Hospital Aachen, Germany who were treated with cytokine in refractory septic shock defined as contin-

\begin{tabular}{|l|r|r|r|r|r|r|r|r|r|r|}
\hline id & $\mathrm{pH}$ & lactate & $\mathrm{PCT}$ & $\mathrm{s}$-IL2 & $\mathrm{IL}-6$ & $\mathrm{IL}-8$ & $\mathrm{IL}-10$ & TNF-alpha & LPS-BP & norepinephrin \\
\hline 1 & 7.18 & 16 & 90.4 & 7,500 & 11,596 & 1,898 & 1,000 & 72.2 & 27.8 & \\
\hline 2 & 7.18 & 4.6 & 81.5 & 1,556 & 1,800 & 410 & 80 & 15.5 & 163 & \\
\hline 3 & 7.11 & 4.7 & 2.8 & 2,162 & 199,380 & 7,500 & 455 & 200 & 7.9 & \\
\hline 4 & 7.20 & 4.6 & 100.0 & 7,500 & 76,801 & 7,500 & 340 & 65.2 & 110.7 & 2.8 \\
\hline 5 & 7.32 & 4.1 & 100.0 & 5,567 & 4,522 & 672 & 46 & 110.2 & 128.6 & 2.7 \\
\hline 6 & 7.30 & 4.8 & 100.0 & 2,966 & 5,084 & 530 & 80 & 109 & 68.5 & 2.5 \\
\hline 7 & 7.21 & 15.4 & 46.6 & 7,500 & 10,578 & 2,100 & 1,000 & 87.2 & 32.8 & 14.5 \\
\hline 8 & 7.37 & 5.6 & 36.2 & 6,513 & 5,291 & 786 & 54 & 128.9 & 150.5 & \\
\hline 9 & 7.36 & 12.4 & 100.0 & 5,775 & 59,137 & 5,775 & 262 & 50.2 & 85.2 & \\
\hline 10 & 7.21 & 7.2 & 52.5 & 7,500 & 10,552 & 1,727 & 910 & 65.7 & 25.3 & 3.2 \\
\hline 11 & 7.34 & 9.7 & 92.4 & 2,739 & 4,695 & 489 & 74 & 100.7 & 63.3 & 2.7 \\
\hline 12 & 7.19 & 12.4 & 47.2 & 1,450 & 7,512 & 1,745 & 1,000 & 92 & 21.5 & 3.2 \\
\hline 13 & 7.01 & 14.7 & 100.0 & 7,500 & 13,854 & 1,544 & 1,000 & 81.2 & 31.2 & 2.5 \\
\hline 14 & 7.12 & 11.8 & 3.2 & 5,443 & 257,667 & 7,500 & 230 & 201 & 28.2 & 3.5 \\
\hline 15 & 7.01 & 17.1 & 67.3 & 7,500 & 16,782 & 1,765 & 1,000 & 98.7 & 47.4 & 4.5 \\
\hline
\end{tabular}

$\mathrm{PCT}=$ procalcitonin

sIL2 = soluble interleukin2 receptor

IL-6 $=$ interleukin 6

IL-8 $=$ interleukin 8

IL-10 = interleukin 10

TNF-alpha = tumor necrosis factor alpha

LPS-BP = lipopolysaccharide binding protein
Units:

Lactate in $\mathrm{mmol} / \mathrm{l}$

PCT in $\mathrm{ng} / \mathrm{ml}$

s-IL2 in units/ml

IL-6 in $\mathrm{pg} / \mathrm{ml}$.

IL-8 in $\mathrm{pg} / \mathrm{ml}$

$\mathrm{IL}-10$ in $\mathrm{pg} / \mathrm{ml}$

TNF-alpha in ng/l

LPS-BP in $\mathrm{mcg} / \mathrm{ml}$

Norepinpehrin in $\mathrm{mg} / \mathrm{hour}$

Abb. 1 | P16 $\Delta$ Baseline values for $\mathrm{pH}$, lactate, vasopressor dose and cytokine measurements 


\begin{tabular}{|l|r|r|r|r|}
\hline & All & survivors & non-survivors & $p$ \\
\hline PCT & $20.6 \pm 122.3$ & $-11.6 \pm 14.9$ & $57.5 \pm 178.1$ & 0.2918 \\
\hline slL-2 & $-12.7 \pm 24.8$ & $-22.8 \pm 18.0$ & $-1.2 \pm 27.8$ & 0.0944 \\
\hline IL-6 & $57.7 \pm 220.0$ & $-47.5 \pm 28.0$ & $178.1 \pm 283.5$ & 0.0424 \\
\hline IL-8 & $10.8 \pm 59.5$ & $-9.4 \pm 26.6$ & $33.9 \pm 29.9$ & 0.1676 \\
\hline IL-10 & $26.0 \pm 113.5$ & $-27.8 \pm 22.6$ & $87.4 \pm 145.6$ & 0.0449 \\
\hline TNF-alpha & $-25.7 \pm 19.3$ & $-35.8 \pm 11.2$ & $-14.2 \pm 11.2$ & 0.0239 \\
\hline LPS-BP & $-25.5 \pm 15.7$ & $-23.7 \pm 13.5$ & $-27.6 \pm 18.8$ & 0.6478 \\
\hline
\end{tabular}

suchung. ${ }^{18}$ FDG reichert sich in Regionen mit erhöhtem Glukosemetabolismus wie entzündliche Herde an. Das Verfahren ist mit hohem zeitlichem und finanziellem Aufwand verbunden. Wir untersuchten den Nutzen des ${ }^{18}$ FDG-PET/CTs bei septischen Intensivpatienten.

Methode: Retrospektiv wurden alle Patienten eingeschlossen, die von Januar 2007 bis einschl. Juli $2018 \mathrm{im}$ UKE auf einer ICU ein ${ }^{18} \mathrm{FDG}-\mathrm{PET} / \mathrm{CT}$ zur Suche nach einem Infektfokus erhielten.

Ergebnisse: Bei 103 Patienten wurden $108{ }^{18} \mathrm{FDG}-\mathrm{PET} / \mathrm{CT}$ durchgeführt. Durchschnittsalter 59,2 Jahre (18 bis 88 J.), 71,8 \%m, 28,2 \%w. Zum Zeitpunkt des PET/CTs waren 50,9\% der Patienten beatmet, 55,6 \% erhielten kreislaufunterstützende Medikamente, 90,7 \% erhielten Antibiotika und 26,9 \% Antimykotika. 74,3 \% der Patienten überlebten den Intensivaufenthalt.

$\mathrm{PCT}=$ procalcitonin

sIL2 $=$ soluble interleukin2 receptor

IL-6 $=$ interleukin 6

IL-8 = interleukin 8

IL-10= interleukin 10

TNF-alpha = tumor necrosis factor alpha

LPS-BP = lipopolysaccharide binding protein

Abb. 2 | P16 \ Mean cytokine elimination in \% from baseline to 8 hours treatment

ued clinical deterioration despite optimal standard treatment. We measured pH, lactate, PCT, IL-2, IL-6, IL-8, IL-10, TNF-alpha, lipopolysaccharide binding protein and norepinephrin dosage at baseline and in 2-hour intervals for the $8 \mathrm{~h}$ treatment and $4 \mathrm{~h}$ afterwards. We evaluated hospital mortality for the patient's current hospitalization.

Results: Of the 15 pts treated with cytokine removal, 9 were also treated with ECMO. $73 \%$ of patients were male with a mean age of 51.9 years. Mortality was $46.7 \%$ overall and $66.7 \%$ in pts. with ECMO. Mean SOFA score at baseline was $16.9 \pm 1.5$. Baseline cytokine levels were extremely high and elimination rates varied widely $(\bullet$ Abb. $1 \mid$ P16).

In 4 pts levels for PCR, sIL-2, IL-8 and IL-10 stayed above the measurable upper limit during the cytokine elimination. A drop from baseline was measured in 8 pts for PCT, 9 pts for s-IL2, 12 pts for IL-6, 7 pts for IL-8, 9 pts for IL-10, 12 pts for TNF-alpha and 13 pts for LPS-BP, Lactate and norepinephrin dosage dropped in all pts. Only clearance from baseline to end of treament for IL-6, IL-10 and TNF-alpha differed significantly between survivors and non-survivors ( $p<0.05$ each) (• Abb. $2 \mid$ P16).

For these cytokines treatment was associated with an overall reduction of circulating levels of IL-6.IL-10 and TNF-alpha in all but 3 patients. In these 3 patients, all of whom died, IL- 6 and IL-10 increased several folds while TNF-alpha remained nearly unchanged. When stratified by the use of ECMO, the statistical significance between survivors and non-survivors only remained for TNF-alpha.

Conclusion: The use of the HA 330 cartridge reduced IL-6,IL-10 and TNF-alpha to a higher extend in surviving patients with septic shock and MOF in a cohort with very high mortality. Further investigation of the effects of this device on cytokine levels and patient centered outcomes seems warranted

\section{P17}

Diagnostische Wertigkeit des 18FDG-PET/CTs bei Intensivpatienten mit Sepsis: Hilft ein 18FDG-PET/CT zuvor unbekannte Infektherde zu identifizieren und gehen daraus therapeutische Konsequenzen hervor?

T. Strohm', C. Berliner', S. Klutmann', S. Kluge', K. Kampe ${ }^{1}$

${ }^{1}$ Klinik für Intensivmedizin, Zentrum für Anästhesiologie und Intensivmedizin, Universitätsklinikum Hamburg-Eppendorf, Hamburg, Deutschland; ${ }^{2}$ Abteilung für Nuklearmedizin, Klinik und Poliklinik für Diagnostische und Interventionelle Radiologie, Universitätsklinikum Hamburg-Eppendorf, Hamburg, Deutschland

Hintergrund: Die Kombination von PET und CT ermöglicht die Vereinigung von funktionellen und anatomischen Informationen in einer Unter-

Bei 73 von 108 PET/CTs (67,6 \%) wurde ein Entzündungsfokus detektiert. In 38 Fällen wurde ein vorher nicht bekannter Fokus lokalisiert und in 53 ein bekannter Fokus bestätigt. Bei 18 Befunden traf beides zu. Bei $58(53,7 \%)$ von 108 Untersuchungen wurden durch den PET/CT-Befund neue Erkenntnisse zum Krankheitsverständnis gewonnen. Davon änderte sich bei 50 (86,2\%) das Behandlungskonzept.

Zur Analyse der therapeutischen Konsequenzen der 108 PET/CT Untersuchungen wurde jeder erhobene Befund einzeln betrachtet, aus denen 179 Einzelbefunde hervorgehen. 76 der Einzelbefunde führten zu weiteren, nicht-invasiven diagnostischen Maßnahmen, die $62 \mathrm{Mal}(81,6 \%)$ den PET-Befund bestätigten. 79 Einzelbefunde lösten invasive Diagnostik-/Therapiemaßnahmen aus (z.B. Punktion, operative Sanierung). Bei $73(92,4 \%)$ wurde der Fokus dabei verifiziert und/oder saniert. Aus 68 Einzelbefunden folgte eine Änderung und/oder Verlängerung der Antibiotikatherapie. 2 Patienten erhielten neu Antibiotika.

In $25 \%$ der 108 PET/CTs wurden Zusatzbefunde mit therapeutischen Konsequenzen detektiert, z. B. Lungenembolien.

Transportassoziierte Komplikationen traten nicht auf. Der zeitliche Aufwand betrug durchschnittlich 107,7 min.

Zusammenfassung: Unsere Datenanalyse zeigt, dass bei strenger Indikationsstellung ${ }^{18} \mathrm{FDG}$-PET/CT auch bei Intensivpatienten, trotz erheblichem Aufwand, sinnvoll eingesetzt werden kann. Die PET/CT Befunde hatten häufig weiterführende therapeutische Konsequenzen und waren für die Diagnose hilfreich.

\section{Case Reports 1 (P18-P23)}

\section{P18}

Surviving the storm: Stellenwert der Plasmapherese im multimodalen Therapiekonzept der thyreotoxischen Krise

\section{S. Rudolf', S. Hey' ', C. Betz' ', H. Geiger', S. Büttner ${ }^{1}$}

${ }^{1}$ Medizinische Klinik III, Nephrologie, Universitätsklinikum, Johann Wolfgang Goethe-Universität, Frankfurt a. M., Deutschland; ' ${ }^{2}$ Medizinische Klinik III, Kardiologie, Universitätsklinikum, Johann Wolfgang Goethe-Universität, Frankfurt a. M., Deutschland

Hintergrund: Die thyreotoxische Krise, eine Multisystemerkrankung mit hoher Letalität, führt unbehandelt unweigerlich zum Tod und bedarf einer raschen Diagnose sowie einem multimodalen Therapiekonzept wodurch die Prognose wesentlich verbessert werden kann.

Ergebnisse: Notfällige Vorstellung einer 43-jährigen Frau mit M. Basedow mit Dyspnoe, Palpitationen und progredienter Symptomatik in Form einer hämodynamisch relevanten Tachyarrythmia absoluta mündend in einer Asystolie mit Reanimation. Es fiel ein TSH $<0,01$ und erhöhte fT3 $(29,8$ $\mathrm{pmol} / \mathrm{l})$ und fT4 $(6,7 \mathrm{ng} / \mathrm{ml})$, sowie hohe anti-TPO- und TRAK-Ak auf. Fremdanamnestisch wurde eine unregelmäßige Einnahme von Carbimazol eingeräumt. Nach erfolgreicher Reanimation wurde eine Therapie mit Thiamazol, Irenat und Hydrokortison sowie supportiven Maßnahmen eingeleitet. Überlappend erfolgte bei hämodynamisch relevantem tachykard übergeleitetem Vorhofflimmern erfolgte die Digitoxin-Aufsättigung und elektrische Kardioversion. Bei fulminanter, rasch progredienter Sympto- 
matik wurde bei vitaler Bedrohung eine Plasmaseparation durchgeführt. Unter der Therapie fielen die Schilddrüsen(SD)werte einhergehend mit einer klinischen Stabilisierung und kontinuierlichen Besserung, sodass im Intervall die Thyreoidektomie erfolgen konnte.

Die medikamentöse Therapie verhindert die weitere Bildung der SD-Hormone: Thiamazol durch die Synthesehemmung von T3+T4, Irenat durch die Jodidaufnahme in die SD. Die langen Halbwertszeiten der zirkulierenden SD-Hormone (T3 $24 \mathrm{~h}$, T4 eine Wo) stellen eine therapeutische Herausforderung dar. Durch ergänzende Plasmaseparation gelingt die Elimination von SD-Hormonen, darüber hinaus werden Auto-Ak und Cytokine entfernt. Zudem werden Thyreoglobulin und Albumin substituiert, welche freie SD-Hormone binden. Da Heparin zu einer Verdrängung von SD-Hormonen aus der Plasmaproteinbindung mit konsekutivem Anstieg der freien Hormonspiegel führt, ist eine regionale Citratantikoagulation dem Heparin vorzuziehen.

Zusammenfassung: Im polypragmatischen Therapiekonzept der thyreotoxischen Krise kann, bei vitaler Bedrohung oder Versagen der medikamentösen Therapie, eine Plasmaseparation erwogen werden. Neben der Elimination von SD-Hormonen können Medikamente mit einer langen Halbwertszeit (Amiodaron) und Iod entfernt werden und sie stellt auch eine Therapiealternative bei Nebenwirkungen der medikamentösen Therapie (Agranulozytose) dar.

\section{P19}

\section{Lebensbedrohliche Komplikationen einer perkutanen dilatativen Tracheotomie}

\section{T.S. Meisel', M. Schröder', F. Langer ${ }^{2}$, H.-J. Schäfers ${ }^{2}$}

${ }^{1} K$ linik für Anästhesiologie, Intensivmedizin und Schmerztherapie, Universitätsklinik Homburg, Universität des Saarlandes, Homburg/Saar, Deutschland; ${ }^{2}$ Klinik für Thorax- und Herz-Gefäßchirurgie, Universitätsklinik Homburg, Universität des Saarlandes, Homburg/Saar, Deutschland

Hintergrund: In der Kasuistik werden schwerwiegende Komplikationen der perkutanen dilatativen Tracheotomie sowie deren Therapie-Möglichkeiten beschrieben.

Methode: Bei einem polytraumatisierten 16-jährigen Patienten wurde eine perkutane dilatative Tracheotomie zwischen der 4. und 5. Trachealspange durchgeführt. Es kam zu einer massiven Blutung aus dem Truncus brachiocephalicus. Eine sofortige operative Versorgung in Form von Ersatz des Truncus brachiocephalicus erfolgte. Es verblieb ein der Defekt der Trachea in unmittelbarer Nähe der Gefäßprothese. In den folgenden Tagen entwickelte sich eine Mediastinitis. Bei Sepsis und offensichtlichem Prothesen-Infekt erfolgte die Verlegung in unsere Klinik. Nach Re-Sternotomie wurde der tracheale Defekt mit einem gestielten Perikardflicken verschlossen. Die alte Gefäßprothese wurde entfernt und durch eine neue ersetzt, anschließend durch eine mediastinale Omentumplastik abgedeckt.

Ergebnisse: Eine operative Tracheotomie zwischen 2. und 3. Trachealspange wurde sekundär angelegt und der Patient von der Beatmung entwöhnt. Bei Nachweis von massiven Candida-Befall von Prothese und Mediastinum wurde eine prolongierte antifungale Therapie begonnen. Der Patient konnte nach 2 Wochen in eine neurologische Rehaklinik verlegt werden, die Tracheoskopie vor Verlegung zeigte eine gute Heilung des Defektes.

Zusammenfassung: Bei einer Tracheotomie unterhalb der 4. Trachealspange steigt die Gefahr von Gefäßverletzungen. Besonders gefürchtet ist die akute oder sekundäre Verletzung/Arrosion des Truncus brachiocephalicus. Die akute Mediastinitis ist eine gravierende Erkrankung mit eingeschränkter Prognose. Zur Prophylaxe ist die präzise Kenntnis der Anatomie wichtig; im Zweifelsfall ist die operative Tracheotomie der sicherere Weg. Das Auftreten von Komplikationen erfordert die zeitnahe und problemorientierte operative Versorgung. Auch die Mediastinitis erfordert die chirurgische Sanierung sowie eine gezielte und prolongierte antiinfektive Therapie.

\section{P20}

\section{Belastungsprobe - Ein chronischer Perikarderguss immensen Ausmaßes}

\section{A. Junker, T. Moeckl, P. Lebiedz}

Klinik für Innere Medizin und Internistische Intensivmedizin, Evangelisches Krankenhaus Oldenburg, Medizinischer Campus Universität Oldenburg, Oldenburg, Deutschland

Hintergrund: Akute Perikardergüsse gelten ab ca. $150 \mathrm{ml}$ als hämodynamisch relevant. In unserem Fall erweist sich, wie anpassungsfähig das Herz auf einen chronischen Erguss enormen Ausmaßes reagieren kann.

Methode: Fallvorstellung

Ergebnisse: Wir berichten über eine 26-jährige kolumbianische Patientin mit Belastungsdyspnoe und thorakalen Schmerzen. Die Beschwerden seien sporadisch seit Jahren in unterschiedlicher Ausprägung aufgetreten. Linkslateral fiel eine etwa $15 \mathrm{~cm}$ lange Narbe entlang der 6. Rippe auf. Hier sei 2006 in Kolumbien ein gutartiger Tumor entfernt worden. Ein Echobefund aus 2006 bescheinigte Normwerte, Näheres war nicht zu erheben. An B-Symptomatik wies die Patientin einen als verstärkt empfundenen Nachtschweiß auf, keinen Gewichtsverlust, jedoch moderat erhöhte Temperaturen und ein generelles Wärmegefühl.

Im Röntgen-Thorax zeigte sich, neben einem Zwerchfellhochstand links, eine rechtsbetonte Verbreiterung der Herzsilhouette, welche sich im CT und Echo als enormer Perikarderguss mit $2^{\circ}$ Dextrokardie erwies. Trotzdem zeigte sich keine Beeinträchtigung der diastolischen Herzfüllung. Nebenbefundlich fielen zahlenmäßig vermehrte und teils vergrößerte Lymphknoten auf (• Abb. 1 | P20).

Im Rahmen der Perikardiozentese konnten 1,2 1 altblutiges Sekret drainiert werden. Im Erguss konnten keine pathogenen Erreger oder maligne Zellen nachgewiesen werden, vor allem fanden sich keine Mykobakterien und serologisch kein Hinweis auf Trypanosomen. Die Autoimmundiagnostik blieb ebenfalls negativ.

Das Kardio-MRT ergab das Bild einer abklingenden Perikarditis, welche mit NSAR behandelt wurde (- Abb. $2 \mid$ P20). Hierunter kam es binnen eines Monats zu einem Rezidiv mit erhöhten Infektparametern und Fieber. Unter der Arbeitshypothese einer autoimmunen Entzündung erfolgte die probatorische Kortikoidtherapie mit $1 \mathrm{mg} / \mathrm{kg}$. Hierunter kam es binnen Tagen zur Entfieberung sowie einem Rückgang der Schmerzen und Infektparameter. Im Echo ließ sich zuletzt kein Perikarderguss mehr nachweisen, auch war die Dextroversion des Herzens wieder rückläufig.

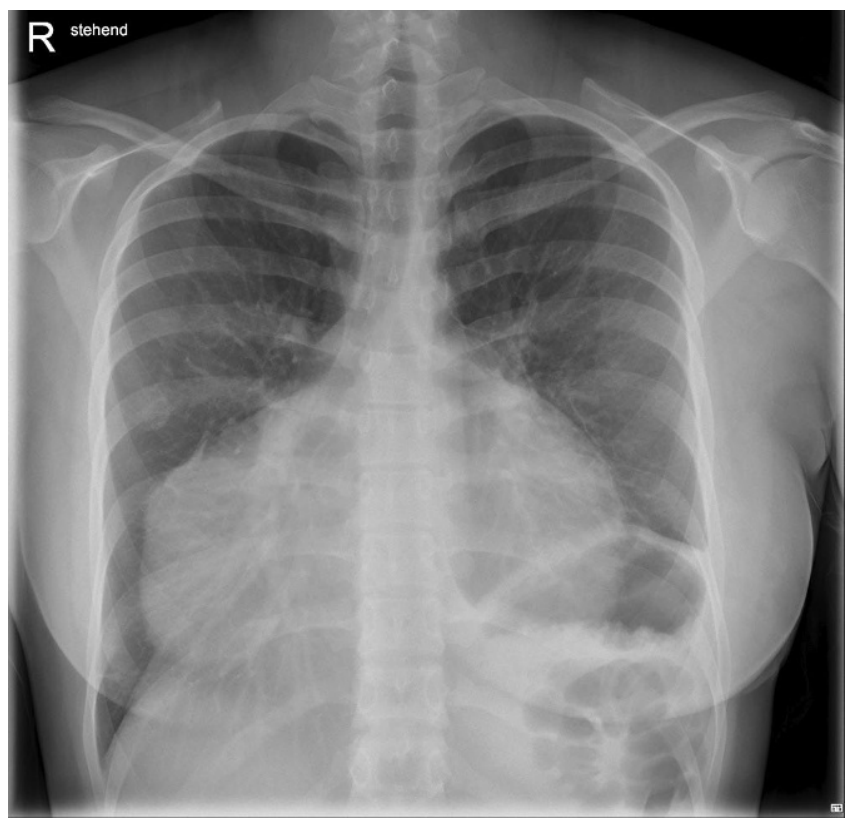

Abb. 1 | P20 A 


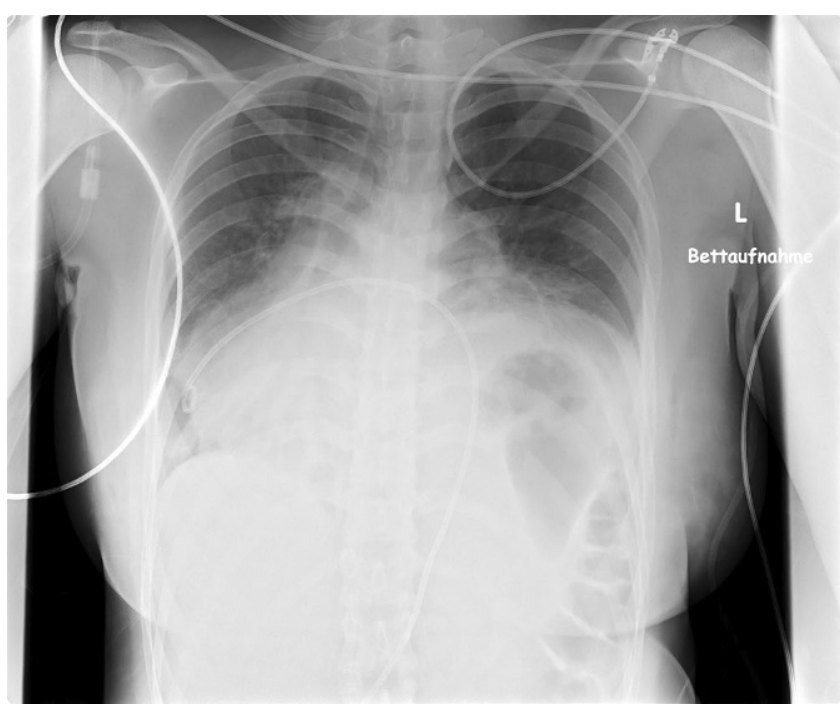

Abb. $2 \mid$ P20 $\triangle$

Die Kortikoidtherapie wurde ambulant ausgeschlichen. Aktuell ist die Patientin beschwerdefrei.

Zusammenfassung: Der Erguss sowie die Rotation zur Dextrokardie entstanden mutmaßlich über einen Zeitraum von Jahren. Aufgrund des langsamen Zuwachses konnte sich das Herz hämodynamisch adaptieren und zeigte klinisch keinerlei Beeinträchtigung.

\section{P21}

\section{Seltene Ursache eines ARDS: Ein Fallbericht}

\section{J. Kronisch, M. Deppe, P. Lebiedz}

Klinik für Innere Medizin und internistische Intensivmedizin, Evangelisches Krankenhaus Oldenburg, Medizinischer Campus Universität Oldenburg, Oldenburg, Deutschland

Hintergrund: Als ARDS (Acute Respiratory Distress Syndrome) wird nach der Berlin-Definition eine akut einsetzende respiratorische Insuffizienz einhergehend mit bipulmonalen Infiltraten bezeichnet, die nicht durch eine pulmonale Überwässerung oder eine Herzinsuffizienz bedingt ist. In Abhängigkeit vom Horovitz-Index (paO2/FiO2) wird das ARDS in mild, moderat und schwer eingeteilt. Häufigste Ursache sind infektiöse Lungenerkrankungen wie Pneumonien. Aber auch seltene Ursachen wie die Lungenbeteiligung bei nicht-infektiösen Systemerkrankungen wurden beschrieben.

Methode: Fallbericht und Literaturrecherche

Ergebnisse: Wir berichten den Fall einer 52-jährigen Patienten, die bei septischem Schock und respiratorischer Globalinsuffizienz bei bipulmonaler Pneumonie zur Evaluation einer ECMO-Therapie aus einem auswärtigen Krankenhaus übernommen wurde. In der Vorgeschichte wird von einer Episode einer Pneumonie zwei Monate zuvor berichtet.

Bei Übernahme war die Patientin aggressiv beatmet und hochdosiert katecholaminpflichtig, der Horovitz-Index betrug $150 \mathrm{~mm} \mathrm{Hg}$. Auch unter breiter antibiotischer und antimykotischer Therapie konnte der Zustand nicht verbessert werden. Im Thorax-CT zeigte sich eine atypische Pneumonie.

Laborchemisch stellte sich eine Leukozytose (15,2/nl), Anämie (Hb 7,7 g/ $\mathrm{dl}$, normozytär, normochrom) und Thrombopenie (41/nl) dar. Das Bilirubin war erhöht $(8,4 \mathrm{mg} / \mathrm{dl})$ und die Blutgasanalyse zeigte eine Laktatazidose. In den Blutkulturen und der broncho-alveolären Lavage war abgesehen von Candida albicans im respiratorischen Sekret kein Erreger nachweisbar. Im Differenzialblutbild konnte schließlich ein Blastenanteil von 61 \% festgestellt werden. In der FACS-Analyse aus dem peripheren Blut gelang die Erstdiagnose einer monomyelozytären Leukämie (nach FAB-Klassifikation M4). Wir begannen mit einer Induktionschemotherapie mittels $\mathrm{Cy}$ - tarabin und Daunorubicin, worunter sich sowohl die respiratorische als auch hämodynamische Situation rasch stabilisierte und die Laborparameter sich normalisierten. Eine Extubation war an Tag 3 der Chemotherapie möglich. Die Antibiose konnte beendet werden.

Zusammenfassung: Auch myeloproliferative Erkrankungen können ein ARDS bedingen und sollten bei atypischem Verlauf in der Differenzialdiagnostik erwogen werden, da sich andere Therapiekonzepte ergeben.

\section{P22}

\section{Nekrotisierende Tracheobronchitis nach Granatapfelextrakt-} Aspiration - ein Fallbericht

\section{A. Rozen, P. Lebiedz}

Klinik für Innere Medizin und internistische Intensivmedizin, Evangelisches Krankenhaus Oldenburg, Medizinischer Campus Universität Oldenburg, Oldenburg, Deutschland

Hintergrund: Fremdkörperaspiration bei Erwachsenen ist eine seltene, aber mit dem Alter zunehmende Problematik. Risikofaktoren sind kognitive Einschränkungen und Schluckstörungen. Die typischen Symptome sind Dyspnoe, Fremdkörpergefühl, Schmerzen in den betroffenen Atemwegen und Husten. Aspiration von Säuren oder Laugen können endobronchial zu Schleimhautnekrosen führen. Eine mögliche Komplikation ist die Ausbildung von Stenosen.

Methode: Fallbericht und Literaturrecherche

Ergebnisse: Wir berichten den Fall einer 71-jährigen Patientin, die nach einer Tablettenaspiration (Metoprolol und Granatapfel-Extrakt) aufgenommen wurde. Bei Aufnahme präsentierte sie sich mit Dyspnoe und progredienten rechtsthorakalen Schmerzen. Sie hatte im Verlauf bräunliches Sekret abgehustet. Die Blutgasanalyse zeigte eine respiratorische Alkalose. Die Aspiration war zum Zeitpunkt der Bronchoskopie bereits $4 \mathrm{~h}$ her, sodass keine soliden Bestandteile mehr geborgen werden konnten. Die Trachea war bis zur Carina gerötet. Im rechten Hauptbronchus sahen wir bräunlich-zähes Sekret mit Verlegung des rechten Unterlappenbronchus. Wir starteten eine empirische antibiotische Therapie mit Ampicillin/Sulbactam. Am 5. Tag war in der Kontroll-Bronchoskopie am Abgang des rechten Oberlappens-Bronchus eine zirkuläre hämorrhagisch-bräunliche Schwellung zu sehen, a. e. einer Schleimhautnekrose entsprechend. Rechter Unterlappen- und Mittellappenbronchus waren bis ca. 70 \% stenosiert. Dem endobronchialen verheerenden Bild stand stets ein sehr guter Allgemein- und respiratorischer Zustand gegenüber. Am 10. Tag war eine fingerförmige Nekrose direkt nach Abgang des rechten OberlappenBronchus zu sehen. Weiterhin konnte eine zirkuläre schwere Nekrose mit weniger Lumen-Stenosierung und kontaktvulnerable Schleimhaut mit Blutungsbereitschaft beobachtet werden. Am 14. Tag war die bekannte Nekrose mit Fibrin belegt, die Schleimhaut war deutlich weniger vulnerabel. Computertomographisch war eine peribronchiale Verdichtung des ventralen Unterlappen-Bronchus rechts, sowie auch eine streifige peribronchiale Verdichtung des Unterlappenbronchus rechts sichtbar.

Zusammenfassung: Eine Aspiration von Säuren und Laugen führt bekanntermassen zu Schleimhautnekrosen. In dem berichteten Fall bleibt unklar, ob das Granatapfelextakt oder die enthaltenen Zusatzstoffe wie Ascorbinsäure die schwere nekrotisierende Tracheobronchitis ausgelöst hat.

\section{P23}

Fallvorstellung: Kardiogener Schock und TakotsuboKardiomyopathie nach Herz-Kreislaufstillstand mit hypoxischer Hepatitis und schwerer Hypoglykämie

\section{J. Köster, J. Pöss, T. Graf, H. Langer}

Med. Klinik II (Kardiologie, Angiologie, Intensivmedizin), Campus Lübeck, Universitätsklinikum Schleswig-Holstein, Lübeck, Deutschland

Hintergrund: Patienten mit intrahospitalem Herz-Kreislaufstillstand (IHCA) haben ein hohes Mortalitätsrisiko. Nach Wiedereintreten eines Spontankreislaufes (ROSC) entwickeln viele Patienten ein Schocksyndrom mit Multiorganversagen. Die hypoxische Hepatitis $(\mathrm{HH})$ gehört zu den 
häufigsten Organmanifestationen. Hierbei besteht ein hohes Risiko für Dysglykämien. Dennoch sind schwere Hypoglykämien bei nicht-diabetischen Patienten eine Seltenheit. Die Takotsubo Kardiomyopathie (TTC) kann Ursache einer akuten Herzinsuffizienz und schließlich eines solchen Schocksyndroms sein.

Ergebnisse: Eine 72-jährige multimorbide Patientin, die sich zur Abklärung einer unklaren Dyspnoe in stationärer Behandlung befand, erlitt einen unbeobachteten IHCA mit unbekannter no-flow-Zeit. Es wurde eine kardiopulmonale Reanimation (CPR) eingeleitet. Der initiale Rhythmus war eine Asystolie, die zunächst in eine pulslose elektrische Aktivität (PEA) und schließlich in eine pulslose ventrikuläre Tachykardie (VT) konvertierte. Diese wurde erfolgreich defibrilliert und die CPR wurde nach insgesamt $25 \mathrm{~min}$ bei einem ROSC beendet. Blutgasanalytisch zeigten sich eine Laktatazidose ( $\mathrm{pH} 7,11$; Laktat 14,6 mmol/l) mit Hyperkaliämie $(6,1 \mathrm{mmol} / \mathrm{l})$ sowie eine ausgeprägte Hypoglykämie von $<5 \mathrm{mg} / \mathrm{dl}$ Glucose wurde substituiert. Laborchemisch zeigte sich das Bild einer $\mathrm{HH}$ mit deutlich erhöhten Aminotransferasen (ASAT 2012 U/l; ALAT 621 U/l), hoher LDH (3300 U/1), erhöhtem INR $(3,03)$ und normwertigem Bilirubin. Elektrokardiographisch zeigte sich ein neu aufgetretener Linksschenkelblock, so dass bei Verdacht auf Myokardinfarkt eine Herzkatheteruntersuchung durchgeführt wurde. Hier wurde eine koronare Herzerkrankung ausgeschlossen, allerdings zeigte sich in der Ventrikulographie ein apikales Ballooning mit deutlich reduzierter Ejektionsfraktion von $29 \%$, passend zu einer TTC. Die Patientin verstarb schließlich im therapierefraktären Schock.

Zusammenfassung: Die Kombination aus IHCA und TTC führte vermutlich zu einem Schocksyndrom. Ob die TTC Auslöser oder Folge des IHCA war ist unklar. Die anhaltende Hypotonie hat die Entwicklung einer $\mathrm{HH}$ begünstigt. Die schwere Hypoglykämie wird als Zeichen der fulminanten hypoxischen Schädigung interpretiert, die scheinbar bereits einen irreversiblen hepatischen Zellschaden mit Verbrauch der Glykogenspeicher und fehlender Gluconeogenese herbeigeführt hatte.

\section{Case Reports 2 (24-P28)}

\section{P24}

\section{Mehrfache thrombembolische Ereignisse in verschiedenen Organsystemen}

\section{Burger', U. Lange', T. Held', D. H. Walter'², J. Höltje', J. Schönwälder', D. Wietholt \\ 'Innere Medizin/Kardiologie \& Pneumologie, Allgemeines Krankenhaus Wandsbek, Hamburg, Deutschland; ${ }^{2}$ Cardiologicum Hamburg, Hamburg, Deutschland; ${ }^{3}$ Neuroradiologie, Allgemeines Krankenhaus Wandsbek, Hamburg, Deutschland; ' Radiologie, Allgemeines Krankenhaus Wandsbek, Hamburg, Deutschland}

Hintergrund: Wir berichten über einen 45-jährigen Patienten mit diversen thrombembolischen Ereignissen an unterschiedlichen Organsystemen.

Ergebnisse: Der Patient stellte sich initial mit Hemiparese links bei ischämischem Apoplex vor. Nach Beginn der Lysetherapie fiel während der Thrombektomie ein subakuter STEMI mit QS-Komplexen und ST-Hebungen in II, III, aVF, v4-v6 auf. In der direkt hiernach durchgeführte Herzkatheteruntersuchung zeigte sich ein proximaler LAD- und RCXVerschluss. Die Rekanalisation gestaltete sich schwierig. Die LAD wurde zweifach mittels DES versorgt, reokkludierte jedoch bei massiv aggravierter Gerinnung wiederholt. Auch die mittels DES versorgte RCX okkludierte, konnte jedoch mittels Tirofiban-Boli offengehalten werden. Postinterventionell fand eine kontinuierliche Tirofibangabe statt, die doppelte Thrombozytenaggregationshemmung mit ASS und Ticagrelor wurde aufgrund des frischen Insults verzögert begonnen.

Echokardiographisch zeigte sich eine apikale Akinesie mit einem wandständigen Thrombus. Eine hieraus entstandene Embolisation sahen wir als ursächlich für den Apoplex. Aufgrund einer cerebralen hämorrhagi- schen Imbibierung des Infarktareals verzichteten wir auf eine zusätzliche Vollantikoagulation und begannen eine niedrig dosierte Heparinisierung. Hierunter kam es im Verlauf nach kurzzeitiger Beschwerdebesserung zum respiratorischen Einbruch des Patienten mit Intubationspflichtigkeit. CTmorphologisch zeigte sich eine zentrale Lungenembolie rechts. Wegen des neu aufgetretenen thrombembolischen Ereignisses auch im pulmonalarteriellen System führten wir eine HIT Diagnostik durch. Diese zeigte sich positiv, sodass die Antikoagulation auf Argatroban umgestellt wurde. Der Patient verschlechterte sich weiterhin mit ARDS bei pneumogener Sepsis, sodass die weitere Diagnostik mittels TEE (offener Ductus botalli, offenes Foramen ovale) bei Kreislaufinstabilität noch nicht durchgeführt werden konnte.

Zusammenfassung: Eine frühzeitige HIT-Diagnostik sollte bei mehrfach zeitgleichen und Embolien in unterschiedlichen Organsystemen unter Antikoagulation, auch bei normwertigen oder erhöhten Thrombozyten ohne Abfall, in Betracht gezogen werden. Die Ursache der bereits initial massiv gesteigerten Gerrinungsaktivität (noch vor Heparingabe und trotz Lysetherapie) ist bisher noch ungeklärt.

\section{P25 \\ Case report: A rare cause for hypovolemic shock with the need for ICU-admission}

A. Reisinger', G. Hackl', F. Eisner', G. Schilcher ${ }^{2}$, P. Eller ${ }^{1}$

'Internistische Intensivmedizin, Universitätsklinik für Innere Medizin, Medizinische Universität Graz, Graz, Austria; ${ }^{2}$ Klinische Abteilung für Nephrologie und Hämodialyse, Universitätsklinik für Innere Medizin, Medizinische Universität Graz, Graz, Austria

Objective: Hypovolemic shock is caused by severe blood loss or reduction of circulatory volume. Here we present a case with recurrent hypovolemic shocks of initially unknown cause.

Method: A 63-year-old man was transferred to our intensive care unit because of severe hypovolemic shock. Despite several liters of crystalloid infusions, $0.2 \mu \mathrm{g} / \mathrm{kg} / \mathrm{min}$ noradrenalin was necessary for hemodynamic stabilization. Several weeks before he had a similar episode. CT scan of chest to pelvis did not show any free fluids or signs of bleeding, but a gastric wall thickening. In the first $24 \mathrm{~h}$ the patient produced more than $7000 \mathrm{ml}$ of gastric fluids which were drained with a nasogastric tube. Laboratory results showed hypokalemia $(2.98 \mathrm{mmol} / \mathrm{l})$, hypochloridemia $(79 \mathrm{mmol} / \mathrm{l})$, hypocalcemia (1.62 mmol/l total calcium) and metabolic alkalosis with a $\mathrm{pH}$ of 7.6 at a BE of 27.0 with a compensatory elevated pCO2 of $55 \mathrm{~mm}$ $\mathrm{Hg}$. The patient had prerenal acute kidney injury grade 3 and clinically the patient appeared hypovolemic. Third-party medical history yielded several years lasting loose stools, nausea and emesis.

Results: In the further workup, gastroscopy did not show signs of gastric outlet obstruction or Ménétrier's disease, but low-grade ulcerous duodenitis was present. MRI imaging of the gastric and pancreatic region was non-indicatory. In the laboratory high levels of Chromogranin A and gastrin $(>1000 \mathrm{pg} / \mathrm{ml})$ were found. After hemodynamic stabilization, intravenous infusion of high-dose proton-pump inhibitors (PPI) and correction of electrolyte disturbances, he was transferred to the department of gastroenterology for further localization diagnostics of the suspected gastroenteropancreatic neuroendocrine tumor (GEP-NET). After Galium-68-DOTATOC-PET/CT and secretin stimulation testing, gastrinoma with Zollinger-Ellison-syndrome was confirmed. The patient was treated with oral PPI, but symptoms were insufficiently controlled. Therefore, octreotide was initiated with only very little response. An exploratory laparotomy was performed and a pancreatic nodule and a PET-positive lymph node (each histologically with gastrinoma cells) were removed. Consequently, symptoms resolved, and the patient is now in observance.

Conclusion: In otherwise unexplainable losses of electrolytes, severe hypochloremic alkalosis and large quantities of fluids drained from a nasogastric tube, especially in the circumstances of recurring hypovolemic shocks, the diagnosis of a neuroendocrine tumor should be considered. 


\section{P26}

\section{Wenn Halsschmerzen lebensbedrohlich werden}

L. Tometten', M. Oppert ${ }^{2}$, L. Nibbe ${ }^{3}$, T. Schumacher', G. Ripberger ${ }^{3}$

${ }^{1}$ Klinik für Gastroenterologie und Infektiologie, Zentrum für Innere

Medizin I, Klinikum Ernst von Bergmann, Potsdam, Deutschland; ${ }^{2}$ Zentrale Notaufnahme, Klinikum Ernst von Bergmann, Potsdam, Deutschland; ${ }^{3}$ Klinik für Notfall- und Internistische Intensivmedizin, Zentrum für Innere Medizin I, Klinikum Ernst von Bergmann, Potsdam, Deutschland

Hintergrund: Halsschmerzen machen mehr als $1 \%$ der ärztlichen Vorstellungen aus und werden meist durch Viren verursacht. Bei knapp $20 \%$ dieser Patienten ist Fusobacterium necophorum nachweisbar. Dieses obligat-anaerobe, gram-negative Bakterium ist Teil der physiologischen Mundflora. Unter anaeroben Bedingungen können Fusobakterien als opportunistische Erreger Krankheitsbilder wie Abszesse, Wundinfektionen bis hin zu Sepsis verursachen.

Methode: Case Report

Ergebnisse: Ein 23-jähriger Patient stellte sich aufgrund von Fieber, Dyspnoe und Husten vor (RR: 105/65 mm Hg, Puls: 91/min, SpO2: $99 \%$ ) Zuvor hatte der Patient für eine Woche über Schnupfen und Halsschmerzen geklagt. In der klinischen Untersuchung fiel eine Schwellung und ein Druckschmerz links zervikal auf. Laborchemisch zeigten sich massiv erhöhte Infektparameter (Leukozyten: 30.000/ $\mu$ l, CRP: 329,5 mg/l, Procalcitonin: 91,5 ng/ml). Im Röntgen Thorax zeigten sich fleckförmige, flaue Infiltrate beidseits. Eine CT des Thorax zeigte multiple pneumonische Infiltrate mit beginnender Einschmelzung beidseits.

Im MRT der Halsweichteile zeigten sich peritonsilläre Mikroabszedierungen links mit Fistelung in die Vagina carotica sowie eine Teilthrombosierung der V. jugularis interna links (- Abb. 1 | P26). Die Blutkulturen waren positiv auf Fusobacterium necrophorum, so dass die Diagnose eines Lemierre-Syndroms gestellt wurde. Bereits initial erfolgte eine empirische Therapie mit Piperacillin/Tazobactam sowie eine therapeutische Antikoagulation. Im Verlauf erfolgte die chirurgische Sanierung des Peritonsillarabszesses mit Tonsillektomie links. Es kam bei zunehmender Einschmelzung der Infiltrate zu Pleuraempyemen beidseits, die thorakoskopisch saniert wurden. Nach drei Wochen wurde die antibiotische Therapie mit Piperacillin/Tazobactam auf eine orale Sequenztherapie mit Clindamycin für weitere zwei Wochen umgestellt. Der Patient wurde nach drei Wochen beschwerdefrei wieder aus der Klinik entlassen.

Zusammenfassung: Das Lemierre-Syndrom ist mit einer Inzidenz von ca. 1 pro 1.000 .000 ein seltenes, aber lebensbedrohliches Erkrankungsbild, das insbesondere junge Erwachsene betrifft. Während die Todesrate vor Antibiotika-Einführung bei $90 \%$ lag, ist sie heutzutage unter adäquater

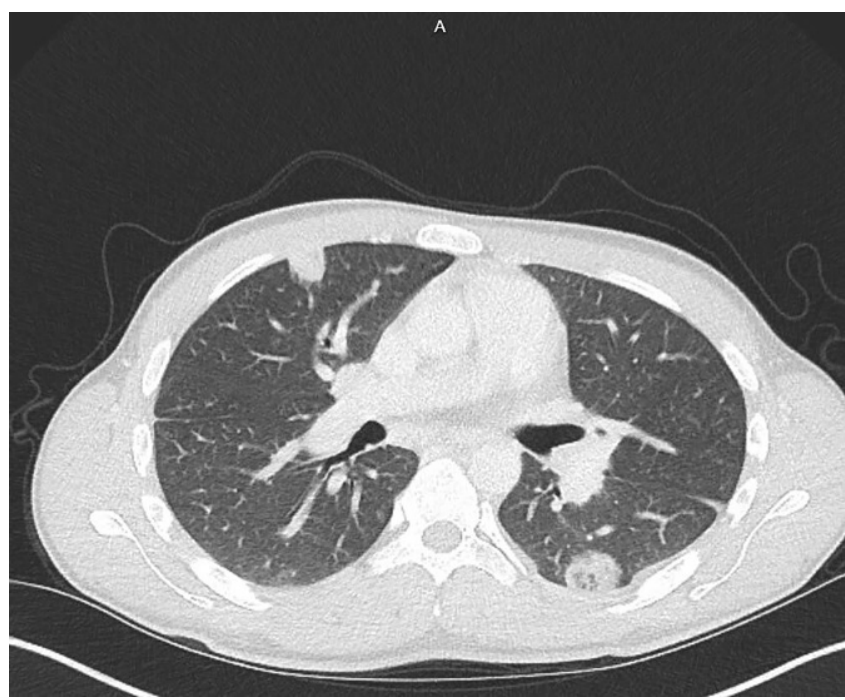

Abb. 1 | P26 A antibiotischer Therapie auf unter $5 \%$ gesunken. Bei schwer erkrankten Patienten mit Halsschmerzen, Fieber und fleckförmigen Infiltraten sollte das Lemierre-Syndrom bedacht werden und eine Antibiotika-Therapie rasch eingeleitet werden.

\section{P27}

Fallbericht: seltene Ursache eines fulminanten Lungenversagens

E. Göncz' , M. Möckel', R. Kleinwächter' ${ }^{2}$, T. Lindner'

'Notfallmedizin/Rettungsstellen Nordcampi, Campus Virchow-Klinikum und Campus Charité Mitte, Charité - Universitätsmedizin Berlin, Berlin, Deutschland; ${ }^{2}$ Klinik für Anästhesiologie mit Schwerpunkt operative Intensivmedizin, Campus Virchow-Klinikum, Charité - Universitätsmedizin Berlin, Berlin, Deutschland

Hintergrund: Fallbericht: 84-jährige Patientin, als Fußgängerin linksseitig von abbiegendem PKW erfasst. Am Unfallort kein A-B-C Problem. D: retrograde Amnesie, E: Hämatom supraorbitaler Gesichtsschädel, distaler Unterschenkel links mit V.a. Fraktur. Keine Allergien angegeben. Voranmeldung durch begleitenden Notarzt. Klinikintern Schockraumalarmierung gemäß S3-Leitlinie zur Schwerstverletztenversorgung.

Methode: Versorgung nach ATLS ${ }^{\circledR}$-Schema. Allzeit GCS 15, kreislaufstabil. Allergien und Vorerkrankungen werden explizit wiederholt verneint. Keine weiteren Verletzungen festgestellt, präklinischer Frakturverdacht am Unterschenkel links nicht bestätigt. Bei gegebenem Unfallmechanismus Indikation zu Ganzkörper-CT-Untersuchung mit Kontrastmittel nach standardisiertem Protokoll. Innerhalb weniger Minuten nach Splitbolus-Kontrastmittelgabe im CT und subjektiv durch die Patientin geäußerte Luftnot (ohne Brustschmerz) kam es bei primärer Hypoxie zu einem Kreislaufstillstand (PEA). Eine unter Reanimation und nach Intubation durchgeführte erneute Röntgenaufnahme des Thorax zeigt ein ausgeprägtes beidseitiges Lungenödem. Die Patientin stirbt nach 40-minütiger leitliniengerechter Reanimation.

Ergebnisse: Das unmittelbar vor dem Kreislaufstillstand angefertigte Ganzkörper- CT zeigt keinen Hinweis für ursächliche pulmonale und/ oder kardiale Pathologien. Während Reanimation Re-Evaluation der Hs und Ts mit Anlage beidseitiger Bülaudrainagen und sonographischem Ausschluss sekundärer Hämorrhagie und/oder Tamponade. Als vermutete Ursache bleibt bei dem rasch entwickelten hypoxischen Lungenversagen eine toxische Wirkung des Kontrastmittels als wahrscheinlichstes Trigger.

Zusammenfassung: Kontrastmittel als Toxin zu beachten. Kausale akute Therapie des pathophysiologisch vermuteten toxischen Lungenödems extrem schwierig. Formal ist ein alveoläres Lungenödem auf Grund eines endothelialen Schadens zu bedenken, mit primär vorliegendem Lungenversagen und sekundär erwartenden kardialen Beteiligung. Kausalkette auf Grund des fulminanten Verlaufes medikamentös meist nicht beherrschbar. Akutes Lungenersatzverfahren in dem Fall potentiell erwähnenswert.

\section{P28}

ACS bei einem jungen Sportler - die virus-negative lymphozytäre Peri-/Myokarditis

C. Römer, A. Berger, R. Spode, A. Slagman, M. Möckel

Notfallmedizin/Rettungsstellen Nordcampi, Campus Virchow-Klinikum und Campus Charité Mitte, Charité - Universitätsmedizin Berlin, Berlin, Deutschland

Hintergrund: Wir berichten über einen 18-jährigen Patienten, welcher sich mit seit drei Tagen bestehenden Husten, progredienter Belastungsdyspnoe (NYHA III) und atemabhängigen Schmerzen vorstellte. Der Patient klagte über eine neue Leistungsminderung sowie eine gering erhöhte Körpertemperatur (max. $38,5^{\circ} \mathrm{C}$ ). Synkopen, Auslandsaufenthalte, Traumata oder Substanzmissbrauch wurden glaubhaft verneint. Bis vor einem Jahr spielte er leistungsorientiert Fußball und ist in guter körperlicher Verfassung ohne bekannte Vorerkrankungen. 

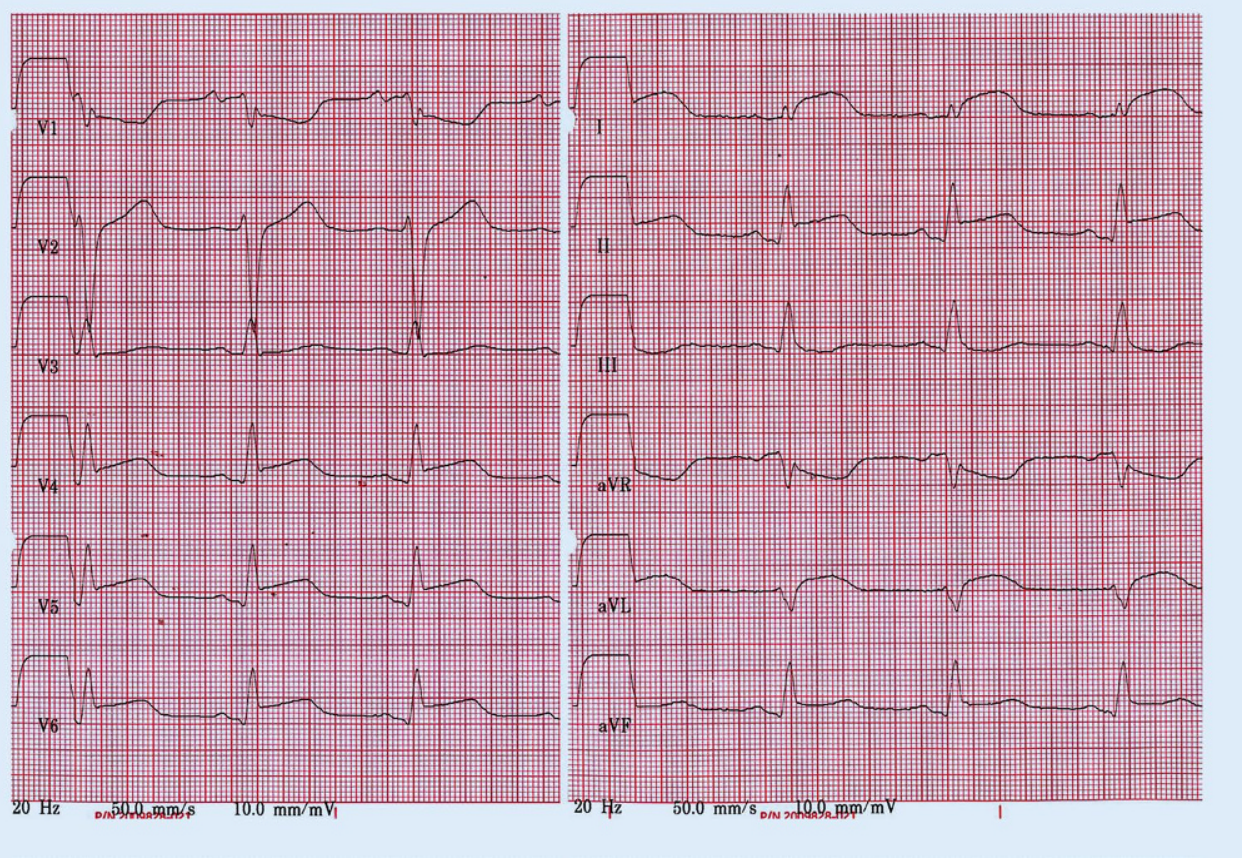

Abb. 1 | P28

Methode: In der körperlichen Untersuchung war eine rhythmische Herzaktion (Herzfrequenz 106/min) mit 3/6 Systolikum p.m. über Erb und pulmonal beidseits ein VAG auskultierbar. Elektrokardiographisch fielen ubiquitäre konkavbogige ST-Hebungen mit Abgang aus der angedeutet tiefen S-Zacke (I, II, aVF, V4-V6) auf (• Abb. 1 | P28). Laborchemisch zeigten sich deutlich erhöhte Herzmarker (hsTroponin I $12.988 \mathrm{ng} / \mathrm{L}$ $(\mathrm{N}: \leq 1,9 \mathrm{ng} / \mathrm{L}), \mathrm{CK} 456 \mathrm{U} / \mathrm{l})$ und Infektparameter. Nach weiteren vier Stunden waren diese rasch steigend (hsTroponin I 21.269 ng/L, CK 400 U/l) und NT-pro-BNP lag bei $7361 \mathrm{ng} / \mathrm{L}(\mathrm{N}:<125 \mathrm{ng} / \mathrm{L})$.

Ergebnisse: Die durchgeführte Echokardiographie ergab einen hypertrophierten linken Ventrikel mit einer hochgradig eingeschränkten linksventrikulären Funktion (LV-EF 30 \%). Aufgrund der vorliegenden Befunde erfolgte eine Links- und Rechtsherzkatheteruntersuchung und Endomyokardbiopsien im rechten Ventrikel. Histologisch und serologisch ergab sich die Diagnose einer subakuten virus-negativen lymphozytären Myokarditis, sodass die Therapie mit Azathioprin und Prednisolon, sowie eine Herzinsuffizienztherapie, eingeleitet wurden. Der Patient konnte nach sechs Wochen mit nur noch leicht eingeschränkter LVEF nach Hause entlassen werden.

Zusammenfassung: Die Myokarditis als entzündliche Erkrankung des Herzmuskels weist eine Inzidenz von 22/100.000 auf, die Inzidenz ist jedoch aufgrund der Vielzahl klinisch unauffällig verlaufenden Myokarditiden, oder nicht korrekt diagnostizierter Fälle schwer zu bestimmen. In bis zu neun Prozent der Fälle mit unklarer DKMP hält man eine Myokarditis für ursächlich. Die endgültige Diagnose einer Myokarditis entsprechend ihrer Ätiopathogenese kann allerdings nur mit einer Myokardbiopsie gestellt werden. Die Myokardbiopsie ist, wie im vorliegenden Fall, bei unklarer stark eingeschränkter Pumpfunktion indiziert.

\section{Gastroenterologie, Hepatologie und Ernährung (P29-P30)}

\section{P29}

The coagulopathy in patients with acute-on-chronic liver failure (ACLF) assessed by thrombelastometry and its correlation with conventional coagulation parameters

\section{J. Seeßle, J. Löhr, J. Michaelis, U. Merle}

Gastroenterologie, Infektionskrankheiten, Vergiftungen, Klinik für Innere Medizin IV, Universitätsklinikum Heidelberg, Heidelberg, Deutschland

Objective: Acute-on-chronic liver failure (ACLF) is defined by an acute deterioration of a pre-existing chronic liver disease. Patients with cirrhosis have been considered as being "autoanticoagulated" due to changes in conventional coagulation tests (CCTs). This paradigm changed and stable cirrhotics are assumed to be in a rebalanced state of hemostasis. ACLF patients might be-due to the greater severity of their disease-more susceptible to dysbalance of hemostasis.

Method: We conducted a prospective single center study. Twenty-two patients with ACLF were compared with fifty-five Non-ACLF patients using CCT and thrombelastometry (ROTEM). ACLF was defined according to EASL/AASLD guidelines. Patients were prospectively followed until hospital discharge or death. ACLF patients were further subgrouped by bleeding event.

Results: ROTEM analysis (INTEM, EXTEM, FIBTEM, APTEM) demonstrated a significant difference between Non-ACLF and ACLF group indicating a balanced hemostasis in Non-ACLF group despite abnormal CCT and beginning dysbalance in ACLF patients. Interestingly, this difference between Non-ACLF and ACLF patients was not seen in NATEM, where all parameters, except of MCF (maximum clot firmness) in bleeding ACLF patients were in the normal range. CCT showed major differences between ACLF and Non-ACLF group. PT/Quick-value and platelets were significantly lower in ACLF group. Bleeding occurred significantly more often in ACLF patients than in Non-ACLF patients ( 40.9 vs. $5.5 \%, p \leq 0.0001$ ). ROTEM $^{\circ}$ analysis in ACLF patients with bleeding events showed further aggravated dysbalance in hemostasis when compared to Non-bleeding ACLF group. Conclusion: Standard ROTEM tests (EXTEM, INTEM, FIBTEM) indicated hypocoagulability in bleeding and non-bleeding ACLF patients, while 
in contrast NATEM-analysis showed hypocoagulabilty only in the subgroup of bleeding ACLF-patients. NATEM might be useful in detecting ACLF patients at bleeding risk.

\section{P30 \\ Herpes Simplex Virus 1 (HSV-1) als Ursache eines fulminanten akuten Leberversagens \\ S. Spahn, R. Riessen \\ Departement für Innere Medizin, Intensivstation, Universitätsklinikum, Eberhard Karls Universität Tübingen, Tübingen, Deutschland}

Hintergrund: Die akute HSV-1-Hepatitis ist eine seltene und unterschätzte Ursache des akuten Leberversagens. Ziel dieser Untersuchung war es, am Beispiel eigener Fälle klinische und virologische Charakteristika dieser Erkrankung detailliert zu beschreiben.

Methode: Im Zeitraum seit 2015 wurden auf der Internistischen Intensivstation des Universitätsklinikums Tübingen drei Fälle mit einem fulminanten HSV-1 assoziierten Leberversagen identifiziert.

Ergebnisse: Bei den drei mit HSV-1 assoziierten akuten Leberversagen handelte es sich um männliche Patienten im Alter von 51, 64 und 71 Jahren. Bei 2 der 3 Patienten fielen in der Anamnese grippale Beschwerden auf. Ein Patient war mit Ciclosporin immunsupprimiert. Laborchemisch fielen bei allen drei Patienten bereits bei Aufnahme extrem hohe Transaminasen (AST: 6595-14.126 U/l; ALT: 2857-8024 U/l) und eine extrem hohe LDH (8005-19.844 U/l) auf. Begleitend zeigte sich eine bereits initial massiv ausgeprägte disseminierte intravasale Koagulopathie (DIC). Die virologische Aufarbeitung ergab, dass bei allen 3 Patienten eine HSV1 Primärinfektion vorlag. Zwei Patienten wurden mit Aciclovir behandelt. Bei einem Patienten wurde die Erkrankung postmortal diagnostiziert. Alle Patienten verstarben zwischen 2-5 Tage nach Aufnahme an einem fulminanten Multiorganversagen

Zusammenfassung: Eine HSV-1-Hepatitis fand sich auf unserer Intensivstation bei drei männlichen Patienten im Alter zwischen 51-71 Jahren und war charakterisiert durch extrem hohen Leberenzyme, eine DIC und eine Mortalität von $100 \%$. Ein bedeutsamer Risikofaktor ist wahrscheinlich eine fehlende Immunität gegen HSV-1. In dieser Population sollte bis zum Ausschluss einer HSV-1-Infektion eine unverzügliche Therapie mit Aciclovir in Betracht gezogen werden, auch wenn unklar ist, ob ein so fulminanter Krankheitsverlauf damit noch positiv beeinflusst werden kann.

\section{Herz-Kreislauf (P31-P34)}

\section{P31 \\ Die Laktatkonzentration nach kardiopulmonaler Reanimation ist ein prognostischer Biomarker für das Versterben auf der Intensivstation}

M. Fritzenwanger, G. Al Hamwi, N. Wystub, C. Schulze, M. Franz, R. Pfeifer Kardiologie, Angiologie, internistische Intensivmedizin, Klinik für Innere Medizin I, Friedrich-Schiller-Universität Jena, Jena, Deutschland

Hintergrund: Das Überleben nach kardiopulmonaler Reanimation (CPR) frühzeitig vorhersagen zu können, ist im klinischen Alltag wünschenswert. Die Konzentration der Neuronen-spezifischen Enolase (NSE) am Tag 3 ist derzeit der beste Laborparameter, die Prognose nach CPR vorhersagen zu können. Wir untersuchten, ob die Laktatkonzentration im zeitlichen Verlauf sowie deren Veränderungen das Outcome auf der Intensivstation vorhersagen können.

Methode: Retrospektive Untersuchung klinischer und laborchemischer Routineparameter bei Aufnahme auf der Intensivstation (ICU) im Vergleich mit der Laktatkonzentration im zeitlichen Verlauf sowie deren Veränderungen während des ICU-Aufenthalts innerhalb der ersten Stunden von 113 Patienten nach primär erfolgreicher CPR. Der primäre Endpunkt war das Versterben auf der Intensivstation. Für die Berechnungen verwen- deten wir den Mann-Whitney Rank Sum Test, Receiver Operator Characteristics (ROC) und die logistische Regression.

Ergebnisse: Bei Patienten, die auf der Intensivstation verstarben, war die Laktatkonzentration bei Aufnahme (median [25, $75 \%]$ mmol/l, 5,6 [3,0, $11,5]$ vs. $2,5[1,4,4,2])$, nach $4 \mathrm{~h}(4,8[2,1,12,2]$ vs. $1,4[0,9,2,5])$, nach $8 \mathrm{~h}$ $(5,2[2,2,11,2]$ vs. $1,4[1,0,2,3])$ und nach $24 \mathrm{~h}(3,7[1,5,8,7]$ vs. $1,4[1,0$, $2,2])$ signifikant höher im Vergleich zu überlebenden. Die Laktatveränderungen zwischen Aufnahme und $4 \mathrm{~h}$, zwischen $4 \mathrm{~h}$ und $8 \mathrm{~h}$ sowie zwischen $8 \mathrm{~h}$ und $24 \mathrm{~h}$ hatten keinen prädiktiven Wert.

In der ROC Analyse betrug die area under the curve (AUC) für die Lak-

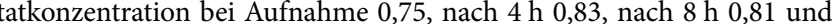
nach $24 \mathrm{~h} 0,78$. Verglichen zu NSE am Tag 3 , welches eine AUC von 0,81 aufwies, war Laktat zu den verschiedenen Zeitpunkten nicht schlechter als NSE am Tag 3.

In der univariaten logistischen Regressionsanalyse konnte die Laktatkonzentration zu jedem untersuchten Zeitpunkt sowie NSE am Tag 3 signifikant das Versterben vorhersagen. In der multivariaten logistischen Regressionsanalyse waren Laktat zum Zeitpunkt $8 \mathrm{~h}$ zusammen mit NSE am Tag 3 die besten Parameter, um das Versterben auf der Intensivstation vorhersagen zu können.

Zusammenfassung: Laktat nach erfolgreicher CPR ist im kurzfristigen Verlauf nach ICU-Aufnahme ein Prognoseparameter für Versterben. Laktat ist dabei nicht schlechter als NSE am Tag 3, dafür aber eine früherer Prognoseparameter. Zudem verbessert Laktat zum Zeitpunkt $8 \mathrm{~h}$ zusammen mit NSE am Tag 3 das Vorhersagemodell.

\section{P32}

\section{Association of sublingual microcirculation parameters and} endothelial glycocalyx dimensions in ICU patients with sepsis

A. Rovas' ', L. Seidel', T. Pohlkötter', H. Pavenstädt' ', C. Ertmer'², M. Hessler'², P. Kümpers'

'Allg. Innere Medizin sowie Nieren- und Hochdruckkrankheiten und Rheumatologie, Medizinische Klinik D, Westfälische Wilhelms-Universität Münster, Münster, Germany; ${ }^{2}$ Klinik für Anästhesiologie, operative Intensivmedizin und Schmerztherapie, Universitätsklinikum, Westfälische Wilhelms-Universität Münster, Münster, Germany

Objective: The endothelial glycocalyx (eGC) covers the luminal surface of the vascular endothelium and plays an important protective role in systemic inflammatory states and particularly in sepsis. Its breakdown leads to capillary leak and organ dysfunction. Moreover, sepsis-induced alterations of sublingual microcirculation are associated with a worse clinical outcome. The present study was performed to investigate associations of eGC dimensions and established parameters of microcirculation dysfunction in sepsis. Method: The observational, prospective, cross-sectional study was performed in the medical and surgical intensive care units (ICU) of a university hospital and included 40 participants (30 ICU sepsis patients and 10 healthy controls). The established microcirculation parameters were obtained and analyzed according to current recommendations. Using a novel data acquisition and analysis software $\left(\right.$ GlycoCheck $\left.{ }^{\mathrm{TM}}\right)$, we measured the perfused boundary region (PBR) sublingually, an inverse parameter of the endothelial glycocalyx dimensions. To validate our eGC data in vitro, we exposed living endothelial cells to $5 \%$ serum from a subgroup of study participants and correlated the delta eGC breakdown-measured with atomic force microscopy (AFM)-with the paired PBR values.

Results: PBR values were significantly higher in sepsis compared to healthy controls. The in vitro AFM data correlated exceptionally with paired PBR values obtained at the bedside ( $r s=-0.94, p=0.02)$. Microvascular flow index (MFI) and proportion of perfused vessels (PPV) showed an impaired microcirculation in our sepsis cohort compared to healthy individuals. Both PBR values and microcirculation parameters correlated well with markers of critical illness. Interestingly, no association was observed between the PBR values and established microcirculation parameters.

Conclusion: Our findings reveal that eGC damage can occur independently from microcirculatory impairment measured by classical consensus parameters. Future experimental and clinical studies are therefore needed to 
unravel the relationship of glycocalyx damage and microvascular impairment, as well as their prognostic and therapeutic importance in sepsis.

\section{P33}

\section{Prognostic value of fibroblast growth factor 23 (FGF-23) serum levels on admission after cardiac arrest}

\section{S. Spaich, F. Steger, T. Zelniker, J. Stiepak, H. A. Katus, M. Preusch}

Kardiologie, Angiologie und Pneumologie, Klinik für Innere Medizin III, Universitätsklinikum Heidelberg, Heidelberg, Germany

Objective: Risk stratification in survivors of out-of-hospital cardiac arrest (OHCA) remains a paramount challenge in post-resuscitation care with biomarkers serving as a critical adjuvant for prognostication. While among these early predictors lactate levels on admission have demonstrated robust prognostic performance, the role of Fibroblast Growth Factor 23 (FGF-23) on admission after OHCA has not been elucidated yet.

Method: This study was designed as a registry-based pilot study to analyze the predictive value of FGF-23 levels on admission after ROSC from OHCA with time to all-cause mortality (ACM) as the primary endpoint. Treating physicians had access to all data from the clinical core laboratory including levels of lactate, CRP, cTNT, GFR. Yet, retrospective batch analysis of FGF-23 levels using a commercially available ELISA kit was only performed after treatment of all patients was completed. Therefore, clinicians were blinded to both FGF-23 measurements and levels.

Results: Between 2013 and 2016 a total of 190 consecutive patients with available blood samples were identified from the Heidelberg Resuscitation Registry (HRR) and included in the present analysis. Mean age of patients was 68.8 years with $71.1 \%$ of patients being male. Of the 190 patients included in our study 119 patients died during follow-up.

Median FGF-23 serum levels on admission were $445 \mathrm{pg} / \mathrm{ml}$ with FGF-23 being significantly higher in non-survivors (mean $1070 \mathrm{pg} / \mathrm{ml}$ ) as compared to survivors (mean $745 \mathrm{pg} / \mathrm{ml}$ ). After 30 days of follow-up $80.9 \%$ of patients in the top quartile (Q4) of FGF-23 levels had died as opposed to $52.3 \%$ in Q1, 61.2\% in Q2 and 64.9\% in Q3.

As expected, lactate levels on admission also demonstrated significant differences between non-survivors (mean $10.0 \mathrm{mmol} / \mathrm{l}$ ) and survivors (mean $6.3 \mathrm{mmol} / \mathrm{l})$. ROC analysis for FGF-23 levels yielded an AUC of 0.613 for prediction of overall survival, while ROC analysis of lactate levels provided an AUC of 0.754 .

Conclusion: Preliminary data ofour study on the value of initial FGF-23 serum levels after OHCA for early risk stratification demonstrate FGF-23 to be elevated in non-survivors as compared to survivors with a fraction of $80.9 \%$ ACM in the top FGF-23-quartile as compared to $52.3-64.9 \%$ in the lower FGF-23 quartiles. While overall ROC analysis of FGF-23 levels only yielded an AUC of 0.613, the strong prognostic value of lactate levels was validated once again (AUC 0.754).

\section{P34}

\section{Effektivität der medikamentösen Kardioversion durch Vernakalant und Ibutilid bei Vorhofflimmern- und flattern in Abhängigkeit des Körpergewichtes}

T. Lindmayr', P. Sulzgruber' ${ }^{2}$, A. Simon', J. Niederdöckl', N. Schütz', S. Schnaubelt', H. Domanovits', A. Spiel ${ }^{1}$

'Universitätsklinik für Notfallmedizin, Medizinische Universität Wien, Wien, Österreich; ${ }^{2}$ Universitätsklinik für Kardiologie, Medizinische Universität Wien, Wien, Österreich

Hintergrund: Vorhofflimmern/-flattern ist die häufigste anhaltende Herzrhythmusstörung, die oftmals einer notfallmedizinischen Versorgung bedarf. Die zur Kardioversion eingesetzten Medikamente werden entweder gewichtsadaptiert oder in einer Fixdosis verabreicht. Dadurch könnte sich abhängig vom Patientengewicht ein Einfluss auf den Konversionserfolg ergeben. Diese Arbeit beschäftigt sich mit der Frage, ob das Körpergewicht Einfluss auf den Behandlungserfolg der medikamentösen Kardioversion durch Vernakalant (gewichtsadaptierte Gabe) oder Ibutilid (gewichtsunabhängige Fixdosis) bei Vorhofflimmern und -flattern hat.

Methode: Es wurden insgesamt 316 Episoden von Vorhofflimmern oder -flattern, die an der Univ.-Klinik für Notfallmedizin im Zeitraum zwischen Jänner 2013 bis Dezember 2016 mit Vernakalant oder Ibutilid behandelt wurden, eingeschlossen. Ausgeschlossen wurden Episoden von permanentem Vorhofflimmern, da hier als Therapieziel keine Rhythmuskontrolle angestrebt wird. Die Daten der Teilnehmer stammen aus dem seit 2012 bestehenden prospektiven Vorhofflimmer-Register der Universitätsklinik. Mit Hilfe eines Modells der binär logistischen Regression wurde

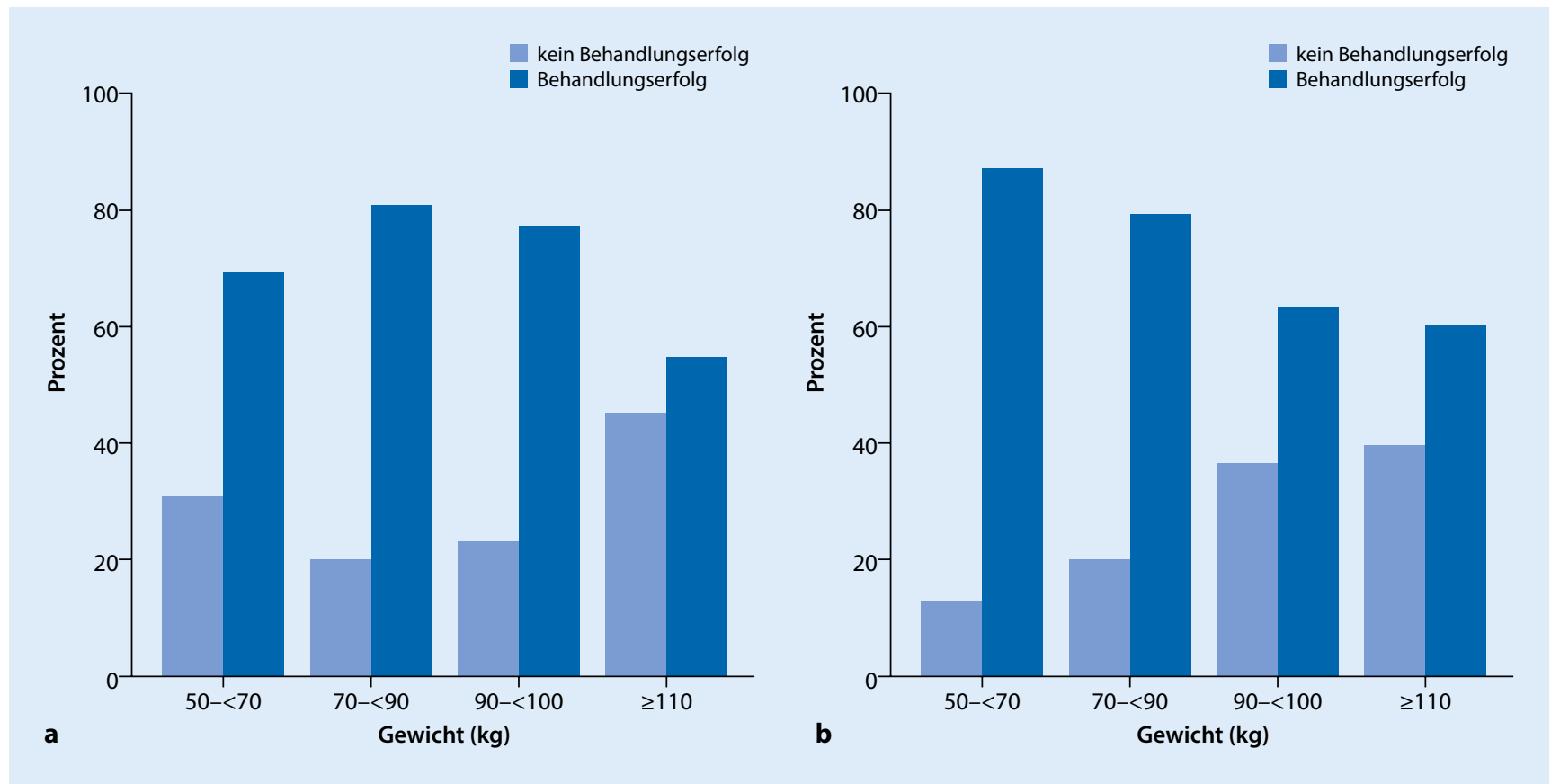

Abb. 1 | P34 $\Delta$ a Vernakalant, b lbutilid 
die Wahrscheinlichkeit berechnet, mit welcher das Patientengewicht den Kardioversionserfolg beeinflusst.

Ergebnisse: Von den 316 Studienpatienten erhielten 135 Ibutilid und 181 Vernakalant. Bei insgesamt 241 PatientInnen (76,3\%) konnte eine erfolgreiche Rhythmuskontrolle erzielt werden. Beide Medikamente hatten schlussendlich eine vergleichbare Erfolsrate von 76 \% (Vernakalant: 138/181; Ibutilid 103/135). Im errechneten Modell präsentiert sich mit steigendem Körpergewicht ein signifikant abnehmender Konversionserfolg, adjusted $\mathrm{OR}=0,69(0,51-0,94) ; p=0,018(p<0,05)$. In den einzelnen Medikamentengruppen zeigt sich dieser Effekt bei Ibutilid, adjusted $\mathrm{OR}=0,55(0,38-0,92) ; p=0,022(p<0,05)$, nicht jedoch bei Vernakalant, adjusted OR=0,85(0,58-1,24); $p=0,403(p<0,05)((\bullet$ Abb. $1 \mid$ P34 $)$.

Zusammenfassung: In dieser Arbeit zeigte sich, dass das in einer gewichtsunabhängigen Fixdosis verabreichte Medikament Ibutilid im Gegensatz zu dem gewichtsadaptiert verabreichten Medikament Vernakalant einen abnehmenden Therapieerfolg bei steigendem Körpergewicht hat Dieses Ergebnis könnte in Zukunft die Therapieauswahl der medikamentösen Kardioversion bei übergewichtigen Patienten mit Vorhofflimmern oder -flattern beeinflussen.

\section{Hämatoonkologische Intensivmedizin (P35-P36)}

\section{P35}

\section{Case report: Acquired hemophilia A, a rare but life-threatening disorder}

\section{Valzolgher}

Notaufnahme, Südtiroler Sanitätsbetrieb, Bozen, Italy

Objective: Acquired hemophilia A is a rare bleeding disease due to an autoantibody to factor VIII, which interferes with clotting factor activity VIII and it is termed inhibitor. Major identifiable causes for the production of the inhibitor are: pregnancy or postpartum, malignancy, autoimmune disorders and drug reactions. In about half of the patients there is no detectable underlying cause. The main manifestation of the disorder is bleeding, that can occur after surgical procedures but also spontaneously. Patients present with large hematomas, gastrointestinal bleeding, epistaxis, and hematuria, that can be a real medical emergency. This case report is about a patient with acquired hemophilia A presenting with major bleeding, which was promptly diagnosed and successfully treated with the use of repeated doses of recombinant factor VIII, and high dose Prednisone. Method: A 81 year-old man was admitted to our regional hospital at the end of november 2018 because of general weakness, and pain in the right leg. He had recently experienced persistent gingival bleeding after dental extraction, was on oral medications because of type II Diabetes and has had in the past a dermatological resection for a melanoma. At the admission a complete blood count showed significant blood lost $(\mathrm{Hb}=7 \mathrm{~g} / \mathrm{dl})$. On the physical examination was noted a hematoma on the right leg. Initial treatment included blood transfusion, with very little improvement on the hemoglobin level.

Results: Coagulation tests showed prolonged activated partial thromboplastin time $(\mathrm{aPTT}=2.38)$ and normal prothrombin time $1.16(N<1.20)$. Factor VIII clotting assay activity was reduced $<1 \%$ (normal: $50-186$ ). An inibitor of factor VIII was found in blood and hence the diagnosis of Acquired hemophilia A was made. No specific underlying cause was found. For the control of bleeding we administered intravenously recombinant factor VIII (Obizur). For the elimation of the inhibitor we administered high dose steroid therapy. As the patient was discharged from hospital, was still taking Prednisone $(2 \mathrm{mg} / \mathrm{kg})$, which was planned to be tapered in $1-2$ months. We achieved remission, with stable normalization of the aPTT. Conclusion: Acquired hemophilia A is a very rare disorder that can cause life-threatening bleeding complications. Management relies on a rapid and accurate diagnosis, control of bleeding episodes, and eradication of the inhibitor by immunosuppression therapy.

\section{P36}

\section{Fulminante myasthene Krise mit Myokarditis unter Therapie mit Pembrolizumab}

\section{Y. d'Hargues, B. Böll, A. Shimabukuro-Vornhagen, M. Kochanek}

Klinik I für Innere Medizin, Universitätsklinikum Köln, Köln, Deutschland

Hintergrund: In der Krebstherapie werden mit Checkpointinhibitoren (CPIs) große Erfolge erzielt. Diese sind in der Regel verträglich, zeigen jedoch charakteristische, teilweise lebensbedrohliche immunvermittelte $\mathrm{Ne}$ benwirkungen (irAEs). Durch die steigende Zahl an Patienten unter CPI, werden Intensivmediziner mit einer zunehmenden Inzidenz solcher irAEs konfrontiert sein. Die vielfältigen Symptome erschweren die Diagnosestellung, gerade für Ärzte ohne Erfahrung mit onkologischen Intensivpatienten. Schwerwiegende Verläufe können durch die rechtzeitige Einleitung einer adäquaten Therapie häufig kontrolliert u nd letale Verläufe verhindert werden. Anhand eines Falles unserer Klinik stellen wir eine seltene irAE dar und hoffen für mögliche Symptome dieser Patienten zu sensibilisieren. Methode: Case Report eines Patienten unserer internistischen Intensivstation und Einordnung in aktuelle Literatur.

Ergebnisse: Ein Patient mit einem metastasierten Adenokarzinom der Lunge stellte sich nach Gabe des zweiten Zyklus Pembrolizumab initial extern mit progredienter muskulärer Schwäche und dropped-head Syndrom vor. Im weiteren Verlauf treten zudem eine proximale Schwäche der Extremitäten, Lidschwäche, Schluckbeschwerden und Dyspnoe auf. Nach Übernahme des Patienten auf unsere Intensivstation erfolgte die Intubation bei respiratorischer Erschöpfung (• Abb. 1|P36).

Unter Therapie mit Steroiden, Immunadsorption und Neostigmin bei Verdacht auf eine immunvermittelte myasthene Krise kam es zu keiner Besserung der Symptomatik. Bei hämodynamischer Instabilität mit stark erhöhtem Troponin-T, CK sowie EKG-Veränderungen, wurde zunächst eine Stabilisierung nach HKU mit Stentimplantation erreicht (• Abb. 2|P36).

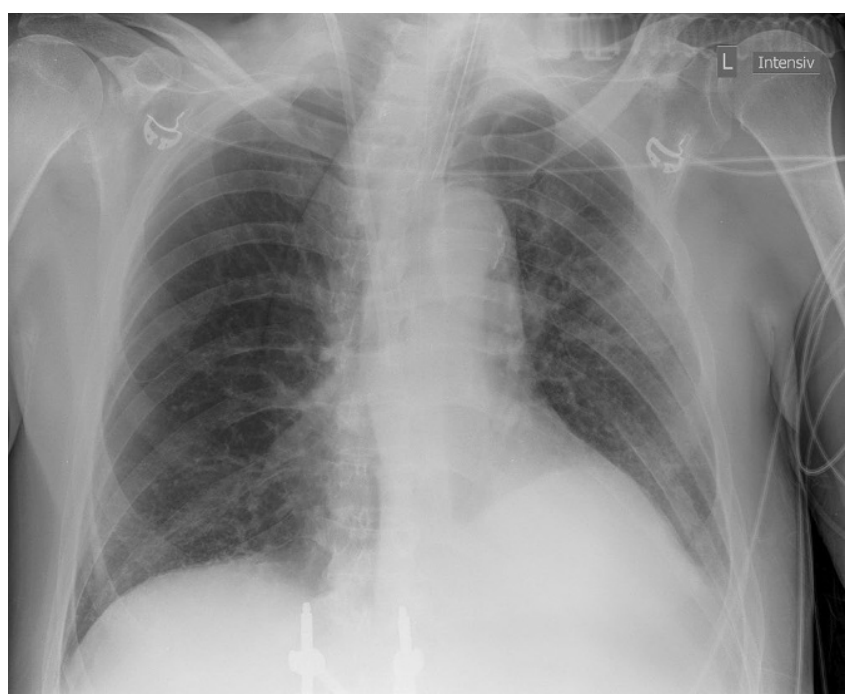

Abb. 1 | P36 4

\begin{tabular}{|l|l|l|l|l|}
\hline & $\begin{array}{l}\text { Übernahme } \\
\text { (Tag 4) }\end{array}$ & Tag 5 & Tag 7 & Tag 12 \\
\hline CK (U/I) & 2518 & 788 & 266 & 181 \\
\hline CK-MB (U/I) & 119 & 51 & 23 & 30 \\
\hline Troponin-T (ug/I) & & 5.450 & 5.050 & 7.720 \\
\hline LDH (U/I) & 812 & 724 & 505 & 358 \\
\hline
\end{tabular}

Abb. 2 |P36 $\triangle$ 
Im weiteren Verlauf trat eine erneute hämodynamische Instabilität mit ausgeprägter Katecholaminpflichtigkeit auf, am ehesten im Sinne einer nun generalisierten Myositis und Myokarditis. Bei beginnendem Multiorganversagen verstarb der Patient am 13. Tag der stationären Aufnahme. Zusammenfassung: Die irAEs von CPIs präsentieren sich häufig mit diffusen Symptomen, die eine Diagnosestellung erschweren. Wie in dem Case Report gezeigt, sind fulminante und tödliche Verläufe auf Intensivstation möglich, wobei die Pathogenese bisher unklar bleibt. Daher sollte bei Patienten unter Therapie mit CPIs immer differentialdiagnostisch an eine irAE gedacht werden.

\section{Infektologie/Immunologie (P37-P39)}

\section{P37}

Tiefe Atemwegsinfektionen nach kardiopulmonaler Reanimation (CPR)

\section{Weidhase, N. E. Friebe, F. Seidel, S. Petros}

Interdisziplinäre Internistische Intensivmedizin, Department für Innere Medizin, Neurologie und Dermatologie, Universitätsklinikum Leipzig A.ö. R., Leipzig, Deutschland

Hintergrund: Ziel der Studie war die Ermittlung von Prävalenz und Risikofaktoren für die Entwicklung einer tiefen Atemwegsinfektion nach CPR auf der internistischen Intensivstation des Universitätsklinikums Leipzig unter Berücksichtigung von Keimspektrum und Resistogramm. Aus diesen Daten sollten Vorschläge für eine kalkulierte Antibiotikatherapie erarbeitet werden unter Würdigung der individuellen Risikokonstellation. Methode: Es erfolgte die retrospektive Analyse aller Patienten, die vom 01.01.2014 bis 12.08.2018 reanimiert und im Rahmen der Postreanimationsbehandlung auf der internistischen 28-Betten-Intensivstation des Universitätsklinikums Leipzig behandelt wurden. Alle Patienten wurden über eine Datenabfrage anhand der ICD10-Kodierung (I46.0) gescreent. Anschließend erfolgte eine systematische Durchsicht der elektronischen Pati- entenakten. Von einer weiteren Analyse ausgeschlossen wurden innerhalb der ersten $24 \mathrm{~h}$ verstorbene Patienten, Patienten mit einer vorbestehenden Pneumonie oder einer Sepsis als Ursache des Kreislaufstillstandes sowie mit aktuell laufender antibiotischer Therapie.

Ergebnisse: Im Untersuchungszeitraum wurden 654 Patienten nach stattgehabter CPR gescreent. Davon erfüllten 292 die Einschlusskriterien zur weiteren Analyse. 62 \% der Reanimationsbehandlungen erfolgten außerklinisch. Das Alter betrug im Median 68,0 [55,3;76,8] Jahre. 66,1 \% der untersuchten Patienten waren männlich. Als primärer Rhythmus lag in 101 Fällen (34,6 \%) ein Kammerflimmern, 95 Fällen (32,5 \%) eine Asystolie und 51 Fällen (17,5\%) eine pulslose elektrische Aktivität zugrunde. Bei 34,9\% der Patienten gelang ein Erregernachweis aus den tiefen Atemwegen in signifikanter Keimzahl. Am häufigsten ließen sich Staphylocccus aureus $(22,2 \%)$, E. coli $(14,6 \%)$, Klebsiella oxytoca $(10,1 \%)$, Klebsiella pneumoniae $(8,2 \%)$ und Haemophilus influenzae $(8,2 \%)$ sowie Serratia$(4,4 \%)$ und Enterobacter-Stämme $(4,4 \%)$ nachweisen.

Zusammenfassung: Nach stattgehabter CPR entwickeln sich häufig tiefe Atemwegsinfektionen. Das Keimspektrum unterscheidet sich erheblich von einer ambulant erworbenen Pneumonie. Geeignete Kandidaten für eine kalkulierte Initialtherapie wären zum Beispiel Cephalosporine der Gruppe 3a.

\section{P38}

\section{Das invasive Klebsiella pneumoniae-Syndrom - eine Fallserie}

\section{S. von Bonin', R. Schneider', P. Schröttner ${ }^{3}$}

${ }^{1}$ Medizinische Klinik und Poliklinik I, Universitätsklinikum Carl Gustav Carus, Technische Universität Dresden, Dresden, Deutschland; ${ }^{2}$ Medizinische Klinik und Poliklinik III, Universitätsklinikum Carl Gustav Carus, Technische Universität Dresden, Dresden, Deutschland ${ }^{3}$ Institut für medizinische Mikrobiologie und Hygiene, Universitätsklinikum Carl Gustav Carus, Technische Universität Dresden, Dresden, Deutschland

Hintergrund: Im Zeitraum 11/2018-2/2019 wurden 3 Patienten intensivmedizinisch wegen einer lebensbedrohlichen Infektion mit hypervirulen-

\begin{tabular}{|c|c|c|l|l|}
\hline Patient & Sex & Alter & Herkunft & Risikofaktoren \\
\hline 1 & $\mathrm{~m}$ & 40 & Deutschland & Kanalarbeiter \\
\hline 2 & $\mathrm{~m}$ & 44 & Polen & Alkoholabusus \\
\hline 3 & $\mathrm{~m}$ & 39 & Pakistan & Diabetes mellitus Typ 2, Erstmanifestation \\
\hline
\end{tabular}

\begin{tabular}{|c|l|l|l|}
\hline Patient & $\begin{array}{l}\text { Manifestationen } \\
\text { - Pneumonie (nicht } \\
\text { abszedierend) } \\
\text { - Leberabszesse } \\
\text { - Prostataabszesse } \\
\text { - Endophthalmitis links } \\
\text { - Meningitis } \\
\text { - Hirnabszesse } \\
\text { - Abszedierende } \\
\text { Pneumonie } \\
\text { - Pleuraempyem } \\
\text { - Endophthalmitis } \\
\text { - Meningitis } \\
\text { - Hirnabszesse } \\
\text { - Abszedierende } \\
\text { Pneumonie } \\
\text { - Leberabszesse } \\
\text { - Prostataabszesse }\end{array}$ & $\begin{array}{l}\text { Intervention } \\
\text { 2. Vitrektomie links }\end{array}$ & $\begin{array}{l}\text { Outcome } \\
\text { Entlassen } \\
\text { Amaurosis linkes } \\
\text { Auge }\end{array}$ \\
\hline 3 & $\begin{array}{l}\text { 1. Tracheotomie } \\
\text { 2. Bilobektomie rechts } \\
\text { 3. Hirndrucksonde }\end{array}$ & $\begin{array}{l}\text { Aktuell stationär } \\
\text { Schwere Critical- } \\
\text { illness Neuropathie } \\
\text { Kognitive Defizite }\end{array}$ \\
\hline & 1. Leberabszessdrainge & $\begin{array}{l}\text { Aktuell stationär } \\
\text { Invasiv beatmet - im } \\
\text { Weaning }\end{array}$ \\
\hline
\end{tabular}

Abb. 1 | P38 < 
ten Klebsiella pneumoniae (hvKp) behandelt. HvKp sind endemisch im asiatischen Raum. Es werden Kolonisationen ohne klinisches Korrelat, aber auch schwere, invasive Infektionen beschrieben. Ungefähr $70 \%$ der hvKp sind Kapseltyp K1 oder K2. Die von hvKp induzierten Krankheitsbilder unterscheiden sich von den in Europa vorkommenden klassischen Klebsiella pneumoniae.

Methode: Wir berichten über 3 Patienten (• Abb. 1 | P38).

Alle Patienten erkrankten akut und entwickelten innerhalb von Stunden septische Krankheitsbilder mit Notwendigkeit einer intensivmedizinischen Versorgung.

Alle Patienten zeigten eine Leukozytose und CRP-Erhöhung. In den Blutkulturen wurden cephalosporinsensible Klebsiella pneumoniae nachgewiesen.

Ergebnisse: Die empirische Antibiotikatherapie erfolgte bei allen Patienten mit Piperacillin/Tazobactam. Nach Eingang der mikrobiologischen Befunde erfolgte resistogramm-gerecht die Umstellung auf Ceftriaxon.

Die weitere Diagnostik ergab multifokale Abszedierungen, welche interdisziplinär unter Einschluss chirurgischer/interventioneller Verfahren behandelt wurden (- Abb. 2 | P38). Echokardiographisch zeigten sich bei keinem der Patienten Vegetationen. Bei Verdacht auf eine hvKp Infektion wurden weitere mikrobiologische Untersuchungen veranlasst. Bisher konnte bei Patient 1 der Kapseltyp K1 nachgewiesen werden, was die klinische Verdachtsdiagnose unterstreicht.

Zusammenfassung: Infektionen mit hvKp werden zunehmend im europäischen Raum bei nicht-asiatischen Patienten beobachtet. Risikofaktoren sind nicht obligat. Diagnostisch sind der kulturelle Erregernachweis, wenn möglich vor Antibiotikabeginn und die prothrahierte Sepsis mit dem Nachweis von multifokalen Abszedierungen, die auch erst im Verlauf klinisch evident werden können. Die bildgebende Diagnostik sollte entsprechend angepasst werden. Eine interdisziplinäre Betreuung ist notwendig.

Mikrobiologisch kann der Nachweis bestimmter Kapseltypen die klinische Verdachtsdiagnose untermauern

\section{P39}

\section{Einsatz einer Multiplex-PCR zur Erregerdiagnostik bei Patienten mit Sepsis}

\section{N. Nagler', F. Diehlmann'2, M. Abele-Horn', S. Maier'}

${ }^{1}$ Kardiologie, Medizinische Klinik und Poliklinik I, Universitätsklinikum Würzburg, Würzburg, Deutschland; ${ }^{2}$ Kardiologie, Pneumologie und internistische Intensivmedizin, Asklepios Klinik Altona, Hamburg, Deutschland; ${ }^{3}$ nstitut für Hygiene und Mikrobiologie, Universitätsklinikum Würzburg, Würzburg, Deutschland; ${ }^{4} I$. Medizinische Klinik - Innere Medizin, Kardiologie, Intensivmedizin, Angiologie, Barmherzige Brüder Klinikum St. Elisabeth Straubing GmbH, Straubing, Deutschland

Hintergrund: Die antimikrobielle Therapie von Patienten mit Sepsis kann durch eine frühzeitige Erregeridentifizierung optimiert werden. Durch den direkten Nachweis bakterieller oder fungaler DNA aus Vollblut erreichen molekularbiologische Detektionsmethoden eine kürzere „time-toresult" und sind theoretisch unabhängiger von einer antibiotischen Vorbehandlung. Ziel unserer Studie war der Vergleich eines PCR-basierten, kulturunabhängigen Verfahrens mit der Blutkulturdiagnostik in Abhängigkeit von einer antibiotischen Vorbehandlung.

Methode: In die Studie wurden Patienten eingeschlossen, die sich in der internistischen Notaufnahme oder Intensivstation der Universitätsklinik mit einer Sepsis vorstellten. Es wurde dokumentiert, falls ambulant oder in einem Primärkrankenhaus bereits eine antibiotische Therapie initiiert wurde. Zusätzlich zur Routinediagnostik wurden $2 \times 5 \mathrm{ml}$ EDTA-Blut für die VYOO ${ }^{\circ}$-PCR entnommen. Die Ergebnisse von der PCR- und Blutkultur-Diagnostik wurden auf klinische Plausibilität geprüft und je nach Vortherapie analysiert.

Ergebnisse: Insgesamt hatten 57 der 183 Patienten, die in die Studie eingeschlossen wurden, vor der Vorstellung eine Antibiotikatherapie erhalten. Das Durchschnittsalter aller Patienten betrug 64,2 $\pm 16,6$ (MW \pm SD) Jahre, der Anteil weiblicher Patienten $39 \%$ und der Anteil immun- supprimierter Patienten $36 \%$. Bei $49 \%$ der Patienten lag eine schwere Sepsis oder ein septischer Schock vor. Die Mortalität betrug bei allen eingeschlossen Patienten $14 \%$. Insgesamt wurden bei $21 \%$ der Patienten $(n=38)$ klinisch relevante Erreger detektiert. In 11 Fällen wurde der Erreger von beiden Verfahren nachgewiesen, in 17 Fällen nur von der Blutkultur und in 12 Fällen nur von der PCR. Die Detektionsrate der Blutkultur bzw. PCR betrug $15 \%$ bzw. $13 \%$. $(p=0,458)$. Die BlutkulturErgebnisse zeigten hinsichtlich der antibiotischen Vorbehandlung keine signifikanten Unterschiede ( $13 \%$ bzw. $17 \%, p=0,515$ ). Die Detektionsrate der PCR hingegen war bei antibiotisch vorbehandelten Patienten signifikant höher bei als bei Patienten ohne antibiotische Vorbehandlung ( $21 \%$ bzw. $9 \%, p=0,029$ ).

Zusammenfassung: Bei Patienten mit Verdacht auf Sepsis kann eine Multiplex-PCR-basierte Nachweismethode - als komplementäres Verfahren zur konventionellen Blutkultur - dazu beitragen, zusätzliche Erreger zu identifizieren, insbesondere bei antibiotisch vorbehandelten Patienten.

\section{Nephrologie (P40)}

\section{P40}

Risikofaktoren für Kurz- und Langzeitüberleben nierentransplantierter Patienten auf der Intensivstation

S. Büttner', M. Urschbach', S. Rudolf', S. Patyna', I. A. Hauser', H. Geiger', H. Farnik ${ }^{2}$

'Medizinische Klinik III, Nephrologie, Universitätsklinikum, Johann Wolfgang Goethe-Universität, Frankfurt a. M., Deutschland; ${ }^{2}$ Medizinische Klinik I, Gastroenterologie und Hepatologiie, Universitätsklinikum, Johann Wolfgang Goethe-Universität, Frankfurt a.M., Deutschland

Hintergrund: Eine intensivmedizinische Behandlung ist bei Patienten nach Nierentransplantation mit einer erhöhten Morbidität und Mortalität assoziiert. Insbesondere multiresistente Erreger (MRE) stellen ein zunehmendes Problem der intensivmedizinischen Behandlung dar. Bisher gibt es jedoch nur wenig Daten zu Kurz und Langzeitmortalität und dem Einfluss multiresistenter Keime in diesem besonderen Patientenkollektiv.

Methode: Retrospektive, monozentrische Analyse des Kurz- und Langzeitüberlebens aller Patienten mit funktionierendem Nierentransplantat, die zwischen 2007 und 2017 eine intensivmedizinische Behandlung benötigten. Zweit- oder Mehrfacheinweisungen, ITS-Aufenthalte kürzer als 24 h, sowie Patienten mit kombinierter Pankreas-/Nierentransplantation oder mit terminalem Transplantatversagen vor dem ICU Aufenthalt wurden ausgeschlossen.

Ergebnisse: Insgesamt wurden 127 Patienten analysiert. Davon verstarben 20 (16\%) während des ITS-Aufenthaltes und die Krankenhausmortalität lag bei $19 \%$ (24 Patienten). Eine invasive Beatmung (OR: 8,702, CI: $1,907-39,704, p=0,005)$, der Nachweis einer Candida Co-/Infektion (OR: 7,262, CI: 1,635-32,243, $p=0,009)$ und das Alter (OR: 1,094, CI: $1,007-1,189, p=0,035)$ waren mit einer erhöhten Mortalität assoziiert. Zudem wiesen verstorbene Patienten eine signifikant niedrigere CD4 und CD8-Zellzahl (CD4: $p=0,019, \mathrm{CD} 8 p=0,022)$ auf. Über die Studiendauer von insgesamt 10 Jahren beobachteten wir eine zunehmende Prävalenz von nachgewiesenen MRE pro Patient. Insgesamt wurde bei 51 (40\%) der Patienten mindestens ein MRE nachgewiesen (ITS-Überleber $36 \%$ vs. Verstorbener $65 \%, p=0,015$ ). Neben dem Alter (HR: 1,089, CI: $1,040-1,139, p=0,0003$ ) war ein MRE-Nachweis (HR: 2,661, 1,265-5,596, $p=0,01)$ während des Aufenthaltes auch mit einem schlechteren Langzeitüberleben assoziiert.

Zusammenfassung: Candida Co-Infektionen und der Nachweis Multiresistenter Erreger sind bei kritisch kranken Patienten nach Nierentransplantation mit einer erhöhten Mortalität assoziiert. 


\section{Ethik (P41)}

\section{P41}

\section{Therapiezieländerung - Palliativmedizin auf der Intensivstation}

F. Müller, M. Bernd, V. Schächinger

Medizinische Klinik I - Kardiologie, Angiologie, Intensivmedizin, Kardiologie/Intensivmedizin, Klinikum Fulda, Fulda, Deutschland

Hintergrund: Die palliative Therapie nach Therapiezieländerung stellt einen wichtigen Bestandteil der intensivmedizinischen Versorgung dar. Im Folgenden werden die Häufigkeit einer Therapiezieländerung/palliativen Therapie sowie häufige Gründe hierfür vorgestellt. Grundlage bildet das Patientenkollektiv der internistisch-neurologischen Intensivstation des Klinikums Fulda im Jahr 2018.

Methode: Auswertung aller im Jahr 2018 auf der internistisch-neurologischen Intensivstation des Klinikums Fulda behandelten Patienten $(n=855)$ anhand der Entlassbriefe und vorliegender Dokumentation. Erfasst wurden

- dokumentierte, nachvollziehbare Therapiezieländerungen mit anschließender palliativer Therapie

- wichtige Faktoren/Erkrankungen als Grundlage der Therapiezieländerung

Ergebnisse: Die Patienten $(n=855)$ hatten ein mittleres Alter von 69 Jahren, 134 Patienten (16\%) verstarben auf der Intensivstation, 80 Patienten (9\%) im Verlauf des Weiteren stationären Aufenthaltes. Bei 79 Patienten (9,2\%) erfolgte auf der Intensivstation eine Therapiezieländerung mit nachfolgender palliativer Therapie, die Patienten verstarben noch im Verlauf des stationären Aufenthaltes.

Zusammenfassung: Die Palliative Begleitung unserer Patienten stellt einen integralen und wichtigen Bestandteil unserer Intensivmedizinischen Versorgung dar, auf unserer Station bei fast $10 \%$ der Patienten. Diese Aufgabe sollte von uns bewusst wahrgenommen werden und genauso sorgfältig wie die kurative Therapie erfolgen.

Der weitaus wichtigste Grund für eine Therapiezieländerung ist auf unserer Station ein angenommen schlechtes neurologisches Outcome, dies ist sicherlich dem hohen Anteil reanimierter Patienten sowie Patienten mit Schlaganfall geschuldet. Weitere wichtige Faktoren sind Tumorerkrankungen sowie vorbestehende oder neu eingetretene Dialysepflichtigkeit.

\section{Pflege (P42-P43)}

\section{P42}

\section{A systems approach to burnout syndrom in intensive care unit nurses: a mixed methods study in Heidelberg, Germany \\ C. Roth \\ University of Dundee, Dundee, United Kingdom}

Objective: The primary aim of this study was to measure burnout rates in ICU nurses in one university hospital in Germany (University Hospital Heidelberg). The secondary aim was to examine if there is an association between these burnout rates and the work systems

Method: Single-centre study design, including an online survey using the adapted Copenhagen Burnout Inventory and semi-structured interviews. Results: Of the 30 nurses who filled in the survey $60.0 \%(n=18)$ experienced personal-burnout, $60.0 \%(n=18)$ experienced work-related burnout, $26.7 \%(n=8)$ experienced patient-related burnout, and 30.0\% $(n=9)$ experienced co-workers-related burnout. Four nurses decided to take part in an interview. The nurses identified 36 factors (barriers) which have a negative impact on their mental well-being and 32 factors (facilitators) which influenced their well-being positively. Factors of the work system contributing to personal burnout are personal characteristics, the quality of the relationship among the medical team as well as poor organisational behaviour like for example insufficient teamwork or no team-based learn- ing after challenging situations and a poor external environment. Factors of the work system contributing to work-related burnout are a poor ICU environment, factors related to the organisation, lack of tools and technology and poor organisation of tasks. Additionally, showed the analyses that there might an association between working under constant time pressure, the high-stress level due to the nature of the ICU environment and work-related burnout. Factor of the work system contributing to co-workers-related burnout are factors related to the organisation like poor staffing, lack of open culture or no team-based learning after challenging situation, personal characteristics of the ICU nurses and poor communication among the medical team as well as poor task organisation (e.g. inability to prioritise). No factor of the work system contributed to patient-related burnout. The nurses mentioned that although that the work with critically ill patients is demanding they do not feel like that the task 'taking care of critically ill patients' itself is exhausting

Conclusion: This pilot study showed that over $50 \%$ of the participating nurses experience mental health issues due to poor work conditions. It should, therefore, be of great interest of employers to eliminate unhealthy work environment factors and promote employees' mental and physical well-being to keep them healthy

\section{P43}

Evaluation möglicher Einflussfaktoren für das Auftreten von isolationspflichtigen Keimen auf der Intensivstation

\section{Brand, H.-J. Trappe}

Medizinische Klinik II - Kardiologie und Angiologie, Marien Hospital Herne, Ruhr-Universität Bochum, Herne, Deutschland

Hintergrund: Es zeigt sich ein Zunahme isolationspflichtiger Keime auf Intensivstationen, obwohl sich das Bewusstsein darüber und der Umgang mit Antibiotika gewandelt hat.

Ziel dieser retrospektiven Studie war es, mögliche Einflussfaktoren herauszufinden, welche das Auftreten von isolationpflichtigen Keimen auf einer Intensivstation begünstigen.

Methode: Auf unserer interdisziplinären Intensivstation mit 26 Patientenbetten wurden über den Zeitraum von 12 Monaten (01/2018-12/2018) verschiedene Behandlungsparameter analysiert. Neben der tagesaktuellen Auswertung nach Fachrichtungen und Pflegeschlüssel wurde unter anderem die Gesamtbettenauslastung sowie die Anzahl an invasiven Beatmungen oder Nierenersatzverfahren erfasst. Als abhängige Variable wurde der Anteil von Patienten mit isolationspflichtigen Keimen definiert.

Ergebnisse: Über den Beobachtungszeitraum zeigten sich erwartungsgemäß ausgeprägte Schwankungen im Auftreten isolationspflichtiger Keime. Der Monatsmittelwert des Anteils von isolationspflichtigen Patienten reichte von $27 \%$ im Minimum bis zu $52 \%$ bei Tageshöchstraten von teilweise über $70 \%$. Während die Zuordnung zu Fachrichtungen, die Jahreszeit oder die Gesamtbettenauslastung keinen signifikanten Einfluss auf die Isolationsrate hatte, zeigt sich eine signifikanter Korrelation mit der Anzahl invasiver Beatmungen und dem Pflegeschlüssel auf der Intensivstation.

Zusammenfassung: In dieser Studie konnte gezeigt werden, dass die Beachtung eines adäquaten Pflegeschlüssels das Auftreten und Ausbreiten isolationspflichtiger Keime auf der Intensivstation möglicherweise reduzieren kann

\section{Respiratorisches Versagen (P44-P46)}

\section{P44}

Eine positve Volumenbilanz ist ein früher Prädiktor für Mortalität von Patienten an veno-venöser Membranoxygenierung

S. Petzoldt, P. M. Lepper, F. Seiler

Pneumologie, Allergologie, Beatmungs- und Umweltmedizin, Klinik für Innere Medizin V, Universität des Saarlandes, Homburg/Saar, Deutschland 
Hintergrund: Um einen Kreislauf an vv-ECMO zu aufrecht zu erhalten, ist häufig parenterale Volumengabe nötig. Studien suggerieren jedoch einen Zusammenhang zwischen Volumenüberladung und schlechtem Outcome bei Patienten mit Sepsis und ARDS. Diese Arbeit untersucht den Einfluss der Volumenbilanz im Krankheitsverlauf auf das Überleben von erwachsenen Patienten an vv-ECMO.

Methode: Retrospektive Analyse von Patienten unter vvECMO-Therapie im Zeitraum 2013-2016. Patienten an veno-arterieller ECMO oder an extrakorporaler $\mathrm{CO} 2$-Elimination wurden nicht eingeschlossen. Es wurde Flüssigkeitszu- und ausfuhr 6, 12 und $24 \mathrm{~h}$ nach ECMO-Anlage und anschließend tagesgenau bestimmt.

Ergebnisse: 83 Patienten wurden eingeschlossen (Alter $48 \pm 17$ Jahre, $58 \%$ männlich). Bei ECMO-Anlage waren $78 \%$ der Patienten intubiert und $72 \%$ vasopressorpflichtig. 45 Patienten (62\%) überlebten. 6, 12 und $24 \mathrm{~h}$ nach Anlage unterschied sich die Volumenbilanz nicht signifikant zwischen Überlebenden und Nicht-Überlebenden. Patienten, die an Tag $5 \mathrm{mehr}$ als $250 \mathrm{ml}$ positiv bilanziert waren, zeigten eine signifikant höhere ICU- und 60 -Tages-Mortalität (57\% und $54 \%$ vs $32 \%$ und $30 \%$, $p=0,029)$. Ab Tag 6 ließ sich ein signifikanter Unterschied in der mittleren täglichen Volumenzufuhr zwischen Überlebenden und Nicht-überlebenden feststellen ( $3859 \pm 1095 \mathrm{ml}$ vs. $4898 \pm 2344 \mathrm{ml} ; p=0,016)$. Patienten, deren Volumenbilanz zu Therapiende in der untersten Quartile lag, hatten die beste Überlebensrate, während Patienten in der höchsten Quartile auch die höchste Mortalität aufwiesen. Der beste Cut-Off Wert für Volumenbilanz zu Therapieende, um zwischen Überlebenden und Nicht-Überlebenden zu unterscheiden, lag bei $0 \mathrm{ml}$. 6/32 (18\%) Patienten mit einer niedrigeren Volumenbilanz und 32/51 (62 \%) Patienten mit einer höheren Volumenbilanz $(p<0,001)$ verstarben unter der Therapie.

Zusammenfassung: Bei Patienten unter vv-ECMO Therapie ist eine negative Volumenbilanz mit einer niedrigeren Mortalität und verkürzter Beatmungs- und ECMO-Dauer assoziiert.

\section{P45}

Impact of sweep gas flow on extracorporeal $\mathrm{CO}_{2}$ removal $\left(\mathrm{ECCO}_{2} \mathrm{R}\right)$

S. Strassmann', M. L. Merten', S. Schäfer', J. de Moll', D. Brodie'2, A. Larsson', W. Windisch' ${ }^{7}$ C. Karagiannidis ${ }^{7}$

'Pneumologie, Intensiv- und Beatmungsmedizin, Krankenhaus Merheim, Kliniken der Stadt Köln, Cologne, Germany; '²Division of Pulmonary, Allergy and Critical Care, Columbia University College of Physicians and Surgeons, New York-Presbyterian Hospital, New York, USA ${ }^{3}$ Hedenstierna Laboratory, Anesthesiology and Intensive Care, Department of Surgical Sciences, Uppsala University, Uppsala, Sweden

Objective: Veno-venous extracorporeal carbon dioxide $\left(\mathrm{CO}_{2}\right)$ removal $\left(\mathrm{vv}-\mathrm{ECCO}_{2} \mathrm{R}\right)$ is increasingly being used in the setting of acute respiratory failure. Blood flow rates range in clinical practice from $200 \mathrm{ml} / \mathrm{min}$ to more than $1500 \mathrm{ml} / \mathrm{min}$, and sweep gas flow rates range from less than 1 to more than $10 \mathrm{~L} / \mathrm{min}$. The present porcine model study was aimed at determining the impact of varying sweep gas flow rates on $\mathrm{CO}_{2}$ removal under different blood flow conditions and membrane lung surface areas. Method: Two different membrane lungs, with surface areas of 0.4 and $0.8 \mathrm{~m}^{2}$, were used in nine pigs with experimentally-induced hypercapnia. During each experiment, the blood flow was increased stepwise from 300 to $900 \mathrm{ml} / \mathrm{min}$, with further increases up to $1800 \mathrm{ml} / \mathrm{min}$ with the larger membrane lung in steps of $300 \mathrm{ml} / \mathrm{min}$. Sweep gas was titrated under each condition from $2-8 \mathrm{~L} / \mathrm{min}$ in steps of $2 \mathrm{~L} / \mathrm{min}$. Extracorporeal $\mathrm{CO}_{2}$ elimination was normalized to a $\mathrm{PaCO}_{2}$ of $45 \mathrm{~mm} \mathrm{Hg}$ before the membrane lung.

Results: Reversal of hypercapnia was only feasible when blood flow rates above $900 \mathrm{ml} / \mathrm{min}$ were used with a membrane lung surface area of at least $0.8 \mathrm{~m}^{2}$. The membrane lung with a surface of $0.4 \mathrm{~m}^{2}$ allowed a maximum normalized $\mathrm{CO}_{2}$ elimination rate of $41 \pm 6 \mathrm{~mL} / \mathrm{min}$ with $8 \mathrm{~L} / \mathrm{min}$ sweep gas flow and $900 \mathrm{ml}$ blood flow $/ \mathrm{min}$. The increase in sweep gas flow from 2 to $8 \mathrm{~L} / \mathrm{min}$ increased normalized $\mathrm{CO}_{2}$ elimination from $35 \pm 5$ to $41 \pm 6$ with $900 \mathrm{ml}$ blood flow/min, whereas with lower blood flow rates, any increase was less effective, levelling out at $4 \mathrm{~L}$ sweep gas flow $/ \mathrm{min}$. The membrane lung with a surface area of $0.8 \mathrm{~m}^{2}$ allowed a maximum normalized $\mathrm{CO}_{2}$ elimination rate of $101 \pm 12 \mathrm{ml} / \mathrm{min}$ with increasing influence of sweep gas flow. The delta of normalized $\mathrm{CO}_{2}$ elimination increased from $4 \pm 2$ to $26 \pm 7 \mathrm{~mL} / \mathrm{minwith}$ blood flow rates being increased from 300 to $1800 \mathrm{ml} /$ min, respectively.

Conclusion: The influence of sweep gas flow on the $\mathrm{CO}_{2}$ removal capacity of $\mathrm{ECCO}_{2} \mathrm{R}$ systems depends predominantly on blood flow rate and membrane lung surface area. In this model, considerable $\mathrm{CO}_{2}$ removal occurred only with the larger membrane lung surface of $0.8 \mathrm{~m}^{2}$ and when blood flow rates of $\geq 900 \mathrm{ml} / \mathrm{min}$ were used.

\section{P46}

The impact of ventilator settings and tube size on development of hypercapnic acidosis during bronchoscopy-guided percutaneous dilatational tracheostomy

\section{Karagiannidis', M. L. Merten' ', S. Strassmann', S. Schäfer', F. S. Magnet',} L. Heunks' W. Windisch'

'Pneumologie, Intensiv- und Beatmungsmedizin, Krankenhaus Merheim, Kliniken der Stadt Köln, Cologne, Germany; ${ }^{2}$ Department of Intensive Care Medicine, Amsterdam Cardiovascular Sciences, VU University Medical Centre, Amsterdam, The Netherlands

Objective: The current study systematically investigates the dynamic evolution of $\mathrm{PCO}_{2}$ during bronchoscopy-guided tracheostomy depending on differences in ventilator settings and endotracheal tube sizes. The study also determines if transcutaneous $\mathrm{PCO}_{2}\left(\mathrm{PtcCO}_{2}\right)$ reliably monitors alveolar ventilation during tracheostomy.

Method: Sixty-three patients undergoing bronchoscopy-guided percutaneous dilatational tracheostomy were included. Two groups of patients with varying tidal volumes were consecutively investigated: $6 \mathrm{ml} / \mathrm{kg}$ ( $N=29$, mean age $57.4 \pm 14.5$ years) and $12 \mathrm{ml} / \mathrm{kg}$ predicted body weight $(N=34$, mean age $59.5 \pm 12.8$ years).

Results: The mean intervention time during all procedures lasted $10 \pm 3$ $\mathrm{min}$. The combination of low tidal volumes and small endotracheal tubes (internal diameter/ID of $7.5 \mathrm{~mm}$ ) resulted in the most profound increase in $\mathrm{PaCO}_{2}(32.2 \pm 11.6 \mathrm{~mm} \mathrm{Hg})$ and decrease of $\mathrm{pH}$-value $(-0.18 \pm 0.05)$. In contrast, the combination of high tidal volumes and large endotracheal tubes (ID of $8.5 \mathrm{~mm}$ ) resulted in the least profound increase in $\mathrm{PaCO}_{2}(8.8$ $\pm 9.0 \mathrm{~mm} \mathrm{Hg})$ and decrease of $\mathrm{pH}(-0.05 \pm 0.04)$. The intervention-related increase in $\mathrm{PaCO}_{2}$ was significantly lower when using higher tidal volumes for larger endotracheal tubes: ID 7.5, 8.0, and 8.5: $P>0.05,=0.006$, and $=0.002$, respectively. $\mathrm{PtcCO}_{2}$ monitoring revealed steadily worsening hypercapnia during the intervention with a high correlation of 0.87 and a low bias according to the Bland-Altman analysis when compared to $\mathrm{PaCO}_{2}$ measurements (Bias: $0.7 \pm 9.4 \mathrm{~mm} \mathrm{Hg}$ ).

Conclusion: The present study clearly shows the rapid dynamically occurring process of evolving hypercapnia and subsequent respiratory acidosis during bronchoscopy-guided dilatational tracheostomy. This is reliably assessed by $\mathrm{PtcCO}_{2}$ monitoring. Moreover, higher tidal volumes in combination with larger endotracheal tubes are capable of substantially attenuating alveolar hypoventilation during the intervention.

Trial registration: DRKS00011004. Registered 20th September 2016. 


\section{Autorenverzeichnis}

$\begin{array}{ll}\begin{array}{ll}\text { A } \\ \text { Abele-Horn, M. }\end{array} & \text { P39 } \\ \text { Al Hamwi, G. } & \text { P31 } \\ \text { Amann, D. } & \text { FV06 } \\ & \\ \text { B } & \\ \text { Barthel, P. } & \text { FV07 } \\ \text { Bayraktar, E. } & \text { FV02 } \\ \text { Beelen, D. } & \text { FV02 } \\ \text { Berger, A. } & \text { P28 } \\ \text { Berliner, C. } & \text { P17 } \\ \text { Bernd, M. } & \text { P41 } \\ \text { Berndt, K. } & \text { FV07 } \\ \text { Betz, C. } & \text { P18 } \\ \text { Bogdanov, R. } & \text { FV02 } \\ \text { Bolanaki, M. } & \text { P07, P10 } \\ \text { Böll, B. } & \text { P36 } \\ \text { Brand, M. } & \text { P43 } \\ \text { Braun-Dullaeus, R. } & \text { P14 } \\ \text { Brockenauer, S. } & \text { FV04 } \\ \text { Brodie, D. } & \text { P45 } \\ \text { Buchtele, N. } & \text { P01 } \\ \text { Burdelski, C. } & \text { P15 } \\ \text { Burger, C. } & \text { P24 } \\ \text { Büttner, S. } & \text { P18, P40 }\end{array}$

\section{D}

d'Hargues, $Y$.

de Heer, G. FV06, P15

de Moll, J. P45

Deppe, M. P21

Deutschbein, J. P04

Diehlmann, F. P39

Domanovits, $\mathrm{H}$. P34

Dreher, M. P16

\section{E}

$\begin{array}{ll}\text { Eisner, F. } & \text { P25 } \\ \text { Eller, P. } & \text { P25 }\end{array}$

Ertmer, $C . \quad P 32$

\section{$\mathrm{F}$}

Farnik, $\mathrm{H} . \quad \mathrm{P} 40$

Figura, A. P03, P04

Fischer-Rosinský, A. FV05, P07, P08, P09, P11

Franz, M. P31

Friebe, N.E. $\quad$ P37

Fritzenwanger, M. P31

Fuhrmann, V. FV01, FV06

G

Gamerdinger, E. FV04

Gastmeier, P. P12

Geiger, $\mathrm{H}$. P18, P40

Göncz, E. P27

\begin{tabular}{|c|c|}
\hline Graf, T. & P23 \\
\hline \multicolumn{2}{|l|}{$\mathrm{H}$} \\
\hline Haab, M. & $\mathrm{P} 13$ \\
\hline Hackl, G. & P25 \\
\hline Hauser, I. A. & P40 \\
\hline Held, T. & P24 \\
\hline Herkner, $\mathrm{H}$. & FV01, P01 \\
\hline Hessler, M. & P32 \\
\hline Heunks, L. & P46 \\
\hline Heyl, S. & P18 \\
\hline Holert, F. & $\mathrm{P} 12$ \\
\hline Höltje, J. & P24 \\
\hline \multicolumn{2}{|l|}{ | } \\
\hline Ibrahim, K. & FV07 \\
\hline \multicolumn{2}{|l|}{ J } \\
\hline Junker, A. & P20 \\
\hline \multicolumn{2}{|l|}{$\mathrm{K}$} \\
\hline Kampe, K. & P17 \\
\hline Karagiannidis, C. & $\mathrm{P} 45, \mathrm{P} 46$ \\
\hline Katus, H. A. & FV04, P02, P33 \\
\hline Kern, $\mathrm{H}$. & P02 \\
\hline Kersten, A. & P16 \\
\hline Kleinwächter, R. & P27 \\
\hline Kluge, S. & FV06, P15, P17 \\
\hline Klutmann, S. & P17 \\
\hline Kochanek, M. & P36 \\
\hline Kola, A. & $\mathrm{P} 12$ \\
\hline Kollertz, L. & P09 \\
\hline Köster, J. & P23 \\
\hline Kotorova, E. & P05 \\
\hline Kronisch, J. & P21 \\
\hline Kuhlmann, S.L. & P03, P04, P07 \\
\hline Kümpers, P. & P32 \\
\hline \multicolumn{2}{|l|}{ L } \\
\hline Lange, U. & P24 \\
\hline Langer, F. & P19 \\
\hline Langer, H. & P23 \\
\hline Larsson, A. & P45 \\
\hline Lebiedz, P. & $\mathrm{P} 20, \mathrm{P} 21, \mathrm{P} 22$ \\
\hline Lepper, P.M. & P44 \\
\hline Liebregts, T. & FV02 \\
\hline Lindmayr, T. & P34 \\
\hline Lindner, T. & P07, P27 \\
\hline Linke, A. & FV07 \\
\hline Löhr, J. & P29 \\
\hline \multicolumn{2}{|l|}{$M$} \\
\hline Magnet, F.S. & P46 \\
\hline Maier, S. & P39 \\
\hline
\end{tabular}

\begin{tabular}{|c|c|}
\hline Marx, N. & P16 \\
\hline Meisel, T.S. & P13, P19 \\
\hline Merle, U. & P29 \\
\hline Merrelaar, A. & P01 \\
\hline Merten, M.L. & P45, P46 \\
\hline Michaelis, J. & P29 \\
\hline Möckel, M. & $\begin{array}{l}\text { FV03, FV05, P03, P04, P06, } \\
\text { P07, P08, P09, P10, P11, P12, } \\
\text { P27,P28 }\end{array}$ \\
\hline Moeckl, T. & $\mathrm{P} 20$ \\
\hline Muhler, F. & FV04 \\
\hline Müller, F. & P41 \\
\hline Müller, J. & FV06 \\
\hline Muracher, L. & P01 \\
\hline \multicolumn{2}{|l|}{$\mathbf{N}$} \\
\hline Nagler, N. & P39 \\
\hline Nibbe, L. & P26 \\
\hline Niederdöckl, J. & P34 \\
\hline Nierhaus, A. & FV06 \\
\hline \multicolumn{2}{|l|}{0} \\
\hline Ogica, A. I. & P15 \\
\hline Oppert, M. & P05, P26 \\
\hline \multicolumn{2}{|l|}{$P$} \\
\hline Patyna, S. & P40 \\
\hline Pavenstädt, $\mathrm{H}$. & P32 \\
\hline Petros, S. & P37 \\
\hline Petzoldt, S. & P44 \\
\hline Pfeifer, R. & P31 \\
\hline Pflücke, C. & FV07 \\
\hline Pohlkötter, T. & P32 \\
\hline Poitz, D. & FV07 \\
\hline Popp, E. & $\mathrm{P} 02$ \\
\hline Pöß, J. & $\mathrm{P} 23$ \\
\hline Prautzsch, C. & FV08 \\
\hline Preusch, M. & FV04, P02, P33 \\
\hline \multicolumn{2}{|l|}{$\mathbf{R}$} \\
\hline Recknagel, N. & P09 \\
\hline Reisinger, $\mathrm{A}$. & P25 \\
\hline Riedlinger, D. & $\mathrm{P} 12$ \\
\hline \multicolumn{2}{|c|}{ Rieger-Langenberg, M. FV02 } \\
\hline Riessen, $R$. & P30 \\
\hline Ripberger, G. & $\mathrm{P} 05, \mathrm{P} 26$ \\
\hline Roedl, K. & FV01, FV06 \\
\hline Römer, C. & P09, P11, P28 \\
\hline Rose, M. & $\mathrm{P} 03, \mathrm{P} 04$ \\
\hline Roth, C. & P42 \\
\hline Rovas, A. & P32 \\
\hline Rozen, A. & P22 \\
\hline Rudolf, S. & P18, P40 \\
\hline
\end{tabular}




\section{Autorenverzeichnis}

\section{$\mathrm{S}$}

Salaymeh, A.E.-M. I. P05

Schächinger, V.

Schäfer, $S$.

Schäfers, H.-J.

P41

P45, P46

P19

P03

P25

Schilcher, G.

Schmeißer, A.

Schmieder, K.

Schmiedhofer, M.

Schnaubelt, $S$.

Schneider, A.

Schneider, R.

Schon, U.

Schönwälder, J.

Schörgenhofer, C.

Schröder, M.

Schröttner, P.

Schulze, C.

Schumacher, $\mathrm{T}$.

Schütz, N.

Schwameis, M.

Searle, J.

Seeßle, J.

Seidel, F.

Seidel, L.

Seiler, $F$.

Shimabukuro-

Vornhagen, A.

Simon, A.

Slagman, A.

Somasundaram, R.

Spacek, M.

Spahn, S.

Spaich, S.

Spiel, A.

Spode, R.

Steckel, N.K.

Steger, F.

Sterz, F.

Stiepak, J.

Stierholz, M.

Strassmann, $\mathrm{S}$.

Strohm, T.

Sulzgruber, $P$.

P14

P07

FV05, P04, P08

P34

P04

P38

P14

P24

P01

P19

P38

P31

P26

P34

P01

FV05, P06, P08

P29

P37

P32

P44

P36

P34

FV03, FV05, P03, P04, P06,

$\mathrm{P} 07, \mathrm{P} 08, \mathrm{P} 09, \mathrm{P} 10, \mathrm{P} 11, \mathrm{P} 12$,

$\mathrm{P} 28$

P05, P06

FV08

P30

$\mathrm{FV} 04, \mathrm{P} 02, \mathrm{P} 33$

FV01, P34

$\mathrm{P} 09, \mathrm{P} 11, \mathrm{P} 28$

FV02

FV04, P33

FV01

FV04, P02, P33

$\mathrm{P} 06$

P45, P46

P17

P34

T

Tanev, I. $\quad$ P14

Tometten, L. $\quad$ P26

Trappe, H.-J. $\quad$ P43

Turki, A. FV02

Tzalavras, A. FV02

U

Urschbach, M. P40

V

Valzolgher, L. P35

Volk, T. P13

von Bonin, S. P38
W

Walter, D.H. $\quad$ P24

Weidhase, L. P37

Weiser, C. $\quad P 01$

Wietholt, D. P24

Willamowski, N. FV03

Windisch, W. P45, P46

Wrobel, T. FV05, P08

Wydra, S. $\quad$ FV07

Wystub, N. P31

Z

Zelniker, T. $\quad$ FV04, P02, P33 